\title{
Imprecise and Informative: Lessons from Market Reactions to Imprecise Disclosure
}

\author{
J. Anthony Cookson \\ S. Katie Moon \\ Joonki Noh*
}

November 30, 2020

\footnotetext{
${ }^{*}$ Cookson and Moon are at University of Colorado at Boulder, Leeds School of Business, Campus Box 419, Boulder, CO 80309, USA, [tony.cookson@colorado.edu; katie.moon@colorado.edu]. Noh is at Case Western Reserve University, Weatherhead School of Management, 11119 Bellflower Rd, Cleveland, Ohio 44106 [joonki.noh@case.edu]. The authors are grateful to conference and seminar participants at the 2018 Midwest Finance Association Conference, the 2018 China International Conference in Finance, the 2018 International Industrial Organization Conference, the 2020 Future of Financial Information Conference, the SEC DERA group, the 2020 Asia-Pacific Association of Derivatives Conference, the 2020 Northern Finance Association Conference, the 2020 Financial Management Association Conference, Arizona State University, Brigham Young University, Case Western Reserve University, Drexel University, SungKyunKwan University, Texas Christian University, University of Colorado brownbag, and the University of Utah, as well as Gustaf Bellstam, Asaf Bernstein, Steve Billings, Stefan Bueller, Brendan Daley, Naveen Daniel, Diego Garcia, Jerry Hoberg, Dave Ikenberry, Ryan Israelsen, Hogyu Jhang, Fuwei Jiang, Ron Kaniel, Hugh Hoikwang Kim, Wendy Rotenberg, Noah Stoffman, Shawn Thomas, Ralph Walkling, Brian Waters, Jaime Zender, and Dexin Zhou for helpful comments and suggestions. In addition, the authors are grateful to Jerry Hoberg and Bill McDonald for making their textual measures available on their respective websites. All remaining errors are our own.
} 


\title{
Imprecise and Informative: Lessons from Market Reactions to Imprecise Disclosure
}

\begin{abstract}
Imprecise language in corporate disclosures can convey valuable information on firms' fundamentals during uncertain times. To evaluate this idea, we develop a novel measure of linguistic imprecision based on sentences marked with the "weasel tag" on Wikipedia. For a 10-week window following the 10-K disclosure, we find that the use of imprecise language in 10-Ks predicts 1) positive and non-reverting abnormal returns, 2) improvements to stock liquidity, 3) greater intensities of insider and informed buying, and 4) higher news sentiment. These findings are the strongest when the firm disclosures are more forward looking, and for firms with greater idiosyncratic volatility. Taken together, our findings imply that the imprecise language in 10-Ks contains new information on positive but yet immature prospects of future cash flow.
\end{abstract}




\section{Introduction}

The clarity of writing is an important consideration in financial disclosures. Indeed, concerns about unclear financial disclosures have led to the mandate that disclosures be as simple as possible (e.g., the Plain Writing Act). Despite the compelling motivation to keep disclosures simple, the academic literature disagrees regarding whether complex language contains more or less information. On one hand, the "obfuscation view" suggests that managers strategically increase the complexity of their disclosures, which increases information asymmetry (Li 2008) and decreases valuations (Hwang and Kim 2017). On the other hand, complex language can convey important information that cannot be disclosed in simple terms (e.g., Bushee, Gow, and Taylor (2018)). To help resolve this tension, we develop a novel measure of the clarity of financial disclosures - linguistic imprecision extracted from firms' $10-\mathrm{K}$ filings - and use it to understand the information content of linguistic imprecision. We find that greater imprecision predicts permanent and positive abnormal returns, improvements to stock liquidity, the arrival of positive-sentiment news about the firm, and greater intensities of insider and informed buying (but not those of insider and informed selling). Together, these findings support the counterintuitive view that linguistic imprecision reflects value-relevant firm activities.

It is empirically challenging to measure linguistic imprecision in financial disclosures for at least two reasons. First, the selection of a list of imprecision words is likely to be fraught with subjectivity, leading to concerns about researcher degrees of freedom (Simmons, Nelson, and Simonsohn 2011). Second, despite there being related concepts in the literature (e.g., uncertainty, weak modality, vagueness), there is not a pre-existing list of imprecision keywords. We address these dual challenges by constructing a new dictionary of imprecise words and phrases (henceforth "imprecision keywords") that draws on Wikipedia's crowdsourced solution to identify the linguistic imprecision — "weasel tags." Specifically, we analyze the text of Wikipedia articles and, more importantly, the weasel tags embedded into these articles. Wikipedia advises its users to attach weasel tags when they encounter 
sentences or phrases in Wikipedia articles that have vague phrasing that accompanies unverifiable information. By appealing to Wikipedia's crowdsourced solution, we simultaneously provide an externally-reliable basis for identifying keywords associated with imprecision and "tie our hands" by eliminating researchers' subjective choices typically involved in building a dictionary of keywords. ${ }^{1}$

Using our dictionary of imprecision keywords, we generate a measure of linguistic imprecision at the firm-year level by computing the fraction of imprecision keywords in each firm's annual 10-K filing. ${ }^{2}$ Consistent with the idea that our measure captures the linguistic imprecision in $10-\mathrm{Ks}$, we find that $10-\mathrm{Ks}$ with greater linguistic imprecision tend to exhibit greater uncertainty and to contain more modal words that convey differing shades of meaning. Yet, we uncover that the information contained in our linguistic imprecision measure has distinctive and unique aspects beyond existing textual measures proposed in earlier studies. We also find that $10-\mathrm{K}$ disclosures with higher linguistic imprecision tend to have higher positive sentiment.

For a 10 -week window following the $10-\mathrm{K}$ disclosure, our core findings are that the linguistic imprecision in $10-\mathrm{K}$ predicts (i) positive return reactions (CARs and BHARs) that do not eventually revert, (ii) greater stock liquidity, evidenced in lower bid-ask spreads, (iii) greater probability of informed buying, based on Brennan, Huh, and Subrahmanyam (2018), and greater volume of insider purchases, ${ }^{3}$ and (iv) more positive-sentiment news, using sentiment data available from RavenPack. With the exception of insider purchases, which are likely informed before the $10-\mathrm{K}$ disclosure, these outcomes all exhibit no pre-trends in the 5 -week period prior to the $10-\mathrm{K}$ disclosure, and there is no perceptible effect of linguis-

\footnotetext{
${ }^{1}$ Our approach of appealing to an external source to ground our textual analysis of linguistic imprecision is similar to that taken in Bellstam, Bhagat, and Cookson (2020) who use an innovation textbook as a benchmark to evaluate which topics discussed by analysts reflect the innovation activities of the firms they cover.

${ }^{2}$ In the context of legally-required corporate disclosures, e.g., 10-Ks, we expect the incentives to use the imprecise language to be distinct from other source texts such as political statements and informal conference calls. As we discuss later at length, this distinction is important for how to interpret the use of the linguistic imprecision in $10-\mathrm{K}$ disclosures.

${ }^{3}$ In contrast, we find no significant association of our linguistic imprecision measure with the probability of informed selling and the volume of insider selling before and after the 10-K disclosure.
} 
tic imprecision past 10 weeks. Together, these core empirical results provide compelling evidence that the use of imprecise language in $10-\mathrm{K}$ disclosures reflects the value-relevant information on firms' fundamentals, which contrasts with the dominant obfuscation view in the literature.

As a complement to these core tests, we also evaluate the textual content of the disclosures that drive these results. Based on this textual content, our linguistic imprecision measure appears to reflect immature information on upcoming positive but yet uncertain prospects of earnings. Specifically, we detect two notable and consistent features of the textual disclosures in the sentences that surround imprecision keywords: (1) disclosures of product innovation and R\&D terms, both as words and bigrams (e.g., "clinical trial" or "product candidate"), and (2) forward-looking disclosures about the firm's uncertain, but potentially valuable, plans (e.g., "forward-looking statement" and "future cash"). Building on these textual indicators, we conduct a series of heterogeneity tests, and find that the cumulative market reactions to the linguistic imprecision in 10-Ks become stronger for firms that use more forward-looking terms, disclose more about $\mathrm{R} \& \mathrm{D}$, have greater idiosyncratic volatility, have less liquidity, and have no analyst coverage. These findings corroborate our interpretation that the linguistic imprecision in 10-Ks reflects uncertain, yet valuable, information that is eventually digested by market participants.

Several aspects of our test results contrast with notable alternative interpretations. First, we observe no pre-trends in abnormal returns prior to the $10-\mathrm{K}$ disclosure date, and find that after 10 weeks, there is no reversal in the returns. This pattern of returns is inconsistent with the possibility that investors overreact to the imprecise language in $10-\mathrm{Ks}$, and it is difficult to explain via a risk-based explanation. ${ }^{4}$ Second, during the same time frame when there are significant positive abnormal returns, stock liquidity also improves, contrasting further with a risk-based explanation. Third, consistent with the realization of positive information in the 10 weeks following 10-Ks with high imprecision, we find that both the

\footnotetext{
${ }^{4}$ Beyond showing this pattern of results, we also show that our finding is not driven by the changes in systematic risks captured by Fama-French three-factor model.
} 
probability of informed buying measure and news sentiment about the firm are greater. Finally, during the entire test period around 10-K disclosures with high imprecision, we find that insiders purchase significantly more of the firm's shares. ${ }^{5}$

Our paper makes several contributions to the existing literature. First, our evidence on the use of imprecise language in firm disclosures relates to the work on the discretionary disclosure and persuasion through information revelation (e.g., Bloomfield (2002)). Discretionary disclosure leads to full disclosure in a perfect information environment, but not in the presence of proprietary costs or other market frictions (Ross 1979, Verrecchia 1983, Kamenica and Gentzkow 2011, Ely 2017). Following this line of research, recent empirical applications have focused on how the disclosure of bad news can signal firm's quality (Gormley, Kim, and Martin 2012, Gao, Liang, Merkley, and Pacelli 2017). Our results on the informational value of imprecise language provide a novel and unique perspective on this research question. We show that our explicit measure of linguistic imprecision is more related to information than obfuscation. Our results suggest that managers act in their decisions to provide more voluntary information on immature but positive earnings opportunities.

Second, our identification and analysis of linguistic imprecision in 10-K disclosures provide a useful perspective on the SEC regulatory mandate (the Plain Writing Act) to use plain English in firm disclosures, studied in Hwang and Kim (2017). The use of linguistic imprecision is not especially discouraged in this SEC mandate that regulates the readability of firm disclosure documents for the general public because our imprecision words and phrases accord with plain English. Our finding that the imprecise language can reflect the informational content of disclosures that affects firm value, calls for more attention to the use of plain English and more careful conclusion in drawing a link between imprecise language and intentional obfuscation. At least in the average case, the linguistic imprecision in corporate disclosures should be separately interpreted in the context of upcoming positive but immature prospects of earnings, rather than being used to discount the validity of the

\footnotetext{
${ }^{5}$ Complementary to this main set of test results, we also find that the imprecise language in $10-\mathrm{Ks}$ is associated with future positive earnings surprises. See Appendix Table A.9.
} 
information in the disclosures.

Finally, our work is a part of a growing literature within finance and accounting that makes use of text descriptions to study important aspects of financial market reactions (Tetlock 2007, Hoberg and Phillips 2016, Hoberg and Moon 2017, Hoberg and Lewis 2017, Bellstam, Bhagat, and Cookson 2020). Within the broader literature on textual analysis in finance, our work is most closely related to applying textual analysis tools to analyze the tone of financial information (Hanley and Hoberg 2010, Dougal, Engelberg, Garcia, and Parsons 2012, Loughran and McDonald 2013, Garcia 2013, Jegadeesh and Wu 2017). As we will show in our regression analyses later, our measure is sensibly related to, but distinct from the existing lexicon of measures - many of which are available at the master dictionary by Loughran and McDonald (2011). Relative to these other textual measures, our linguistic imprecision measure provides a useful description of the imprecise language in financial disclosures, which is distinctive unto itself. In this respect, we anticipate fruitful applications of our linguistic imprecision measure to understand better the information environment into which the linguistic imprecision can be injected.

The remainder of the paper proceeds as follows. Section 2 provides a description of Wikipedia's weasel tags, the construction of our dictionary of imprecision keywords, and the development of our linguistic imprecision measure in 10-Ks. Section 3 describes our sample and presents results relating our linguistic imprecision measure to other existing variables to obtain a better understanding of which firms employ more imprecise language in their 10-Ks. Section 4 provides the main empirical results from the tests that investigate the relations between linguistic imprecision in 10-Ks and subsequent abnormal returns, liquidity, intensities of informed and insiders trading, and news sentiment after 10-K filing. Section 5 concludes with directions for future research. 


\section{Linguistic Imprecision in 10-K Disclosures}

\subsection{Weasel Words in Wikipedia Articles}

To construct a dictionary of imprecise language, we take the entire Wikipedia articles as our text corpus, identify sentences with Weasel tags attached, and compile a list of linguistic imprecision keywords from these weasel-tagged sentences. Ganter and Strube (2009) suggest three broad categories of weasel words or phrases used in Wikipedia articles: 1) numerically vague expressions (e.g., many), 2) the passive voice (e.g., it is said), and 3) adverbs that weaken (e.g., probably). Examples of these weasel words directly given by Wikipedia as style guidelines include "People are saying...", "There is evidence that...", and "It has been mentioned that...". ${ }^{6}$ Wikipedia users are then advised to avoid using weasel words and at the same time to detect and mark excessive uses of such words by others using a special weasel tag, $\{\{$ Weasel-inline $-\{\{$ subst:DATE $\}\}\}\}$, for improvement. The following examples illustrate how the weasel tag is used in a sentence of each Wikipedia article:

- "The Tic Tok Men"

Many $\{\{$ weasel inline - date $=$ March 2009$\}\}$ consider this album to be the quintessential Tic Tok sound.

- "Manu Parrotlet"

It has been said $\{\{$ weasel inline - date=January 2014\}\} that the Manu parrotlet can be seen along the Man on top of trees across from the Altamira beach about 25 minutes from the Manu Resort.

- "Nathaniel Mather"

He finished his studies in England probably $\{$ \{weasel inline-date=January 2014\}\} returning with his brother [[Samuel Mather (Independent minister)—Samuel]] in 1650.

We process a recent Wikipedia dump completed on April 20, 2017 and comprised of

\footnotetext{
${ }^{6}$ See Wikipedia's own article about weasel words for more details at https://en.wikipedia.org/wiki/ Weasel\_word.
} 
17,483,910 articles, and extract sentences that contain weasel tags. ${ }^{7}$ Motivated by Ganter and Strube $(2009),{ }^{8}$ we start by extracting all words in sentences that contain weasel tags. We then further calculate the frequencies of all these words and their bigrams and trigrams as well to better identify potential weasel words and phrases. The bigrams and trigrams are particularly useful to capture weasel phrases that use passive voice and appeals to anonymous authority.

Because weasel tags are typically removed after the language is edited and improved, the tags are not frequently observed at any given snapshot of Wikipedia articles. Therefore, sentences containing weasel tags are not abundant despite the large number of Wikipedia articles that we process. We identify 433 sentences with weasel tags from 367 Wikipedia articles after removing corrupt or redundant sentences. ${ }^{9}$

The numbers of unique and total words in the extracted sentences containing weasel tags are approximately 6,000 and 16,000, respectively. We sort these roughly 6,000 weasel unique words and their bigrams and trigrams by frequencies and assess whether each word or phrase correctly qualifies for a weasel word. In this frequency sort of raw words, commonly used words tend to show up as most frequent, despite not being weasel words themselves (e.g., words like "the", "and", and "that"). This is a much larger issue with the unigrams than it is with the bigrams or trigrams. For example, Panel A(a) of Table 1 presents the three separate lists of the top 10 most frequently mentioned unigrams, bigrams, and trigrams in our weasel-tagged sentences.

[Insert Table 1 Here]

To ensure that we do not merely pick up commonly used words for our imprecision keyword list, for each weasel-tagged sentence, we extract a control sentence that occurs three sentences later from the same Wikipedia article. By inspecting them manually, we make sure that these control sentences are free of weasel language and have the virtue that

\footnotetext{
${ }^{7}$ Wikipedia dumps are available for downloading at https://dumps.wikimedia.org/.

${ }^{8}$ Ganter and Strube (2009) analyze the five words occurring right before each weasel-tagged word.

${ }^{9}$ Our number of weasel tags is slightly more than 328 weasel tags identified by Ganter and Strube (2009) who processed two Wikipedia dumps with different completion dates.
} 
they are on the same set of topics as the weasel text. Using these control sentences together with the corresponding weasel-tagged sentences, we compute the saliency of the words in the weasel-tagged sentences relative to control sentences based on Goldsmith-Pinkham, Hirtle, and Lucca (2016). This saliency measure captures the degree to which the words are overused relative to common language, and is thus, appropriate for screening a list of common language. Panel A(b) of Table 1 shows how effective the saliency screen that we use is in filtering out common language from the list of words. ${ }^{10}$

After filtering out common language using the saliency screen on unigrams, we compile our final list of linguistic imprecision keywords (unigrams, bigrams, trigrams). Further, we expand the list of linguistic imprecision keywords using variations on these words such as the singular and plural forms for nouns and the past, present, and future tenses for verbs. We also manually eliminate redundancy in bigrams and trigrams in cases where including both would count the same language twice. ${ }^{11}$

Our dictionary for linguistic imprecision is distinct from notable alternatives. For example, Panel A(c) of Table 1 presents the top 10 most frequently used keywords in 10-Ks based on our dictionary for linguistic imprecision, and for comparison, the dictionaries for uncertainty and weak and strong modality taken from the Loughran and McDonald (2011) master dictionary. The most frequently used words in each of these dictionaries have minimal overlap with one another, indicating that our linguistic imprecision measure using the imprecision keywords is distinct from these related measures and thus can contain unique information. For example, numerically vague expressions such as "other", "number of",

\footnotetext{
${ }^{10}$ Salience $($ word $\mid$ weasel sentence $)=p($ word \& weasel sentence $) \times \log \left(\frac{p(\text { weasel sentence } \mid \text { word })}{p(\text { weasel sentence })}\right)$ is used as an equation for the saliency filter. We also consider a re-weighted version of the list for linguistic imprecision keywords using term frequency-inverse document frequency (tf-idf) weights that mirrors the intuition of the Goldsmith-Pinkham, Hirtle, and Lucca (2016) saliency filter. Results using the saliency filter and tf-idf weighting are nearly identical. Despite this robustness to another sophisticated methodology, we prefer to use the saliency filtered list for linguistic imprecision keywords since it is more transparent and involves fewer researcher choices.

${ }^{11}$ In addition, Wikipedia has published guidelines for weasel words with specific examples to help users identify weasel language. Our methodology captures the vast majority of the example phrases offered by Wikipedia, but several example phrases in the guidelines are not in the Wikipedia dump that we analyze. To maintain the most comprehensive list of linguistic imprecision keywords, we also include these guideline weasel words in our final list. The complete dictionary for linguistic imprecision can be obtained by contacting the authors.
} 
and "various" are uniquely included in the top 10 most frequently used imprecision keywords. ${ }^{12}$ Also, a number of passive expressions such as "said", "considered", and "found" are frequently used imprecision keywords in $10-\mathrm{Ks}$, although those are not included in the top 10 list.

\subsection{Quantifying Linguistic Imprecision in 10-K Disclosures and Under- standing of it}

The final step in our text processing procedure is to download all 10-K filings whose report dates range from 1997 to 2015 and extract the raw counts of how many times a given firm mentions each of the imprecision keywords in a given year. This generates a full panel of linguistic imprecision keyword vectors with 219,491 firm-year observations. Our final sample is reduced to 46,996 firm-year observations after merging with the Compustat and CRSP databases. The number of firm-year observations decreases further to approximately 30,000 when the sample is merged with the product market threats and financial constraints data from Hoberg, Phillips, and Prabhala (2014) and Hoberg and Maksimovic (2015), respectively, for some analysis.

We create our main linguistic imprecision measure, Imprecision, based on the vectors of our imprecision keywords. Imprecision is how many times the imprecision keywords are mentioned (i.e., the sum of all elements in the imprecision keyword vector) in a given firm's 10-K filing in a given year scaled by the total word count in the filing in the percentage term. Throughout the paper, we focus on Imprecision as our main variable of interest.

To provide a contextual understanding of our imprecision measure, we examine neighbor unigrams and bigrams that co-exist with our linguistic imprecision keywords in 10-K disclosures. Neighbor unigrams and bigrams are those that occur in the same paragraph of any of the imprecision keywords. Panel B of Table 1 present the lists of the frequently mentioned neighbor unigrams and bigrams. For unigrams in Panel B(a), we only include

\footnotetext{
${ }^{12}$ The most frequently used unigram, "other", can be simply mentioned in 10-Ks to refer to an accounting item that contains "other", for example, as in "Other Comprehensive Income", "Assets - Other", "Liabilities - Other - Total". We note that our findings discussed in the subsequent sections are robust to excluding "other" from our dictionary for linguistic imprecision.
} 
words in the Loughran and McDonald (2011) master dictionary that are considered to add financial information content. We also identify the part of speech for each of the unique neighbor words and sort them by frequencies.

The three columns in Panel B(a) of Table 1 list verbs, nouns, and adjectives or adverbs, respectively. In the list for verbs, the top 5 most frequently mentioned neighbor words are "hidden", "will", "required", "expected", and "estimated." These words appear to be associated with a firm's discussion on upcoming but uncertain situations. Besides, "anticipate(d)", "assumed", "intended", "achieve", "increasing", and "projected" in lower ranks of the verb list also suggest similar context around an imprecision keyword in a paragraph. The most frequently mentioned noun is "plan", and "future" follows it. These two words are also associated with forward-looking disclosures. The most frequently mentioned adjective or adverb was "approximately." It is worth noting that the adjective or adverb list includes neighbor words that imply positive attributes of circumstances, for example, "effective", "able", "greater", "beneficial", "successful", and "favorable."

Panel $\mathrm{B}(\mathrm{b})$ of Table 1 lists meaningful neighboring bigrams in 10-K paragraphs that contain the linguistic imprecision keywords. We analyze 5,597,740 unique pairs of bigrams in 10-K paragraphs and compute the saliency score of each bigram in the paragraphs with the linguistic imprecision keywords relative to the paragraphs without such keywords. We then classify the top 100 most salient bigrams by the contents of information. Out of the top 100 bigrams, 41 bigrams are classified into innovation terms, forward-looking terms, terms to describe market conditions, and terms to describe firm value. The remainder refers to individuals, days, time periods, or generic terminology. Appendix Table A.1 shows the complete list of the top 100 neighboring bigrams that are overused relative to common language with the saliency screen.

We also examine time-series variations in the degree to which imprecision keywords are used to describe the same topic in a firm's 10-Ks. We present below excerpts from the MD\&A sections of Technical Communications Corp's 10Ks discussing "Liquidity and Capital Resources - Cash Requirements", where imprecision keywords are underlined. 


\section{Technical Communications Corp's 10-K in 2000}

Cash and cash equivalents increased by $\$ 783,000$ or $33 \%$ to $\$ 3,122,000$ as of September 30,2000 , from a balance of $\$ 2,339,000$ at October 2,1999 . This increase was primarily due to the reduction of accounts receivable, which were partially offset by operating losses and a reduction in current liabilities.

\section{Technical Communications Corp's 10-K in 2010}

It is anticipated that cash from operations will fund our near-term research and development and marketing activities. We also believe that, in the long term, based on current billable activities and the improvement in business prospects, cash from operations will be sufficient to meet the development goals of the Company, although we

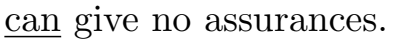

\section{Technical Communications Corp's 10-K in 2015}

We believe that our overall financial condition remains strong. Our cash, cash equivalents and marketable securities at October 3, 2015 totaled $\$ 3,709,000$ and we continue to have no long-term debt. It is anticipated that our cash balances and cash generated from operations will be sufficient to fund our near-term research and development and marketing activities. We believe that the combination of existing cash, cash equivalents, and highly liquid short-term investments, together with future cash to be generated by operations, will be sufficient to meet our ongoing operating and capital expenditure requirements for the foreseeable future and at least through the end of fiscal year 2016. We also believe that, in the long term, an anticipated improvement of business prospects, current billable activities and cash from operations will be sufficient to meet the Company's investment in product development, although we can give no assurances.

The company discusses its liquidity and cash requirements using no imprecise language in 2000 but increases its usage of imprecise language in 2010 and more significantly so in 2015.

We find that sentences containing our linguistic imprecision keywords are particularly to provide the company's anticipation in its future cash situations and to assure its shareholders that cash from its operations will be sufficient. The company's expression of forward-looking information and positive possibility often accompanies with imprecise language in 2010 and 2015 in contrast with its straightforward numerical description of the company's current cash situation in 2000. 
Overall, the picture that emerges from examining words neighboring our linguistic imprecision keywords and examples of time-varying usages of imprecision keywords in 10-K within a firm is that corporate disclosures containing imprecise language are more likely to express shades of possibility and convey forward-looking information that is by nature less specific and precise.

\subsection{Additional Discussion on the Imprecise Language in 10-K Disclosures}

Before describing our empirical tests in the subsequent sections, it is important to comment on the meaning of linguistic imprecision within the context of $10-\mathrm{K}$ disclosures relative to other potential source texts. We expect that the linguistic imprecision measure based on $10-\mathrm{K}$ disclosures — which are required by Regulation S-K to include any information with material effects on the firm's financial condition or results of operations, are carefully curated by the firm's legal team, and should be audited also — is likely different from a similar measure based on other source texts that do not have the same degrees of difficulty of censoring and ex ante scrutiny (e.g., the question and answer portion of the earnings conference call). Because of this high degree of care in preparing the 10-Ks, the imprecise language in $10-\mathrm{Ks}$ is more deliberate than other source texts. With this background in mind, we expect our linguistic imprecision measure based on 10-K disclosures to contain genuine information that is not possible to make precise at the time of the disclosure because of market conditions or timing. This information can be distinctively useful from the standpoint of investors in evaluating the likely consequences of conditions that the firm faces.

\section{Validation and Relation to Firm Characteristics}

In this section, we conduct a series of empirical analyses to obtain an understanding of firms' usage of imprecise language in 10-K disclosures: Which firms employ more imprecise language in their 10-K disclosures under what situations than others? The results from these

analyses are useful to design our main empirical analyses and to interpret the corresponding 
test results in Section 4.

\subsection{Summary Statistics}

Table 2 presents the basic summary statistics for various textual tonal variables (in Panel A) and non-tonal firm-specific characteristics (in Panel B), respectively, which will be used in our subsequent analyses. Each variable is winsorized at the top and bottom $1 \%$ of its distribution. As for the textual tonal variables, we include our linguistic imprecision measure (Imprecision), existing textual tonal variables based on the master dictionary by Loughran and McDonald (2011) (Sentiment, Uncertain, Modal, Constraining, Litigious, Superfluous, and Interesting), and Fog words initially proposed by Robert Gunning in 1952 and used extensively in the literature to quantify the lack of plain English (e.g., Li (2008)). All textual tonal variables are expressed in percentage and their detailed definitions are provided in the Appendix. In Panel A of Table 2, the mean and median of Imprecision are $1.387 \%$ and $1.471 \%$, respectively. The average of Sentiment that is the difference between the percentages of positive words and negative words (out of total words) is $-0.716 \%$, indicating that negative sentiment dominates positive one in our sample of $10-\mathrm{K}$ disclosures. On average, $30 \%$ of words are considered as complex (Fog) words, and uncertain or litigious words are mentioned as many times as our linguistic imprecise keywords.

[Insert Table 2 Here]

As for non-tonal firm-specific characteristics, the average of market value of total assets is approximately $\$ 1.18$ billion (Size in logarithm) and the average of firm age (Age) in our sample is roughly 11 years. We include two growth opportunities proxies: Tobin's Q and Sales growth, whose means are 1.94 and approximately 11\%, respectively. We also consider two proxies for the economic conditions that firms face: Product market fluidity by Hoberg, Phillips, and Prabhala (2014) and Financing constraints by Hoberg and Maksimovic (2015). For the analysis on how stock prices react to our linguistic imprecision measure (Section 4.1), we include share turnover (Turnover), book-to-market ratio (Book-to-market), percentage 
of institutional investors' holdings (Institutional ownership), risk-adjusted return before 10-K filing (Fama-French alpha), and Filing-day abnormal return as control variables.

\subsection{Relations to Other Textual Tonal Variables}

In this section, we examine the relations of our linguistic imprecision measure (Imprecision) to existing textual tonal measures proposed in earlier studies, which can deepen our understanding of the use of imprecise language in 10-K disclosures. Although the imprecise language is distinct from uncertainty and weak modal language, we expect it to be positively related to uncertainty and weak modal language to a certain extent. It is because, intuitively, we expect firms to use more imprecise language in their 10-Ks at times and in situations where they face greater uncertainty, captured by uncertainty and weak modal words. We validate this intuition of linguistic imprecision by using uncertainty keywords, and weak and strong modal keywords from the master dictionary by Loughran and McDonald (2011). Portraying a series of univariate comparisons, Figure 1 presents sets of side-by-side box plots for the usage of linguistic imprecision in 10-Ks by whether uncertainty, weak modality, and strong modality are above versus below the median.

\section{[Insert Figure 1 Here]}

These box plots in Figure 1 indicate that the imprecise language in 10-Ks is more commonly used with high uncertainty words and high modality words. In addition, they show that there are substantial overlaps in the distributions of the linguistic imprecision for high and low uncertainty, weak modality, and strong modality, implying that there is useful residual variation in our linguistic imprecision measure when holding the other textual tonal measures constant.

To examine the associations between our linguistic imprecision measure and other textual tonal measures more systematically, we regress Imprecision on a set of existing textual tonal measures (and an intercept), where all variables are contemporaneous. In Panel A of Table 3 , we report the estimation results of this regression model which also controls for firm and 
year fixed effects. To account for potential serial correlation in the linguistic imprecision measure, the standard errors are clustered by firm.

[Insert Table 3 Here]

In Column (1) of Panel $\mathrm{A}$, we include Fog to quantify the complexity of $10-\mathrm{K}$ disclosures, and Uncertain and Modal constructed based on the master dictionary by Loughran and McDonald (2011) as independent variables. Column (1) show that complexity, uncertainty, and modality are all positively associated with our linguistic imprecision measure, as expected, even when controlling for unobserved firm characteristics by including firm fixed effect. In Column (2), we additionally examine the relations of linguistic imprecision with Sentiment and two other textual tonal variables, Constraining and Litigious, which capture firm's constraining and litigious situations, respectively. We find evidence that our measure of linguistic imprecision is positively associated with Sentiment, Constraining, and Litigious, suggesting an interpretation that firms use less precise language when they discuss their positive prospects that likely have not been realized under those negative situations. In Column (3), we also control for the percentages of superfluous words and interesting words, Superfluous and Interesting, and find that the test results in Columns (1) and (2) remain intact. Although we do not report the results to conserve space, we find that our results are robust to controlling for Size, Age, Tobin's Q, and Sales growth additionally, in terms of the magnitudes and statistical significance of slope coefficients. ${ }^{13}$

Taken together, the evidence in this section suggests that the imprecise language used in 10-Ks captures relatively positive tone with high uncertainty and high modality. Because uncertainty and modality aspects of the text are to a large degree parts of the content of linguistic imprecision, we do not control for Uncertain and Modal in our subsequent

\footnotetext{
${ }^{13}$ We conduct two robustness tests for Panel A of Table 3. First, we repeat the same analyses at the paragraph level, reaching the same conclusions about how the linguistic imprecision relates to uncertainty and modality. In the paragraph-level analyses, we control for firm-year (i.e., report level) fixed effects, identifying only on the variation within $10-\mathrm{K}$ disclosure. Second, beyond the normalization by calculating the percentage of imprecision keywords in our linguistic imprecision measure, we rerun all tests by additionally controlling for the log of the total number of words in 10-K, which is related to readability (e.g., Loughran and McDonald (2014)), and find that our test results are robust.
} 
market-reaction tests in Section 4.

\subsection{Relations to Non-tonal Firm-specific Characteristics}

The language choices in firms' disclosures are likely to be affected by situations that those firms face, which can be captured at least partially by various non-tonal firm-specific characteristics. For example, imprecise language ought to be more frequently used by firms when they face greater growth opportunities that are difficult to quantify at the moment of disclosure. Based on this intuition, we try to relate lagged non-tonal firm-specific characteristics to our linguistic imprecision measure.

\section{[Insert Figure 2 Here]}

We first illustrate graphically which non-tonal firm-specific characteristics (among notable ones) are related to the use of imprecise language in 10-Ks. Figure 2 presents the $95 \%$ confidence intervals for the means of Size, Age, and two proxies for growth opportunities (Tobin's Q and Sales growth) by each quartile of the distribution of our linguistic imprecision measure. From Figure 2, we find strong patterns that smaller and younger firms (Figures 2(a) and 2(b)) which are likely to have more growth opportunities (Figures 2(c) and $2(\mathrm{~d}))$ tend to use more imprecise language in their 10-Ks.

We then investigate the associations with those firm characteristics more systematically with the regression models in Panel B of Table 3. All regression models include firm and year fixed effects and intercepts, and standard errors are clustered by firm to account for potential serial correlation in the linguistic imprecision measure. In Column (1) of Panel B, we consider the first set of non-tonal firm-specific characteristics employed in Figure 2, i.e., Size, Age, Tobin's Q, and Sales growth, which are lagged by on year. The result in Column (1) of Panel B indicates that the strong associations between the linguistic imprecision measure and Size, Age, and Tobin's Q, as indicated in Figure 2, are also present in the regression analysis.

The next set of non-tonal firm-specific characteristics include proxies for product market 
threats and financial constraints, which are lagged by one year. An important strand of the corporate finance literature has paid particular attention to how corporate policies relate to product market threats and financial constraints. In this context, we investigate how firms' use of imprecise language in their disclosures changes upon facing greater product market threats and financial constraints. Column (2) of Panel B in Table 3 provides the test results. We find significant positive associations between our measure of linguistic imprecision and both Product market fluidity and Financial constraints, which are, respectively, proposed by Hoberg, Phillips, and Prabhala (2014) and Hoberg and Maksimovic (2015). This supports the idea that product market threats or financial constraints place pressure on firms to disclose some information, which is potentially useful to alleviate their difficult situations in product markets or financial markets, by using imprecise language in their 10-K disclosures.

As the last set of non-tonal firm characteristics, in Column (3), we consider a list of variables that have been known to affect firms' returns on the event days of $10-\mathrm{K}$ releases. Those variables include Turnover, Institutional ownership, and Fama-French alpha, which are calculated over periods before 10-K filing dates, and Filling-day abnormal return. ${ }^{14}$ The test results in Column (3) show that these firm characteristics are not significantly related to the use of imprecise language in $10-\mathrm{K}$ disclosures.

Overall, the various test results in this section deepen our understanding of firms' usage of imprecise language in their 10-Ks and are particularly informative in designing our main empirical analyses and interpreting the associated results in the next section with respect to market reactions to the linguistic impreciesion in $10-\mathrm{K}$ disclosures.

\section{Reactions to Linguistic Imprecision}

\subsection{Price Reaction to Imprecise Language in 10-K Disclosures}

This section investigates the relation between imprecise language in 10-Ks and subsequent stock returns after 10-K filing. Specifically, for each 10-K release, we compute the buy and

\footnotetext{
${ }^{14}$ We do not include Market value and Book-to-market in Column (3) since their inclusion can be redundant due to Size and Tobin's Q.
} 
hold abnormal returns (BHARs) over weekly windows around its filing and test whether our linguistic imprecision measure predicts abnormal returns using the following regression specification. For stock $i$, over the $n$th week around its $10-\mathrm{K}$ filing in year $t$,

$$
\text { BHAR }_{i t n}=\alpha_{n}+\beta_{n} \text { Imprecision }_{i t}+\eta_{n}^{\prime} \mathbf{X}_{i t}+\epsilon_{i t n},
$$

where $B H A R_{i t n}$ is defined as the return difference between stock $i$ and the CRSP valueweighted index over the $n t h$ week window, ${ }^{15}$ Imprecision $_{i t}$ is the percentage of our linguistic imprecision keywords (out of the total words) in the $10-\mathrm{K}$ disclosure, and $\mathbf{X}_{i t}$ is a column vector that has control variables used in prior studies (e.g., Loughran and McDonald (2011)), including Sentiment, Market value, Book-to-market, Turnover, Institutional ownership, Fama-French alpha, and Filing-day abnormal return. All independent variables in Model (1) are constructed based on the information available as of the 10-K filing date and their detailed definitions are provided in the Appendix. For ease of interpretation, they are standardized to have zero mean and one standard deviation. We estimate Model (1) for each week separately over the previous 3 -week period before the $10-\mathrm{K}$ release date and the subsequent 9 -week period after the $10-\mathrm{K}$ release date (thus $n=-3, \ldots, 9$ ), where we employ clustered standard errors by filing year-month to account for cross-sectional correlation of returns across stocks.

The coefficient of interest in Model (1) is $\beta_{n}$, which captures how each stock's price in the $n$th week reacts to the imprecise language used in its $10-\mathrm{K}$ disclosure. We hypothesize that the linguistic imprecision in 10-K disclosures contains positive but immature value-relevant information about firms and investors need some time to digest it. Thus, we expect positive but delayed price reactions to the linguistic imprecision in $10-\mathrm{Ks}$ after the release dates, that is, $\beta_{n}>0$ for some $n>0$ and no pre-trend exists before the filing dates.

\section{[Insert Table 4 Here]}

\footnotetext{
${ }^{15}$ The 1 st week window starts from the fourth day (inclusive) and ends at the tenth day (inclusive) after the 10-K release date. The 10-K filing-day window, i.e., the 0th week window, covers the four days between the $10-\mathrm{K}$ filing day and three days later. The -1 st week window covers seven days before the $10-\mathrm{K}$ filing day (exclusive).
} 
The test results of Model (1) are presented in Table 4. We only report slope coefficient estimates of two main variables of interest, Imprecision and Sentiment, and Appendix Table A.2 presents the slope coefficient estimates for all control variables. The evidence in Panel A of Table 4 supports our hypothesis. We find positive and significant slope coefficients for Imprecision $_{i t}$ from the 3rd through 7 th weeks after 10-K filing. The slope coefficients for Imprecision $_{i t}$ in weeks 8 and 9 are also positive but statistically insignificant, indicating that the positive price reaction to the linguistic imprecision in 10-Ks does not revert over time. We observe no reversal further until the 15 th week after $10-\mathrm{K}$ filing, although we report the results up to the 9 th week to conserve space. It is also worth noting that there is no evidence of pre-trends, as slope coefficients for Imprecision before 10-K filing are all indistinguishable from zero. To further examine whether systematic risks drive our BHAR predictability, we also include the exposures to the Fama-French three factors in Model (1) as additional control variables, where the factor loadings are estimated over the preceding one year before the $10-\mathrm{K}$ release date. We find that our test results on $\beta_{n}$ remain almost intact even after controlling for those factor loadings.

Panel B of Table 4 reports analogous test results over multiple-week windows to capture longer-term price reactions, where we call them cumulative BHARs and use them as the dependent variable in Model (1). For post-filing weeks, each cumulative BHAR is computed over the period from the start of the 1st week (i.e., the fourth day after 10-K filing) to the end of the $n$th week, where $n=1, \ldots, 9$. For pre-filing weeks and the 0th week, each "reverse" cumulative BHAR is computed over the period from the end of the 0th week (i.e., the third day after $10-\mathrm{K}$ filing) to the start of the $n$th week, where $n=-3, \ldots, 0,{ }^{16}$ and it is used as the dependent variable in Model (1). The positive and significant return effect of imprecise language in 10-K disclosures cumulatively emerges from the 3rd week, monotonically increases until the 9th week, and remains at a similar level afterward. This monotonic increase again indicates that the positive linguistic imprecision effect does not

\footnotetext{
${ }^{16}$ E.g., the reverse cumulative BHAR for Week $[-1,0]$ is computed as follows. Suppose that $B H A R_{-1}$ and $B H A R_{0}$ are, respectively, the weekly BHARs over the -1 st week and 0th week. We then obtain the reverse cumulative BHAR for Week[-1,0] by solving $\left(1+B H A R_{[-1,0]}\right)=\frac{1}{\left(1+B H A R_{-1}\right) *\left(1+B H A R_{0}\right)}$ for $B H A R_{[-1,0]}$.
} 
experience a return reversal. The economic magnitude of this linguistic imprecision effect can be gauged as follows. Based on Column of Week[1,9], one standard deviation increase in the use of imprecise language in $10-\mathrm{K}$ disclosure $(=0.46 \%)$ is associated with about $0.96 \%$ higher BHAR over the nine-week period after its release.

As an alternative presentation of our positive linguistic imprecision effect, Figure 3 plots the slope coefficient estimates of Imprecision for cumulative BHARs over an extended period around $10-\mathrm{K}$ filing with the $95 \%$ confidence intervals.

\section{[Insert Figure 3 Here]}

In Figure 3, the line with black circles shows that on average the cumulative BHAR increases about $1 \%$ eventually over the nine-week period after the $10-\mathrm{K}$ release date. This graphical illustration also explicitly shows that the positive linguistic imprecision effect is not preceded by any pre-trend or followed by a reversal. The positive and delayed price reactions to imprecise language discussed above is strongly consistent with our hypothesis that the linguistic imprecision in $10-\mathrm{Ks}$ can provide positive but immature value-relevant information about firms to investors in financial markets.

We conduct multiple robustness checks. First, to ensure that the positive and significant price reactions to the linguistic imprecision in $10-\mathrm{Ks}$ are not mechanically related to the future earnings announcements (relative to 10-K filing dates), we estimate Model (1) and repeat tests with a refined sample that excludes all $10-\mathrm{K}$ filings that have new earnings announcements over the next three to seven weeks after $10-\mathrm{K}$ release dates. The associated test results are presented in Appendix Table A.3, indicating that the positive linguistic imprecision effect is not mechanically driven by upcoming future earnings announcements over the next three to seven weeks. Second, to ensure that our test results are not sensitive to how to compute abnormal returns, we estimate Model (1) with cumulative abnormal return (i.e., $C A R_{i t n}$ ) as the dependent variable instead of $B H A R_{i t n} .{ }^{17}$ The associated

\footnotetext{
${ }^{17}$ Fama (1998) advocates CAR and argues that BHAR exacerbates the "bad-model problems" by compounding an expected-return model's problem in explaining short-term returns. In contrast, Barber and Lyon (1997) advocates BHAR. Our test results are robust to using either BHAR or CAR.
} 
test results are presented in Appendix Table A.4, which indicates that the positive and significant price reactions to the imprecise language in $10-\mathrm{Ks}$ are robust to how to compute firms' abnormal returns. Third, we include the following additional control variables in Model (1): Sales growth, Product market fluidity, and Financial constraints and repeat the tests. With this extended model, we find qualitatively similar test results for the positive linguistic imprecision effect to Table 4.

\subsection{Liquidity Reaction to Imprecise Language}

In this section, we examine how the use of imprecise language in 10-Ks affects the illiquidity over weekly windows around $10-\mathrm{K}$ release dates. If the positive and significant price reaction to the linguistic imprecision in $10-\mathrm{Ks}$ discussed in the previous section is primarily driven by the release of value-relevant information and investors digest it over the subsequent periods, we expect a negative relation between our linguistic imprecision measure and firms' illiquidity or information asymmetry after $10-\mathrm{K}$ filing with no pre-trend. To test this potential link between linguistic imprecision and illiquidity level, we employ the following specification: For stock $i$, over the $n$th week around its $10-\mathrm{K}$ filing in year $t$,

$$
\text { Spread }_{i t n}=\alpha_{n}+\beta_{n} \text { Imprecision }_{i t}+\eta_{n}^{\prime} \mathbf{X}_{i t}+\epsilon_{i t n}
$$

where Spread $_{i t n}$ is the level of the quoted relative bid-ask spread, which is the average of daily ratios of quoted bid-ask spread to the bid-ask midpoint, over the $n$th week window in logarithm. ${ }^{18}$ Imprecision $_{i t}$ is the percentage of linguistic imprecision keywords (out of total words) used in firm $i$ 's $10-\mathrm{K}$, and $\mathbf{X}_{i t}$ is a column vector that has the same control variables as in Table 4 and two additional control variables, which are Nasdaq dummy and Pre-filing spread. All independent variables in Model (2) are constructed based on the information available as of the 10-K filing date and their detailed definitions are provided in the Appendix. For ease of interpretation, they are standardized to have zero mean and one standard deviation. To model unobserved heterogeneity across firms and a secular reduction

\footnotetext{
${ }^{18}$ We employ the same definition of weekly windows as those for the BHAR regression in Model (1).
} 
in market illiquidity over time, respectively, we also control for firm and filing year-month fixed effects. To account for serial and cross-sectional correlations of quoted relative bid-ask spread, we employ the clustered standard errors by firm and filing year-month (see Amihud (2002) and Chordia, Roll, and Subrahmanyam (1997), respectively).

The coefficient of interest in Model (2) is $\beta_{n}$, which captures how the imprecise language in 10-Ks affects firm's illiquidity level or information asymmetry over the $n$th week window around 10K filing. The test results of Model (2) are presented in Table 5, where we only report the slope coefficient estimates of three main variables of interest, i.e., Imprecision, Sentiment and Pre-filing spread, and those of all control variables are provided in Appendix Table A.5.

[Insert Table 5 Here]

We find that the slope coefficients for Imprecision are negative and significant at the $1 \%$ or $5 \%$ level from the 1 st through 9 th weeks after $10-\mathrm{K}$ filing. We also find no evidence of pre-trends as the slope coefficients for Imprecision before 10-K filing are all statistically indistinguishable from zero. These results indicate that illiquidity or information asymmetry in the subsequent weekly periods decreases with the increase of imprecise language in 10-Ks. Interestingly, we further note that the negative effect of linguistic imprecision on illiquidity is the strongest in the $3 \mathrm{rd}$ and 4 th weeks after $10-\mathrm{K}$ filing and coincides with the time periods when the stock price reaction is the strongest as in Table 4. These results are consistent with the interpretation that greater use of imprecise language in 10-Ks is indeed associated with more value-relevant information about firms and that the information is digested by investors in financial markets, thus leading to a decrease in illiquidity after 10-K filing.

The graphical representation in Figure 4(a) provides the gist of our finding on liquidity improvement over an extended window combining the previous 5-week period before the $10-\mathrm{K}$ release date and the subsequent 15 -week period after the $10-\mathrm{K}$ release date. It confirms that the negative linguistic imprecision effect on illiquidity is not preceded by any pre-trend and concentrated on the nine-week period following 10-K releases. 


\section{[Insert Figure 4 Here]}

As for the control variables in Model (2), their effects on illiquidity are consistent with existing studies in the literature. For example, we find evidence that the slope coefficients for Sentiment are negative in general and significant in the 7 th and 8th weeks. This suggests that the percentages of positive and negative words in 10-Ks can contain value-related information, consistent with the pricing evidence of textual tones in Tetlock, Saar-Tsechansky, and Macskassy (2008), Loughran and McDonald (2011), and Jegadeesh and Wu (2013). It is worth noting that we include a pre-filing level of the quoted relative bid-ask spread in Model (2) and find that the significant negative effect of our linguistic imprecision measure on the illiquidity survives.

Based on the test results so far, we conclude that the linguistic imprecision in $10-\mathrm{Ks}$ delivers the value relevant information on firms rather than obfuscation to financial markets and investors digest it. Our earlier findings that stock prices eventually respond positively to the use of imprecise language in $10-\mathrm{Ks}$ and that this positive reaction does not lead to a reversal are consistent with this conclusion on the liquidity improvement.

\subsection{Informed Traders' Reaction to Imprecise Language}

The above discussed findings that the stock price eventually responds positively to the use of imprecise language in 10-K disclosure and information asymmetry also decreases with it, suggest that there is value-relevant information contained in managers' using imprecise language in corporate disclosure. To understand this implication on a deeper level, we now investigate whether there are informed trading activities associated with the imprecise language in 10-K disclosures by corporate outsiders and insiders.

If the positive value-relevant information contained in the imprecise language in $10-\mathrm{Ks}$ is digested and consumed more quickly by some sophisticated outside investors, we expect to see a positive relation between our linguistic imprecision measure and informed buying activity after 10-K filing. To test this prediction, we employ the following specification: For 
stock $i$, over the $n$th week around $10-\mathrm{K}$ filing in year $t$,

$$
\text { Probability of informed buying } g_{i t n}=\alpha_{n}+\beta_{n} \text { Imprecision }_{i t}+\eta_{n}^{\prime} \mathbf{X}_{i t}+\epsilon_{i t n} \text {, }
$$

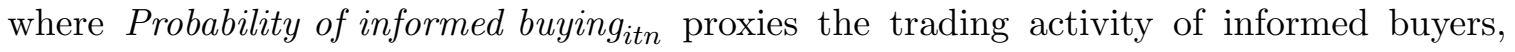
which is the average of daily probability of informed buying proposed by Brennan, Huh, and Subrahmanyam (2018), ${ }^{19}$ over the $n t h$ week window. ${ }^{20}$ Imprecision $_{i t}$ is the percentage of linguistic imprecision keywords (out of total words) used in firm $i$ 's $10-\mathrm{K}$, and $\mathbf{X}_{i t}$ is a column vector that has the same control variables as in Table 4 and two additional control variables, which are Nasdaq dummy and pre-filing probability of informed buying. All of the independent variables in Model (3) are constructed based on the information available as of the 10-K filing date and their detailed definitions are provided in the Appendix. For ease of interpretation, they are standardized to have zero mean and one standard deviation. We also control for filing year-month fixed effect and cluster standard errors by firm and filing year-month.

The slope coefficient of our main interest in Model (3) is $\beta_{n}$, which captures how the imprecise language in 10-Ks affects the informed buying activity of corporate outsiders over the $n$th week window after $10-\mathrm{K}$ filing. The test results of Model (3) are presented in Table 6, where we only report the slope coefficient estimates of three main variables of interest, i.e., Imprecision, Sentiment, and Pre-filing informed buying, and those of all control variables are provided in Appendix Table A.6.

[Insert Table 6 Here]

\footnotetext{
${ }^{19}$ Based on the structural model of the probability of informed trading (PIN) developed by Easley et al. (1996), Brennan, Huh, and Subrahmanyam (2018) propose daily proxies for informed buying and selling activities at the stock level. For each stock and month, Brennan, Huh, and Subrahmanyam (2018) estimate the five parameter of the PIN model using a three-month rolling window, and then calculate the daily posterior probability that a given trading day has a good news or bad news by conditioning on the number of buyer-initiated and seller-initiated trades on each day. In those models, the informed encompasses not only traders who own private information but also those who possess superior information processing skills of publicly available information to others. For more details, see Section 1 of Brennan, Huh, and Subrahmanyam (2018).

${ }^{20}$ We use the same definition of weekly windows as those for the BHAR and illiquidity regressions in Models (1) and (2), respectively.
} 
We find that the slope coefficients for our linguistic imprecision measure are positive and significant not only on the 10-K filing-day window (i.e., the 0th week) but also over the subsequent six weeks. This positive effect of linguistic imprecision on informed buying activity becomes the strongest over the 0 th and 1st weeks, indicating that the informed buyers' reactions to the imprecise language in 10-Ks emerge earlier than the rise of stock price and improvement of liquidity over the 3rd and 4th weeks as shown, respectively, in Tables 4 and 5. We also find no evidence of pre-trends as the slope coefficients for Imprecision before 10-K filing are all statistically indistinguishable from zero. In contrast, when using the probability of informed selling, also proposed by Brennan, Huh, and Subrahmanyam (2018), as the dependent variable in Model (3), we find that the slope coefficient estimates of Imprecision are all insignificant over all weekly windows, which is not reported to save space. All together, these results support the interpretation that positive value-relevant information disseminates into markets through the imprecise language in $10-\mathrm{Ks}$ and it is digested by informed traders more quickly than other market participants. The graphical representation in Figure 4(b) well summarizes our test results on informed buying activity over an extended window combining the previous 5 -week period before $10-\mathrm{K}$ filing and the subsequent 15-week period after 10-K filing.

Next, we investigate how the informed buying activity by corporate insiders is associated with the linguistic imprecision in 10-Ks by replacing the dependent variable in Model (3) with the dollar volume of insider buying over the $n t h$ week window, which we call Dollar volume of insider buying ${ }_{i t n},{ }^{21}$ and by excluding Pre-filing informed buying from the list of control variables. For this new regression, we expect that $\beta_{n}>0$ for some $n$ if the private information that makes managers employ more imprecise language in their 10-Ks is indeed positive. In contrast to the other tests, we expect insider buying to be greater throughout the event window because insiders have access to information prior to the 10-K

\footnotetext{
${ }^{21}$ For each firm $i$, we construct Dollar volume of insider buying ${ }_{i t n}$ by summing up all records of insiders' buying dollar volume over the $n$th week window around $10-\mathrm{K}$ filing date, which are available from the Thomson Reuters' Insiders database. When repeating the same tests using the turnover of insiders' buying as the dependent variable in Model (3), we find qualitatively similar test results and reach the same conclusion.
} 
disclosure. The test results are presented in Table 7, where we only report the slope coefficient estimates of two main variables of interest, i.e., Imprecision and Sentiment, and those of all control variables are provided in Appendix Table A.7.

[Insert Table 7 Here]

We find that the slope coefficients for our linguistic imprecision measure are positive and significant throughout all weekly windows in Table 7. Interestingly, this positive effect of linguistic imprecision on insider buying activity becomes the strongest in the $3 \mathrm{rd}$ and 4th weeks in term of their magnitudes, which is consistent with our earlier test results above. In contrast, we do not find any statistically significant effect of linguistic imprecision on the dollar volume of insider selling over all weekly windows, which is not reported to save space. The graphical representation in Figure 4(c) shows that the positive effect of linguistic imprecision on insider buying activity attenuates over time and appears to end around the 13th week after 10-K filing. All together, these results of insider trading activities reinforce the conclusion that positive value-relevant information accompanies the imprecise language in $10-$ Ks.

\subsection{News Sentiment in the Subsequent Periods}

To further evaluate whether the value-relevant information that comes with the imprecise language in 10-K disclosures is indeed positive and forward-looking, we now test more directly whether our linguistic imprecision measure can predict subsequent news sentiment, a proxy for the positivity or negativity of realized events or unrealized prospects. To test a potential relation between linguistic imprecision and subsequent news sentiment, we employ the following specification: For stock $i$, over the $n$th week around $10-\mathrm{K}$ filing in year $t$,

$$
\text { News sentiment }_{i t n}=\alpha_{n}+\beta_{n} \text { Imprecision }_{i t}+\eta_{n}^{\prime} \mathbf{X}_{i t}+\epsilon_{i t n}
$$


where News sentiment $t_{i n}$ is the average news-related sentiment score over the $n$th week window, ${ }^{22}$ Imprecision $_{i t}$ is the percentage of linguistic imprecision keywords (out of total words) used in firm $i$ 's $10-\mathrm{K}$, and $\mathbf{X}_{i t}$ is a column vector that has the same control variables as in Table 4 and two additional control variables, which are Pre-filing news sentiment, and the $n$th week market-wide news sentiment. ${ }^{23}$ All independent variables in Model (4) are standardized to have zero mean and one standard deviation and their detailed definitions are provided in the Appendix. We cluster standard errors by firm and filing year-month. The test results of news sentiment predictability in Model (4) are presented in Table 8, where we only report the slope coefficient estimates of four main variables of interest, i.e., Imprecision, Sentiment, Pre-filing news sentiment, and nth-week market news sentiment, and those of all control variables are provided in Appendix Table A.8.

\section{[Insert Table 8 Here]}

We find that the slope coefficients for our linguistic imprecision measure are positive and significant from the 1 st through 7 th weeks after $10-\mathrm{K}$ filing. Interestingly, the positive effect of linguistic imprecision on news sentiment becomes the strongest in the $3 \mathrm{rd}$ and 4 th weeks in terms of its magnitude, which is consistent with our earlier test results above. We also find no evidence of pre-trends since the slope coefficients of Imprecision before 10-K filing are all statistically indistinguishable from zero. The graphical representation in Figure 4(d) over an extended window also confirms that the news media describes firms with higher linguistic imprecision in their 10-Ks with more positive sentiment, implying either realizations of positive events or general positive prospects of the firms' businesses in the subsequent periods. ${ }^{24}$

\footnotetext{
${ }^{22}$ We use the same definition of weekly windows as those for our earlier regressions in Sections 4.1 to 4.3. Our daily news-related sentiment score is defined as (ESS-50)/50, where the ESS variables is available in the RavenPack News Analytics database from January, 2000.

${ }^{23}$ Using equal-weighting or value-weighting for the $n$th week market-wide news sentiment does not change our test result qualitatively. For brevity, we mainly report the test result based on the value-weighted market-wide news sentiment.

${ }^{24}$ In Appendix Table A.9, we also investigate the standardized unexpected earnings (SUE) predictability by our linguistic imprecision measure. We find that the linguistic imprecision measure in 10-Ks can predict future SUE positively and significantly both for the SUE indicator and rank variables. The positive effect also attenuates over quarters indicating that security analysts initially under-react to the information contained
} 


\subsection{Firm Heterogeneous Effects}

Lastly, we conduct a series of heterogeneity tests that examine differential price reactions based on various firm characteristics. We consider the following five firm characteristics for the heterogeneity analysis: Forward-looking disclosure, R\&D disclosure, bid-ask spread, idiosyncratic volatility of returns, and analyst coverage. If the underlying mechanism for the positive price reactions is that firms release good but immature forward-looking information with less specific and more imprecise language, we expect there to be stronger positive price reactions for firms that disclose more forward-looking terms. We also predict that firms making more intangible investments tend to use less specific and more imprecise language in their disclosures to convey the relevant information to markets. Furthermore, firms with greater pre-filing information asymmetry, measured by bid-ask spread, idiosyncratic volatility of return, and no analyst coverage, are more likely to have stronger price reactions to the information released through the imprecise language used in 10-Ks. We test these predictions by estimating Model (1) over multiple-week windows (using cumulative BHARs) for the two subgroups of firms with high and low levels of each of the characteristics mentioned above. Table 9 reports the subgroup estimation results of Model (1) and Figure 5 shows their graphical representations over an extended estimation window.

[Insert Table 9 Here]

[Insert Figure 5 Here]

First, for forward-looking disclosure, we uncover that the price reactions to the linguistic imprecision in 10-Ks are greater for firms that use more forward-looking terms. The positive and significant slope coefficients for Imprecision $_{i t}$ are present only in the high forwardlooking disclosure group from the 2 nd week, while those in the low forward-looking disclosure group stay insignificant throughout all weeks. Based on the column of Week[1,9], one standard deviation increase in the use of imprecise language in $10-\mathrm{K}$ disclosure $(=0.46 \%)$ is in the imprecise language in 10-Ks possibly due to its embedded immaturity although they eventually digest and reflect its implication related to future cash flow into their earnings forecasts. 
associated with about $1.23 \%$ higher BHAR over the nine-week period after $10-\mathrm{K}$ filing. In terms of its magnitude, this effect is stronger than that for the whole sample at $0.96 \%$ in Panel B of Table 4. For R\&D disclosure, we also find that the positive linguistic imprecision effect exists only among firms with high $R \& D$ investment and its magnitude is similar to that for the high forward-looking disclosure group.

For each of the other firm characteristics, the top row in each panel of Table 9 represents the group of firms that are likely to have higher information asymmetry. We find that firms with lower liquidity, greater idiosyncratic volatility, and no analyst coverage, experience stronger positive price reactions, starting from the 3rd or 4th week, than their counterparts. For example, looking at the column of Week[1,9], we find that firms with high pre-filing information asymmetry have 1.25 to 2 times stronger linguistic imprecision effects than those with low pre-filing information asymmetry.

In sum, we uncover that the price reactions to the linguistic imprecision in 10-Ks become greater for firms that use more forward-looking terms, disclose more about R\&D investment, have greater idiosyncratic volatility of returns, have lower liquidity, and have no analyst coverage. These findings with heterogeneity tests corroborate our interpretation of the information content of imprecise language in 10-Ks as uncertain, yet positive, value-relevant information that is eventually digested by various market participants.

\section{Conclusions}

In this paper, we introduce a novel textual measure to the finance and accounting literature, which quantifies the degree of linguistic imprecision in firms' disclosures with a minimum level of researchers' subjectivity. Our linguistic imprecision measure is distinct from existing textual measures such as sentiment, uncertainty, and modality, and has ability to identify the unique qualitative information in firm disclosures beyond quantitative information. In contrast to a dominant obfuscation view in the literature, we find strong evidence that firms tend to use more imprecise language in their 10-Ks during uncertain times to deliver new 
information on positive but yet immature prospects of future cash flow. Market participants initially under-react to the information contained in this imprecise language possibly due to its embedded immaturity but eventually understand and digest it. Collectively, our findings and approach suggest that there is much more to learn from the qualitative content of firm disclosures. 


\section{Appendix. Variable Definitions}

This appendix provides the detailed definitions of the variables used in the paper.

Imprecision

Positive

Negative

Sentiment

Uncertain

Modal

Constraining

Litigious

Superfluous

Interesting

Fog

Product market fluidity

Financial constraints

Size

Age

Tobin's $Q$ is the number of imprecision keywords scaled by the total word count in the $10-\mathrm{K}$ filing (in percentage).

is the number of positive words from the master dictionary by Loughran and McDonald (2011) scaled by the total word count in the $10-\mathrm{K}$ filings (in percentage).

is the number of negative words from the master dictionary by Loughran and McDonald (2011) scaled by the total word count in the $10-\mathrm{K}$ filings (in percentage).

is Pct Positive minus Pct Negative.

is the number of uncertain words from the master dictionary by Loughran and McDonald (2011) scaled by the total word count in the $10-\mathrm{K}$ filings (in percentage).

is the number of (weak and strong) modal words from the master dictionary by Loughran and McDonald (2011) scaled by the total word count in the $10-\mathrm{K}$ filings (in percentage).

is the number of constraining words from the master dictionary by Loughran and McDonald (2011) scaled by the total word count in the $10-\mathrm{K}$ filings (in percentage).

is the number of litigious words from the master dictionary by Loughran and McDonald (2011) scaled by the total word count in the $10-\mathrm{K}$ filings (in percentage).

is the number of superfluous words from the master dictionary by Loughran and McDonald (2011) scaled by the total word count in the $10-\mathrm{K}$ filings (in percentage).

is the number of interesting words from the master dictionary by Loughran and McDonald (2011) scaled by the total word count in the $10-\mathrm{K}$ filings (in percentage).

is the number of words of three or more syllables that are not hyphenated words or two-syllable verbs made into three with -es and -ed endings, scaled by the total word count in the $10-\mathrm{K}$ filing (in percentage).

is a $10-\mathrm{K}$ based textual measure for the competitive threats faced by a firm in its product markets that captures the changes in rival firms' products relative to the firm, from Hoberg, Phillips and Prabhala (2014).

is a $10-\mathrm{K}$ based textual measure for financial constraints from Hoberg and Maksimovic (2015) with higher values indicating that firms are more at the risk of delaying their investments due to issues with liquidity.

is the log of market value of total assets (market value of common equity plus book value of preferred stock, long-term and shortterm debt, and minority interest) in a given year.

is the log of one plus firm age in a given year based on its first appearance in Compustat.

is the market value of assets divided by book value of assets in a given year. 
Sales growth

Market value

Book-to-market

Turnover

Institutional ownership

Fama-French alpha

Filing-day abnormal return

Nasdaq dummy

Pre-filing spread

Pre-filing informed buying

Pre-filing news sentiment

nth-week market news sentiment is the log of sales in a given year divided by sales in the prior year.

is the log of market value of equity, which is the number of shares outstanding times the price of the stock on the day before $10-\mathrm{K}$ filing date.

is the log of the book-to-market ratio using the book value from firm's annual report known as of the end of the previous fiscal year and the market value known as of December of the year before the year of analysis.

is the log of the volume of shares traded over the period from the beginning of the prior month to six days (inclusive) before 10-K filing, divided by the number of shares outstanding at the end of the period.

is the percentage of institutional investors' holdings available from the CDA/Spectrum database for the most recent quarter before $10-\mathrm{K}$ filing date. The variable is treated as missing for negative values and winsorized to $100 \%$ for values above $100 \%$.

is the intercept estimated by regressing daily excess returns on daily Fama-French's three factors over one year before 10-K filing date. For each stock, at least 60 observations of daily returns are required to be included in the sample.

is either the BHAR or CAR over the 10-K filing-day window, i.e., the 0 th week window, that covers the four days between the $10-\mathrm{K}$ filing day and three days later.

is one if a stock is listed in the Nasdaq on the day before 10-K filing and zero otherwise.

is the average of daily quoted relative bid-ask spread over the period from the beginning of the prior month to six days (inclusive) before $10-\mathrm{K}$ filing.

is the average of daily probability of informed buying, which is based on Brennan, Huh, and Subrahmanyam (2018), over the period from the beginning of the prior month to six days (inclusive) before 10-K filing.

is the average of daily news-related sentiment score over the period from the beginning of the prior month to six days (inclusive) before 10-K filing, where the daily news-related sentiment score is defined as (ESS-50)/50 based on the ESS variable from the RavenPack News Analytics database.

is the value-weighted cross-stock average of individual newsrelated sentiment scores over the $n$th week before and after $10-\mathrm{K}$ filing. 


\section{References}

Amihud, Y., 2002. Illiquidity and stock returns: cross-section and time-series effects. Journal of financial markets 5, 31-56.

Barber, B. M., Lyon, J. D., 1997. Detecting long-horizon abnormal stock returns: the empirical power and specification of test statistics. Journal of financial economics 43, $341-372$.

Bellstam, G., Bhagat, S., Cookson, J. A., 2020. A Text-Based Analysis of Corporate Innovation. Management Science, Forthcoming.

Bloomfield, R. J., 2002. The "incomplete revelation hypothesis" and financial reporting. Accounting Horizons 16, 233-243.

Brennan, M. J., Huh, S.-W., Subrahmanyam, A., 2018. High-frequency measures of informed trading and corporate announcements. The Review of Financial Studies 31, 23262376 .

Bushee, B. J., Gow, I. D., Taylor, D. J., 2018. Linguistic complexity in firm disclosures: Obfuscation or information? Journal of Accounting Research 56, 85-121.

Chordia, T., Roll, R., Subrahmanyam, A., 1997. Commonality in liquidity. Journal of financial economics 43, 341-372.

Dougal, C., Engelberg, J., Garcia, D., Parsons, C. A., 2012. Journalists and the stock market. Review of Financial Studies 25, 639-679.

Ely, J. C., 2017. Beeps. American Economic Review 107, 31-53.

Fama, E. F., 1998. Market efficiency, long-term returns, and behavioral finance. Journal of financial economics 49, 283-306.

Ganter, V., Strube, M., 2009. Finding Hedges by Chasing Weasels: Hedge Detection Using Wikipedia Tags and Shallow Linguistic Features. In: Proceedings of the ACL-IJCNLP 2009 Conference Short Papers no. 2044. Association for Computational Linguistics pp. $173-176$.

Gao, J., Liang, C., Merkley, K., Pacelli, J., 2017. Do lenders promote the revelation of bad news? Evidence from Lender-side loan defaults. Working Paper.

Garcia, D., 2013. Sentiment during recessions. Journal of Finance 68, 1267-1300.

Goldsmith-Pinkham, P., Hirtle, B., Lucca, D., 2016. Parsing the content of bank supervision. Working Paper FRBNY Staff Report No. 770.

Gormley, T. A., Kim, B. H., Martin, X., 2012. Do firms adjust their timely loss recognition in response to changes in the banking industry? Journal of Accounting Research 50, $159-196$. 
Hanley, K. W., Hoberg, G., 2010. The information content of IPO prospectuses. Review of Financial Studies 23, 2821-2864.

Hoberg, G., Lewis, C., 2017. Do fraudulent firms produce abnormal disclosure? Journal of Corporate Finance, Forthcoming.

Hoberg, G., Maksimovic, V., 2015. Redefining financial constraints: A text-based analysis. Review of Financial Studies 28, 1312-1352.

Hoberg, G., Moon, S. K., 2017. Offshore Activities and Financial vs Operational Hedging. Journal of Financial Economics 125, 217-244.

Hoberg, G., Phillips, G., Prabhala, N., 2014. Product market threats, payouts, and financial flexibility. Journal of Finance 69, 293-324.

Hoberg, G., Phillips, G. M., 2016. Text-based network industries and endogenous product differentiation. Journal of Political Economy 124, 1423-1465.

Hwang, B.-H., Kim, H. H., 2017. It pays to write well. Journal of Financial Economics, Forthcoming.

Jegadeesh, N., Wu, D., 2013. Word power: A new approach for content analysis. Journal of financial economics 110, 712-729.

Jegadeesh, N., Wu, D., 2017. Deciphering Fedspeak: The information content of FOMC meetings. Working Paper SSRN $293993 \%$.

Kamenica, E., Gentzkow, M., 2011. Bayesian Persuasion. American Economic Review 101, $2590-2615$.

Li, F., 2008. Annual report readability, current earnings, and earnings persistence. Journal of Accounting and Economics 45, 221-247.

Loughran, T., McDonald, B., 2011. When is a liability not a liability? Textual analysis, dictionaries, and 10-Ks. Journal of Finance 66, 35-65.

Loughran, T., McDonald, B., 2013. IPO first-day returns, offer price revisions, volatility, and form S-1 language. Journal of Financial Economics 109, 307-326.

Loughran, T., McDonald, B., 2014. Measuring readability in financial disclosures. The Journal of Finance 69, 1643-1671.

Ross, S. A., 1979. Disclosure Regulation in Financial Markets: Implications of Modern Finance Theory and Signaling Theory . Issues in Financial Regulation (McGraw-Hill New York).

Simmons, J. P., Nelson, L. D., Simonsohn, U., 2011. False-Positive Psychology: Undisclosed Flexibility in Data Collection and Analysis Allows Presenting Anything as Significant. Pscyhological Science 22, 1359-1366. 
Tetlock, P. C., 2007. Giving Content to Investor Sentiment: The Role of Media in the Stock Market. Journal of Finance 62, 1139-1168.

Tetlock, P. C., Saar-Tsechansky, M., Macskassy, S., 2008. More than words: Quantifying language to measure firms' fundamentals. Journal of Finance 63, 1437-1467.

Verrecchia, R. E., 1983. Discretionary disclosure. Journal of Accounting and Economics 5, 179-194. 


\section{Figure 1: Linguistic Imprecision versus Uncertainty and Modality}

This figure shows the relation between each of notable textual tonal measures: (a) uncertainty words, (b) weak modal words, and (c) strong modal words (from the master dictionary by Loughran and McDonald (2011)) and the propensity of a firm to use imprecise language in its 10-K disclosure. Each panel presents two side-by-side box plots for the distribution of our linguistic imprecision measure by above and below the median of each textual tonal measure. Each box displays the interquartile range between the 25th to 75th percentiles of the distribution of the linguistic imprecision measure, where the thick solid line inside the box displays the median. The top and bottom solid lines outside the box display the maximum and minimum, respectively, where the maximum and minimum are defined as the 75 th percentile $+1.5 \times$ the interquartile range and 25 th percentile $-1.5 \times$ the interquartile range. Circles above and below those two solid lines represent outliers. The difference in medians for each panel is statistically significant at the $1 \%$ level.

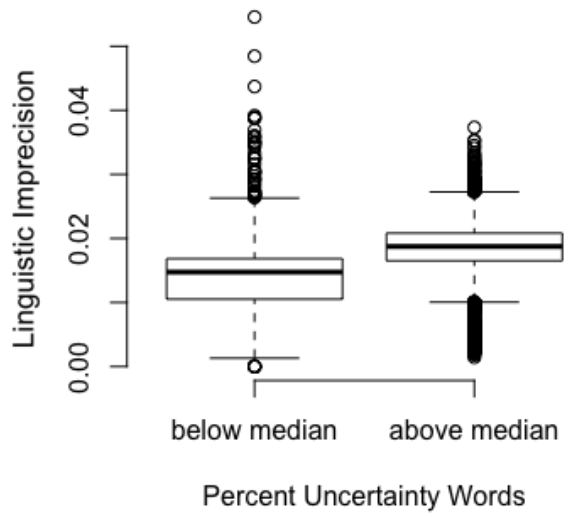

(a) Percentage of Uncertainty Words

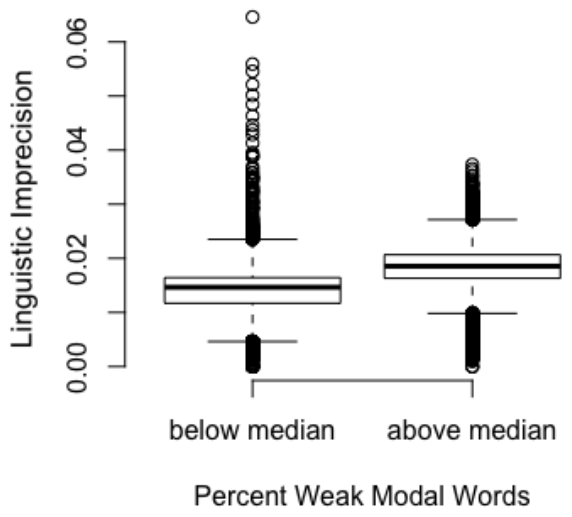

(b) Percentage of Weak Modal Words

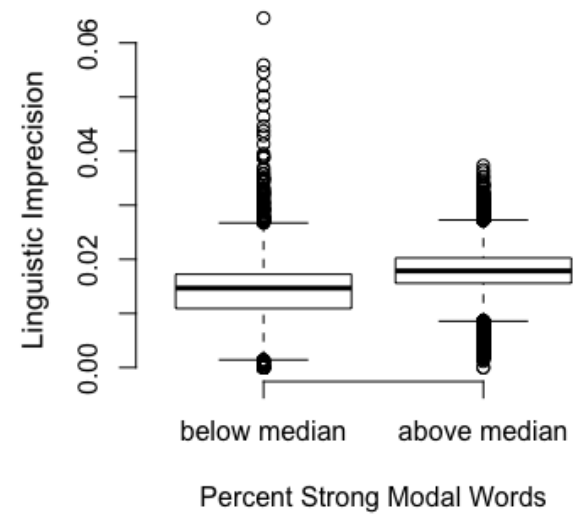

(c) Percentage of Strong Modal Words 


\section{Figure 2: Linguistic Imprecision and Non-tonal Firm-specific Characteristics}

This figure shows the relation between each of notable non-tonal firm-specific characteristics and the propensity of a firm to use imprecise language in its 10-K disclosure. Each panel presents the $95 \%$ confidence interval for the mean of each of four firm characteristics for the first, second, third, and fourth quartile of the distribution of the linguistic imprecision measure. The four firm characteristics are Size, Age, Tobin's Q, and Sales growth.

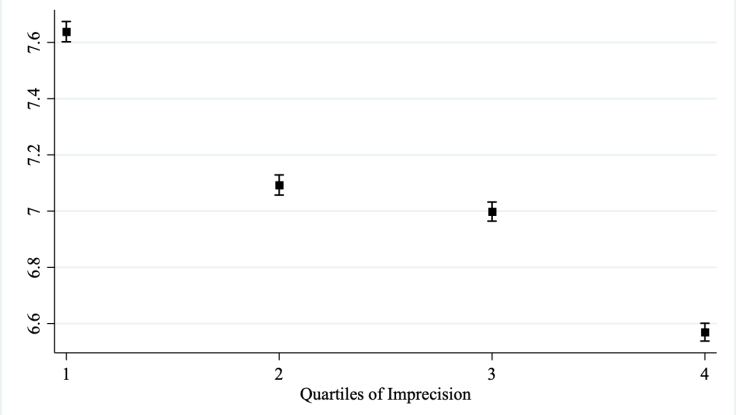

(a) Size

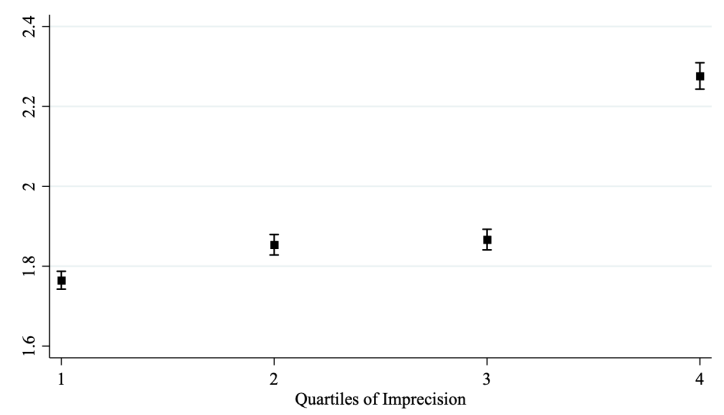

(c) Tobin's Q

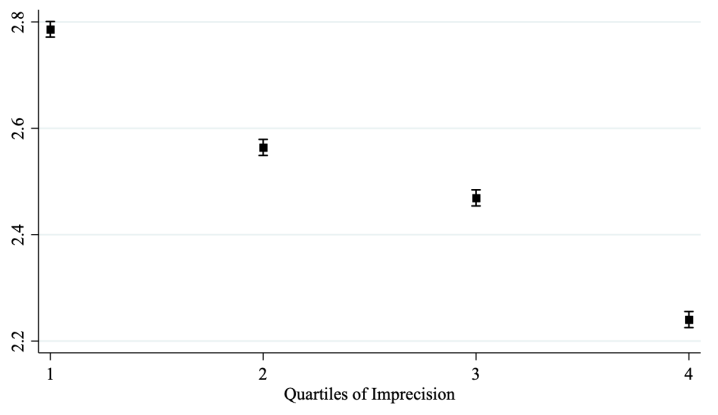

(b) Age

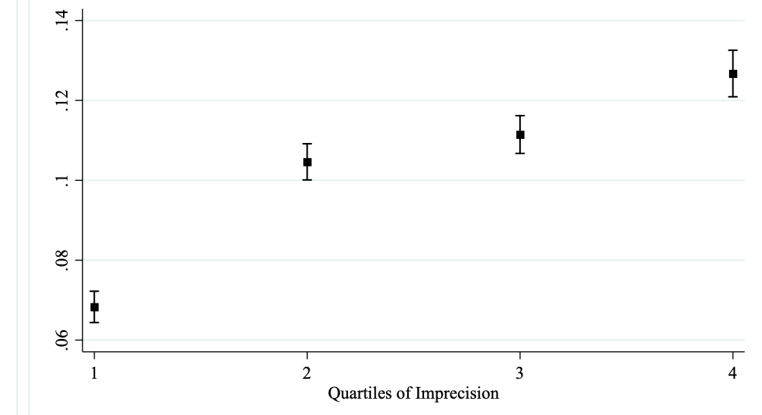

(d) Sales growth 


\section{Figure 3: Linguistic Imprecision and Cumulative BHARs}

This figure presents the slope coefficient estimates for our linguistic imprecision measure (Imprecision) in the regressions of cumulative buy and hold abnormal returns (BHARs) over various multiple-week windows. The shaded area represents the $95 \%$ confidence interval for each slope coefficient estimate (circle marker). For post-filing weeks, each cumulative BHAR is computed over the period from the start of the 1 st week to the end of the $n$th week $(n=1, \ldots, 15)$. For pre-filing weeks and the 0th week, each "reverse" cumulative BHAR is computed over the period from the end of the 0th week to the start of the $n$th week $(n=-5, \ldots, 0)$ and used as the dependent variable in the regressions. The vertical solid line at the 0 th week indicates the filing-day window that covers the four days between the $10-\mathrm{K}$ filing day and three days later.

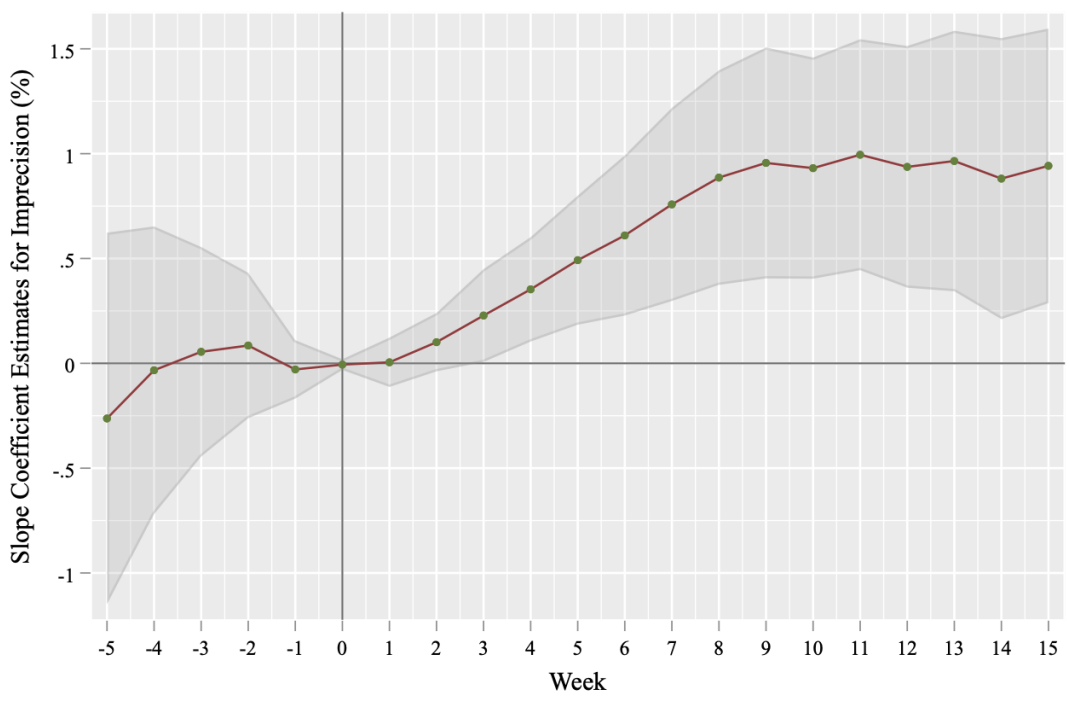




\section{Figure 4: Linguistic Imprecision and Various Reactions}

This figure presents the slope coefficient estimates for our linguistic imprecision measure (Imprecision) in the regressions of the following weekly variables: Quoted relative bid-ask spread, Probability of informed buying, Dollar volume of insider buying, and News sentiment scores, over an extended window ranging from the -5 th week to 15 th week around $10-\mathrm{K}$ filing dates. The shaded area represents the $95 \%$ confidence interval for each slope coefficient estimate (circle marker). The vertical solid line at the 0th week indicates the filing-day window that covers the four days between the 10-K filing day and three days later.

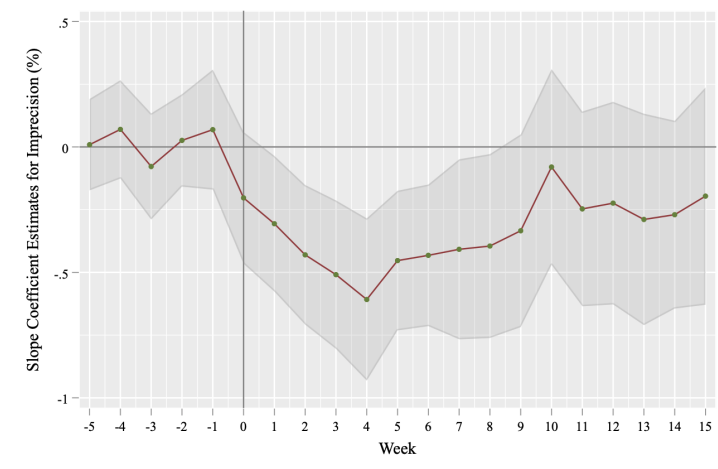

(a) Quoted relative bid-ask spread

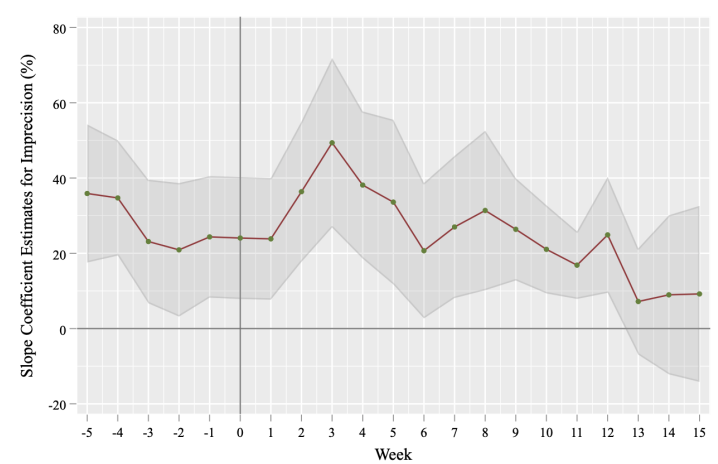

(c) Dollar volume of insider buying

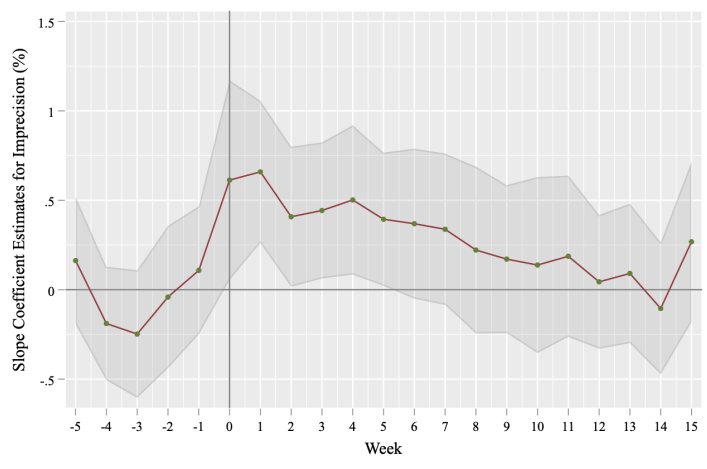

(b) Probability of informed buying

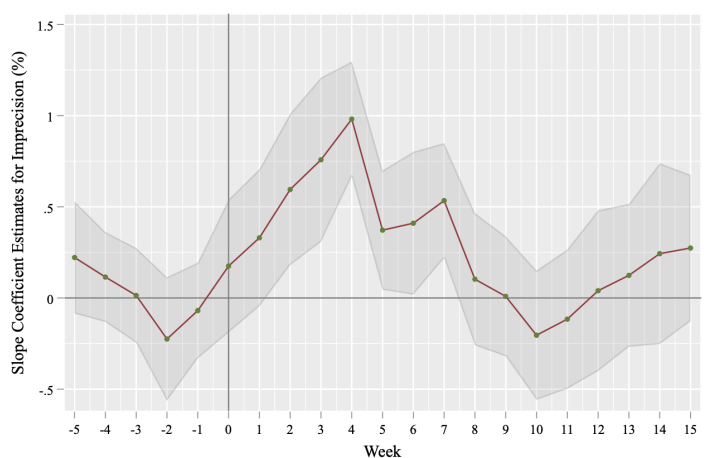

(d) News sentiment scores 
Figure 5: Linguistic Imprecision and Cumulative BHARs by Heterogeneous Characteristics

This figure presents the slope coefficient estimates for our linguistic imprecision measure (Imprecision) in the regressions of cumulative buy and hold abnormal returns (BHARs) over various multiple-week windows by relevant heterogeneous characteristics. The shaded area represents the $95 \%$ confidence interval for each slope coefficient estimate (circle marker). For post-filing weeks, each cumulative BHAR is computed over the period from the start of the 1 st week to the end of the $n$th week $(n=1, \ldots, 15)$. For pre-filing weeks and the 0th week, each "reverse" cumulative BHAR is computed over the period from the end of the 0th week to the start of the $n$th week $(n=-5, \ldots, 0)$ and used as the dependent variable in the regressions. The vertical solid line at the 0 th week indicates the filing-day window that covers the four days between the 10-K filing day and three days later. We consider the following five firm characteristics for heterogeneity tests: Forward-looking disclosure, R\&D disclosure, bid-ask spread, idiosyncratic volatility of returns, and analyst coverage. High and Low of each of these variables refer to firms with the variable above and below its median, respectively. For analyst coverage, firms with at least one analyst following (Presence) and those with no analyst following (Absence) are grouped.

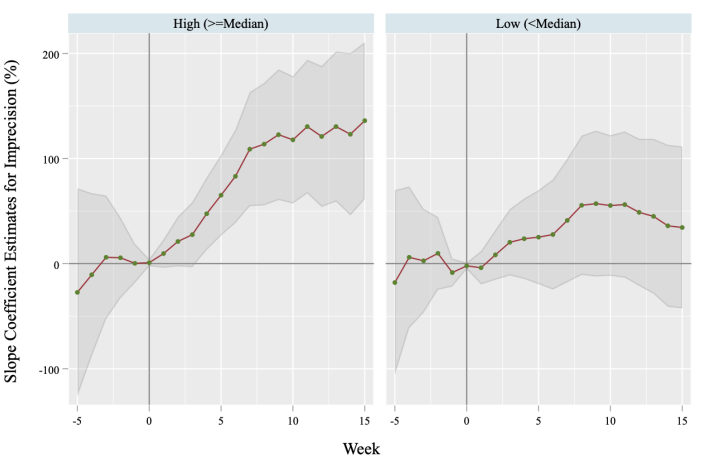

(a) Forward-looking disclosure

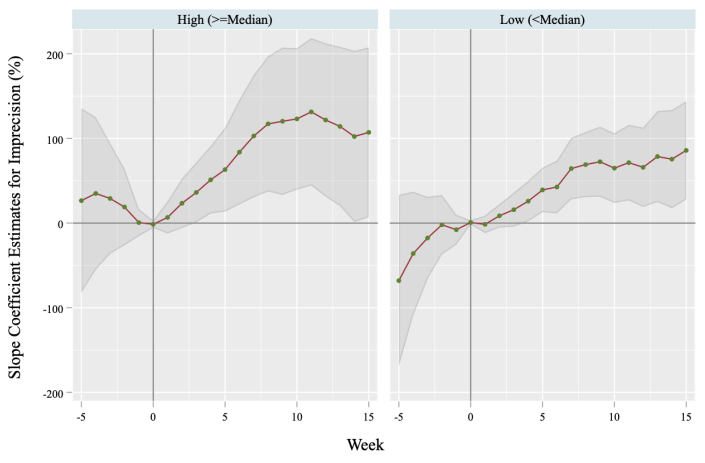

(c) Bid-ask spread

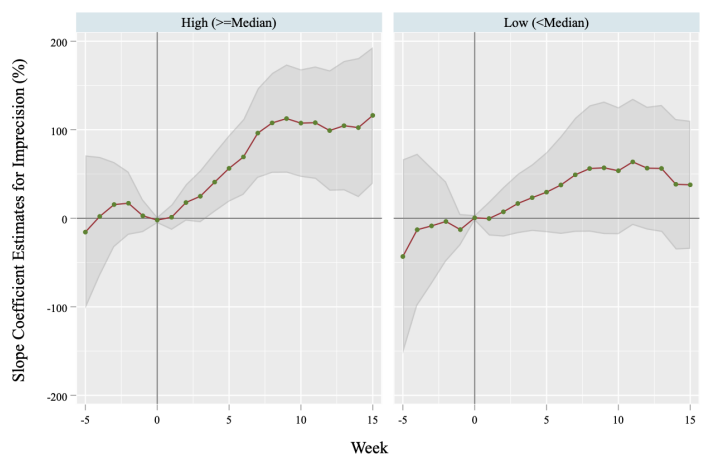

(b) $\mathrm{R} \& \mathrm{D}$ disclosure

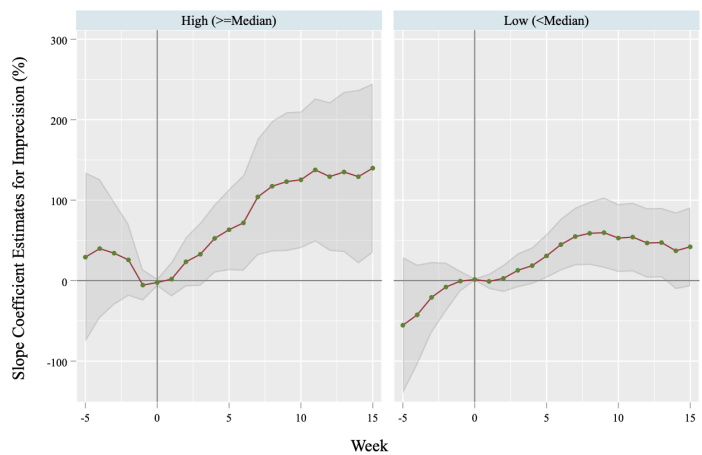

(d) Idiosyncratic volatility of return

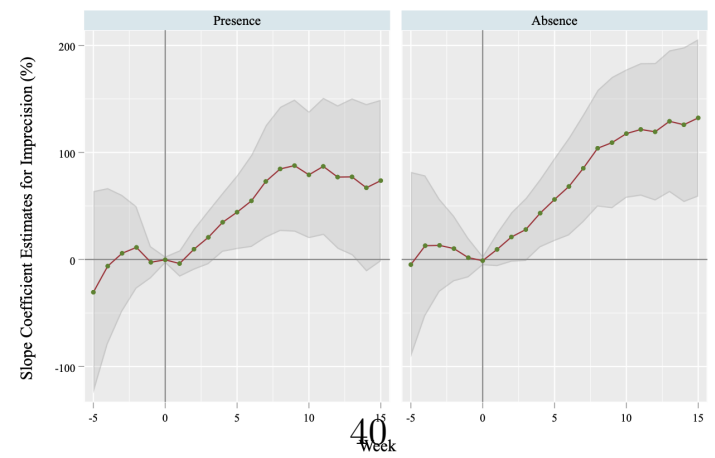

(e) Analyst coverage 
Table 1: Frequently Used Words in Wikipedia Sentences with Weasel Tags and 10-K Paragraphs with Linguistic Imprecision Keywords

Panel A presents frequently used words in Wikipedia Sentences with weasel tags (\{\{Weaselinline $-\{\{$ subst:DATE $\}\}\}\})$ from an Wikipedia dump completed on April 20, 2017. The Wikipedia dump contains 17,483,910 articles. Panel A(a) lists the top 10 most frequently mentioned unigrams, bigrams, and trigrams in the sentences that have weasel tags. Panel A(b) lists the top 10 unigrams and the bottom 10 unigrams sorted on the saliency score of Goldsmith-Pinkham, Hirtle, and Lucca (2016) to illustrate the influence of our saliency screen. Panel A(c) lists the top 10 most frequently mentioned imprecision keywords, uncertainty words, and weak and strong modal words. The keyword lists of uncertainty, weak modality, and strong modality words come from the master dictionary by Loughran and McDonald (2011). Panel B presents frequently used words in paragraphs of 10-K filings that contain our keywords of linguistic imprecision. Panel B(a) lists the top 30 most frequently mentioned nouns, verbs, and adjectives/adverbs in the 10-K paragraphs that contain the linguistic imprecision keywords. We only include words in the Loughran and McDonald (2011) master dictionary that are considered to add financial information content. Panel B(b) lists meaningful neighboring bigrams in the $10-\mathrm{K}$ paragraphs that contain the linguistic imprecision keywords by information contents. We analyze 5,597,740 pairs of bigrams in the 10-K paragraphs and compute the saliency score of each bigram in paragraphs with the linguistic imprecision keywords relative to paragraphs without such keywords. (adverse, material, effect)** represents 13 distinct bigrams that capture the same idea. Appendix Table A.1 shows the complete list of the top 100 neighboring bigrams that are overused relative to common language with the saliency screen.

\section{Panel A: Frequently Used Words in Wikipedia Sentences with Weasel Tags}

(a) Top 10 Unigrams, Bigrams, and Trigrams

\begin{tabular}{lrrr}
\hline Rank & Unigrams & Bigrams & Trigrams \\
\hline 1 & the & of the & one of the \\
2 & and & in the & it has been \\
3 & some & it is & considered by many \\
4 & that & to be & is considered by \\
5 & was & has been & of the most \\
6 & many & to the & is one of \\
7 & for & for the & it can be \\
8 & with & one of & may have been \\
9 & has & and the & according to some \\
10 & have & that the & be one of \\
\hline
\end{tabular}

(b) Top and Bottom 10 Unigrams, Sorted on Saliency

\begin{tabular}{lrr}
\hline Rank & Top 10 Unigrams & Bottom 10 Unigrams \\
\hline 1 & some & the \\
2 & many & and \\
3 & although & for \\
4 & considered & was \\
5 & may & from \\
6 & said & their \\
7 & have & new \\
8 & argued & united \\
9 & believed & also \\
10 & often & first \\
\hline
\end{tabular}

(c) Top 10 Imprecision, Uncertainty, and Modal Words

\begin{tabular}{lrrrr}
\hline Rank & Imprecision Words & Uncertainty Words & Weak Modal Words & Strong Modal Words \\
\hline 1 & other & hidden & may & will \\
2 & may & may & could & must \\
3 & clear & could & possible & best \\
4 & could & approximately & might & highest \\
5 & would & risk & depend & never \\
6 & number of & intangible & uncertain & lowest \\
7 & can & believe & depending & always \\
8 & well & assumptions & depends & clearly \\
9 & however & risks & appears & strongly \\
10 & various & believes & appearing & undisputed \\
\hline
\end{tabular}




\section{Panel B: Frequently Used Words in 10-K Paragraphs with Linguistic Imprecision Keywords}

(a) Top 30 Neighboring Unigrams by Parts of Speech

\begin{tabular}{|c|c|c|c|c|c|}
\hline \multicolumn{2}{|c|}{ Verb } & \multicolumn{2}{|c|}{ Noun } & \multicolumn{2}{|c|}{ Adjective/Adverb } \\
\hline hidden & differ & plan & law & approximately & unpaid \\
\hline will & anticipated & future & regulations & effective & favorable \\
\hline required & impaired & loss & contract & generally & statutory \\
\hline expected & assumed & losses & assumptions & regulatory & difficult \\
\hline estimated & restructuring & obligations & risks & adverse & successfully \\
\hline require & intended & risk & default & legal & duly \\
\hline restricted & discontinued & benefit & decrease & adversely & critical \\
\hline amended & intend & requirements & obligation & able & uncertain \\
\hline requires & restated & estimates & collapse & greater & strong \\
\hline permitted & anticipate & impairment & court & unable & hazardous \\
\hline expect & prevent & plans & closing & contractual & doubtful \\
\hline comply & achieve & contracts & intangible & beneficial & negatively \\
\hline terminated & increasing & termination & amendment & notwithstanding & satisfactory \\
\hline disclosed & projected & laws & failure & pending & furthermore \\
\hline terminate & depend & claims & gains & successful & beneficially \\
\hline
\end{tabular}

(b) Meaningful Neighboring Bigrams by Information Contents

\begin{tabular}{|c|c|c|c|}
\hline Innovation (6) & Forward-looking (5) & Market Conditions (11) & Firm Value (19) \\
\hline $\begin{array}{l}\text { (intellectual, property) } \\
\text { (clinical, trial) } \\
\text { (product, candidate) } \\
\text { (property, right) } \\
\text { (new, product) } \\
\text { (trade, secret) }\end{array}$ & $\begin{array}{l}\text { (forward-looking, statement) } \\
\text { (company, belief) } \\
\text { (management, belief) } \\
\text { (future, cash) } \\
\text { (future, period) }\end{array}$ & $\begin{array}{l}\text { (market, value) } \\
\text { (market, price) } \\
\text { (economic, condition) } \\
\text { (market, condition) } \\
\text { (stock, price) } \\
\text { (equity, instrument) } \\
\text { (public, offering) } \\
\text { (closing, price) } \\
\text { (overall, financial) } \\
\text { (market, participant) } \\
\text { (fair, market) }\end{array}$ & $\begin{array}{l}\text { (adverse, material, effect)** } \\
\text { (comprehensive, income) } \\
\text { (financial, condition) } \\
\text { (operating, result) } \\
\text { (significant, deficiency) } \\
\text { (financial, result) } \\
\text { (actual, result) }\end{array}$ \\
\hline
\end{tabular}




\section{Table 2: Summary Statistics}

This table presents the summary statistics for various variables used in our subsequent empirical analyses. The sample period is from 1997 to 2015. Panel A presents the summary statistics for our linguistic imprecision measure (Imprecision), existing textual tonal variables based on the master dictionary by Loughran and McDonald (2011), and Fog words initially proposed by Robert Gunning in 1952 and used extensively in the literature to quantify the lack of plain English (e.g., Li (2008)), where all statistics are expressed in percentage. Panel B presents the summary statistics for non-tonal firm-specific characteristics. The detailed definitions of all variables are provided in the Appendix. Each variable is winsorized at the top and bottom $1 \%$ of its distribution.

Panel A: Textual Tonal Variables

\begin{tabular}{lcccccc}
\hline & Mean & Std.Dev & Min & Median & Max & Num. of Obs. \\
\hline Imprecision & 1.387 & 0.458 & 0.000 & 1.471 & 4.901 & 46996 \\
Sentiment & -0.716 & 0.443 & -4.362 & -0.671 & 1.670 & 46996 \\
Uncertain & 1.011 & 0.362 & 0.000 & 1.042 & 3.230 & 46996 \\
Modal & 0.790 & 0.369 & 0.000 & 0.832 & 2.607 & 46996 \\
Constraining & 0.571 & 0.245 & 0.000 & 0.590 & 2.116 & 46996 \\
Litigious & 1.207 & 0.874 & 0.039 & 0.966 & 6.819 & 46996 \\
Superfluous & 0.009 & 0.011 & 0.000 & 0.006 & 0.253 & 46996 \\
Interesting & 0.123 & 0.078 & 0.000 & 0.115 & 1.666 & 46996 \\
Fog & 30.416 & 4.504 & 14.066 & 30.145 & 53.947 & 46996 \\
\hline
\end{tabular}

Panel B: Non-tonal Firm-specific Characteristics

\begin{tabular}{lcccccc}
\hline & Mean & Std.Dev & Min & Median & Max & Num. of Obs. \\
\hline Size & 7.075 & 1.942 & 0.515 & 6.981 & 14.776 & 46996 \\
Age & 2.515 & 0.852 & 0.000 & 2.565 & 3.970 & 46996 \\
Tobin's Q & 1.940 & 1.506 & 0.703 & 1.407 & 10.485 & 46996 \\
Sales Growth & 0.103 & 0.266 & -0.778 & 0.079 & 1.223 & 46996 \\
Product market fluidity & 6.994 & 3.500 & 1.449 & 6.379 & 17.336 & 46248 \\
Financial constraints & -0.017 & 0.089 & -0.192 & -0.022 & 0.231 & 30630 \\
Turnover & -1.871 & 1.141 & -10.372 & -1.752 & 3.225 & 46984 \\
Book-to-market & -0.715 & 0.846 & -8.864 & -0.635 & 3.631 & 45771 \\
Institution ownership & 59.419 & 28.734 & 1.340 & 64.360 & 100.000 & 39370 \\
Fama-French alpha & 0.001 & 0.002 & -0.004 & 0.000 & 0.010 & 46996 \\
Filing-day abnormal return & 0.000 & 0.050 & -0.168 & -0.001 & 0.185 & 46996 \\
\hline
\end{tabular}


Table 3: Relations between Linguistic Imprecision and Various Variables

This table presents the estimation results of regressing our linguistic imprecision measure (Imprecision) in 10-K disclosures on various textual tonal measures (Panel A) and non-tonal firm-specific characteristics (Panel B) with an intercept. In Panel A, Fog is based on Robert Gunning in 1952 and the other tonal measures: Uncertainty, Modal, Positive and Negative (for Sentiment), Constraining, Litigious, Superfluous, and Interesting are based on the master dictionary by Loughran and McDonald (2011). Imprecision and these textual tonal variables are contemporaneous in the sense that all of them are based on the same 10-Ks. Panel B includes non-tonal firm-specific characteristics that have been used in existing studies and they are lagged relative to 10-K filing dates. The detailed definitions of all variables are provided in the Appendix. Each variable is winsorized at the top and bottom $1 \%$ of its distribution. $(\mathrm{Z})$ indicates that the variable is standardized to have zero mean and one standard deviation for ease of interpretation. Firm and year fixed effects are also included. Standard errors that are clustered by firm are reported in parentheses. ${ }^{* * *},{ }^{* *}$, and ${ }^{*}$ indicate statistical significance at the 1\%,5\%, and 10\% level, respectively. For brevity, intercept is not reported although it is included in the estimation.

Panel A: Textual Tonal Variables

\begin{tabular}{|c|c|c|c|}
\hline & $\begin{array}{l}\text { Dependent } \\
\text { (1) }\end{array}$ & $\begin{array}{c}\text { t variable } \\
(2)\end{array}$ & $\begin{array}{c}\text { Imprecision } \\
\text { (3) }\end{array}$ \\
\hline $\operatorname{Fog}(\mathrm{Z})$ & $\begin{array}{c}0.065^{* * *} \\
(0.003)\end{array}$ & $\begin{array}{c}0.066^{* * *} \\
(0.003)\end{array}$ & $\begin{array}{c}0.066^{* * *} \\
(0.003)\end{array}$ \\
\hline Uncertain(Z) & $\begin{array}{c}0.102^{* * *} \\
(0.005)\end{array}$ & $\begin{array}{c}0.126^{* * *} \\
(0.005)\end{array}$ & $\begin{array}{c}0.125^{* * *} \\
(0.005)\end{array}$ \\
\hline $\operatorname{Modal}(\mathrm{Z})$ & $\begin{array}{c}0.298^{* * *} \\
(0.005)\end{array}$ & $\begin{array}{c}0.250^{* * *} \\
(0.005)\end{array}$ & $\begin{array}{c}0.244^{* * *} \\
(0.005)\end{array}$ \\
\hline Sentiment(Z) & & $\begin{array}{l}0.005^{* *} \\
(0.002)\end{array}$ & $\begin{array}{c}0.006^{* * *} \\
(0.002)\end{array}$ \\
\hline Constraining $(\mathrm{Z})$ & & $\begin{array}{c}0.052^{* * *} \\
(0.002)\end{array}$ & $\begin{array}{c}0.052^{* * *} \\
(0.002)\end{array}$ \\
\hline Litigious(Z) & & $\begin{array}{c}0.067^{* * *} \\
(0.002)\end{array}$ & $\begin{array}{c}0.069^{* * *} \\
(0.002)\end{array}$ \\
\hline Superfluous(Z) & & & $\begin{array}{c}0.009^{* * *} \\
(0.002)\end{array}$ \\
\hline Interesting(Z) & & & $\begin{array}{c}0.014^{* * *} \\
(0.002)\end{array}$ \\
\hline
\end{tabular}

\begin{tabular}{lccc}
\hline Fixed effect & \multicolumn{3}{c}{ Firm / Year } \\
Observations & 45672 & 45672 & 45672 \\
Adjusted $R^{2}$ & 0.871 & 0.889 & 0.889 \\
\hline
\end{tabular}

Panel B: Non-tonal Firm-specific Characteristics

\begin{tabular}{|c|c|c|c|}
\hline & \multicolumn{3}{|c|}{ Dependent variable $=$ Imprecision } \\
\hline $\operatorname{Size}(\mathrm{Z})$ & $\begin{array}{c}-0.035^{* * *} \\
(0.009)\end{array}$ & $\begin{array}{c}-0.054^{* * *} \\
(0.010)\end{array}$ & $\begin{array}{c}-0.058^{* * *} \\
(0.013)\end{array}$ \\
\hline Age(Z) & $\begin{array}{c}-0.066^{* * *} \\
(0.008)\end{array}$ & $\begin{array}{c}-0.063^{* * *} \\
(0.010)\end{array}$ & $\begin{array}{c}-0.072^{* * *} \\
(0.013)\end{array}$ \\
\hline Tobin's Q(Z) & $\begin{array}{c}0.013^{* * *} \\
(0.003)\end{array}$ & $\begin{array}{c}0.018^{* * *} \\
(0.004)\end{array}$ & $\begin{array}{c}0.015^{* * *} \\
(0.005)\end{array}$ \\
\hline Sales Growth(Z) & $\begin{array}{c}0.000 \\
(0.002)\end{array}$ & $\begin{array}{l}-0.000 \\
(0.002)\end{array}$ & $\begin{array}{c}-0.001 \\
(0.002)\end{array}$ \\
\hline Product market fluidity $(\mathrm{Z})$ & & $\begin{array}{c}0.023^{* * *} \\
(0.005)\end{array}$ & $\begin{array}{c}0.022^{* * *} \\
(0.006)\end{array}$ \\
\hline Financial constraints $(\mathrm{Z})$ & & $\begin{array}{c}0.019^{* * *} \\
(0.003)\end{array}$ & $\begin{array}{c}0.020^{* * *} \\
(0.004)\end{array}$ \\
\hline Turnover $(\mathrm{Z})$ & & & $\begin{array}{l}-0.000 \\
(0.004)\end{array}$ \\
\hline Institution ownership(Z) & & & $\begin{array}{c}0.004 \\
(0.007)\end{array}$ \\
\hline Fama-French alpha(Z) & & & $\begin{array}{c}0.000 \\
(0.002)\end{array}$ \\
\hline Filing-day abnormal return(Z) & & & $\begin{array}{c}0.001 \\
(0.002)\end{array}$ \\
\hline Fixed effect & & Firm / Ye & \\
\hline Observations & 45672 & 29229 & 24128 \\
\hline Adjusted $R^{2}$ & 0.653 & 0.658 & 0.660 \\
\hline
\end{tabular}


Table 4: Imprecise Language in Disclosure and BHARs

This table presents the estimation results of Model (1) regressing buy and hold abnormal returns (BHARs) over various estimation windows around 10-K filing on our linguistic imprecision measure as follows: For stock $i$ in year $t$,

$$
B H A R_{i t n}=\alpha_{n}+\beta_{n} \text { Imprecision }_{i t}+\eta_{n}^{\prime} \mathbf{X}_{i t}+\epsilon_{i t n}
$$

where $B H A R_{i t n}$ is the return difference between stock $i$ and the CRSP value-weighted index over the $n t h$ week window (the 1 st week window starts from the fourth day after the 10-K filing day and the 0th week window covers the four days between the 10-K filing day and three days later), Imprecision It is the percentage of our linguistic imprecision keywords (out of the total words), and $\mathbf{X}_{i t}$ is a column vector that contains various control variables used in prior studies: Sentiment, Market value, Book-to-market, Turnover, Institutional ownership, Fama-French alpha, and Filing-day abnormal return. The detailed definitions of these independent variables are given in the Appendix. In Panel A, we estimate Model (1) for each week separately over the previous 3 -week period before $10-\mathrm{K}$ filing and the subsequent 9 -week period after $10-\mathrm{K}$ filing (thus $n=-3, \ldots, 9$ ). In Panel $\mathrm{B}$, we repeat to estimate Model (1) with cumulative BHARs over multiple-week windows as dependent variable. For post-filing weeks, each cumulative BHAR is computed over the period from the start of the 1 st week to the end of the $n$th week, i.e., Week $[1, \mathrm{n}]$, where $n=1, \ldots, 9$. For pre-filing weeks and the 0 th week, each "reverse" cumulative BHAR is computed over the period from the end of the 0 th week to the start of the $n$th week, i.e., Week[n,0], where $n=-3, \ldots, 0$ and used as the dependent variable. (Z) indicates that the variable is standardized to have zero mean and one standard deviation. Standard errors that are clustered by filing year-month to account for the cross-sectional correlations of BHARs across stocks are reported in parentheses. Slope coefficients and standard errors are reported in percentage. ${ }^{* * *},{ }^{* *}$, and ${ }^{*}$ indicate statistical significance at the $1 \%, 5 \%$, and $10 \%$ level, respectively.

Panel A: Weekly BHARs

\begin{tabular}{|c|c|c|c|c|c|c|c|c|c|c|c|c|c|}
\hline & \multicolumn{13}{|c|}{ Dependent variable $=$ BHARs } \\
\hline & Week $(-3)$ & Week(-2) & Week $(-1)$ & Week $(0)$ & Week(1) & Week(2) & $\operatorname{Week}(3)$ & Week(4) & Week(5) & Week $(6)$ & Week(7) & Week $(8)$ & Week $(9)$ \\
\hline Imprecision(Z) & $\begin{array}{c}0.005 \\
(0.134)\end{array}$ & $\begin{array}{l}-0.108 \\
(0.144)\end{array}$ & $\begin{array}{c}0.033 \\
(0.067)\end{array}$ & $\begin{array}{l}-0.000 \\
(0.000)\end{array}$ & $\begin{array}{c}0.005 \\
(0.060)\end{array}$ & $\begin{array}{c}0.097 \\
(0.060)\end{array}$ & $\begin{array}{c}0.125^{* *} \\
(0.051)\end{array}$ & $\begin{array}{c}0.136^{* * *} \\
(0.048)\end{array}$ & $\begin{array}{c}0.120^{* *} \\
(0.058)\end{array}$ & $\begin{array}{c}0.118^{* *} \\
(0.059)\end{array}$ & $\begin{array}{c}0.134^{* *} \\
(0.062)\end{array}$ & $\begin{array}{c}0.100 \\
(0.063)\end{array}$ & $\begin{array}{c}0.063 \\
(0.054)\end{array}$ \\
\hline Sentiment(Z) & $\begin{array}{c}0.013 \\
(0.088)\end{array}$ & $\begin{array}{c}0.033 \\
(0.094)\end{array}$ & $\begin{array}{l}-0.065 \\
(0.052)\end{array}$ & $\begin{array}{c}0.000 \\
(0.000)\end{array}$ & $\begin{array}{l}-0.019 \\
(0.055)\end{array}$ & $\begin{array}{c}0.062 \\
(0.045)\end{array}$ & $\begin{array}{c}0.029 \\
(0.050)\end{array}$ & $\begin{array}{c}0.049 \\
(0.044)\end{array}$ & $\begin{array}{l}-0.073 \\
(0.050)\end{array}$ & $\begin{array}{c}0.006 \\
(0.058)\end{array}$ & $\begin{array}{c}0.067 \\
(0.043)\end{array}$ & $\begin{array}{l}-0.064 \\
(0.039)\end{array}$ & $\begin{array}{l}-0.044 \\
(0.040)\end{array}$ \\
\hline Observations & 42063 & 42173 & 42262 & 42298 & 41885 & 41711 & 41567 & 41505 & 41398 & 41248 & 41123 & 41010 & 40953 \\
\hline Adjusted $R^{2}$ & 0.013 & 0.011 & 0.020 & 1.000 & 0.003 & 0.002 & 0.004 & 0.002 & 0.002 & 0.001 & 0.001 & 0.002 & 0.001 \\
\hline
\end{tabular}

Panel B: Cumulative BHARs

\begin{tabular}{|c|c|c|c|c|c|c|c|c|c|c|c|c|c|}
\hline & \multicolumn{13}{|c|}{ Dependent variable $=$ Cumulative BHARs } \\
\hline & Week $[-3,0]$ & Week $[-2,0]$ & Week $[-1,0]$ & Week $[0,0]$ & Week $[1,1]$ & Week $[1,2]$ & Week $[1,3]$ & Week $[1,4]$ & Week $[1,5]$ & Week $[1,6]$ & Week $[1,7]$ & Week $[1,8]$ & Week $[1,9]$ \\
\hline $\operatorname{Imprecision}(\mathrm{Z})$ & $\begin{array}{c}0.055 \\
(0.255)\end{array}$ & $\begin{array}{c}0.085 \\
(0.177)\end{array}$ & $\begin{array}{l}-0.029 \\
(0.071)\end{array}$ & $\begin{array}{l}-0.006 \\
(0.013)\end{array}$ & $\begin{array}{c}0.005 \\
(0.060)\end{array}$ & $\begin{array}{c}0.101 \\
(0.071)\end{array}$ & $\begin{array}{c}0.228^{* *} \\
(0.113)\end{array}$ & $\begin{array}{c}0.353^{* * *} \\
(0.127)\end{array}$ & $\begin{array}{c}0.492^{* * *} \\
(0.157)\end{array}$ & $\begin{array}{c}0.610^{* * *} \\
(0.195)\end{array}$ & $\begin{array}{c}0.758^{* * *} \\
(0.235)\end{array}$ & $\begin{array}{c}0.886^{* * *} \\
(0.261)\end{array}$ & $\begin{array}{c}0.956^{* * *} \\
(0.281)\end{array}$ \\
\hline Sentiment $(Z)$ & $\begin{array}{l}-0.096 \\
(0.158)\end{array}$ & $\begin{array}{l}-0.071 \\
(0.113)\end{array}$ & $\begin{array}{l}-0.009 \\
(0.048)\end{array}$ & $\begin{array}{c}-0.042^{* * *} \\
(0.015)\end{array}$ & $\begin{array}{l}-0.019 \\
(0.055)\end{array}$ & $\begin{array}{c}0.045 \\
(0.065)\end{array}$ & $\begin{array}{l}0.086 \\
(0.082)\end{array}$ & $\begin{array}{c}0.130 \\
(0.087)\end{array}$ & $\begin{array}{c}0.058 \\
(0.112)\end{array}$ & $\begin{array}{c}0.026 \\
(0.150)\end{array}$ & $\begin{array}{c}0.107 \\
(0.171)\end{array}$ & $\begin{array}{c}0.077 \\
(0.189)\end{array}$ & $\begin{array}{c}0.002 \\
(0.212)\end{array}$ \\
\hline Observations & 42010 & 42156 & 42262 & 42298 & 41885 & 41681 & 41498 & 41376 & 41116 & 40909 & 40723 & 40570 & 40397 \\
\hline Adjusted $R^{2}$ & 0.173 & 0.241 & 0.381 & 0.928 & 0.003 & 0.003 & 0.004 & 0.004 & 0.006 & 0.006 & 0.006 & 0.007 & 0.007 \\
\hline
\end{tabular}


Table 5: Imprecise Language in Disclosure and Illiquidity

This table presents the estimation results of Model (2) regressing the level of an illiquidity proxy over various weekly windows around 10-K filing on our linguistic imprecision measure as follows: For stock $i$ in year $t$,

$$
\text { Spread }_{i t n}=\alpha_{n}+\beta_{n} \text { Imprecision }_{i t}+\eta_{n}^{\prime} \mathbf{X}_{i t}+\epsilon_{i t n}
$$

where Spread $_{i t n}$ is the average quoted relative bid-ask spread in logarithm over the $n t h$ week window (the 1 st week window starts from the fourth day after the $10-\mathrm{K}$ filing day and the 0 th week window covers the four days between the 10-K filing day and three days later), Imprecision it is the percentage of linguistic imprecision keywords (out of total words), and $\mathbf{X}_{i t}$ is a column vector that contains various control variables: Sentiment, Market value, Book-to-market, Turnover, Institutional ownership, Fama-French alpha, Filing-day abnormal return, Nasdaq dummy, and Pre-filing spread. The detailed definitions of these independent variables are given in the Appendix. We estimate Model (2) for each week separately over the previous 3-week period before $10-\mathrm{K}$ filing and the subsequent 9 -week period after $10-\mathrm{K}$ filing (thus $n=-3, \ldots, 9$ ). (Z) indicates that the variable is standardized to have zero mean and one standard deviation. We also control for firm and filing year-month fixed effects. Standard errors that are clustered by firm and filing year-month are calculated and reported in parentheses. Slope coefficients and standard errors are reported in percentage. ${ }^{* * *},{ }^{* *}$, and ${ }^{*}$ indicate statistical significance at the $1 \%, 5 \%$, and $10 \%$ level, respectively.

\begin{tabular}{|c|c|c|c|c|c|c|c|c|c|c|c|c|c|}
\hline & \multicolumn{13}{|c|}{ Dependent variable $=$ Quoted relative bid-ask spread } \\
\hline & Week $(-3)$ & Week(-2) & Week $(-1)$ & Week(0) & Week(1) & Week $(2)$ & Week(3) & Week(4) & Week(5) & Week(6) & Week $(7)$ & Week(8) & Week $(9)$ \\
\hline Imprecision(Z) & $\begin{array}{l}-0.078 \\
(0.108)\end{array}$ & $\begin{array}{c}0.026 \\
(0.094)\end{array}$ & $\begin{array}{c}0.069 \\
(0.122)\end{array}$ & $\begin{array}{l}-0.203 \\
(0.134)\end{array}$ & $\begin{array}{c}-0.306^{* *} \\
(0.138)\end{array}$ & $\begin{array}{c}-0.430^{* * *} \\
(0.142)\end{array}$ & $\begin{array}{c}-0.509^{* * *} \\
(0.151)\end{array}$ & $\begin{array}{c}-0.608^{* * *} \\
(0.165)\end{array}$ & $\begin{array}{c}-0.453^{* * *} \\
(0.142)\end{array}$ & $\begin{array}{c}-0.432^{* * *} \\
(0.144)\end{array}$ & $\begin{array}{c}-0.408^{* *} \\
(0.183)\end{array}$ & $\begin{array}{c}-0.395^{* *} \\
(0.187)\end{array}$ & $\begin{array}{l}-0.334^{*} \\
(0.196)\end{array}$ \\
\hline Sentiment(Z) & $\begin{array}{l}-0.012 \\
(0.104)\end{array}$ & $\begin{array}{l}-0.076 \\
(0.123)\end{array}$ & $\begin{array}{c}0.037 \\
(0.110)\end{array}$ & $\begin{array}{l}-0.005 \\
(0.175)\end{array}$ & $\begin{array}{c}0.105 \\
(0.134)\end{array}$ & $\begin{array}{c}0.090 \\
(0.136)\end{array}$ & $\begin{array}{c}0.104 \\
(0.155)\end{array}$ & $\begin{array}{c}-0.179 \\
(0.171)\end{array}$ & $\begin{array}{c}-0.009 \\
(0.159)\end{array}$ & $\begin{array}{l}-0.135 \\
(0.186)\end{array}$ & $\begin{array}{l}-0.320^{*} \\
(0.181)\end{array}$ & $\begin{array}{c}-0.397^{* *} \\
(0.179)\end{array}$ & $\begin{array}{l}-0.175 \\
(0.189)\end{array}$ \\
\hline Pre-filing spread(Z) & $\begin{array}{c}49.655^{* * *} \\
(0.337)\end{array}$ & $\begin{array}{c}48.158^{* * *} \\
(0.410)\end{array}$ & $\begin{array}{c}46.462^{* * *} \\
(0.501)\end{array}$ & $\begin{array}{c}41.002^{* * *} \\
(0.742)\end{array}$ & $\begin{array}{c}39.534^{* * *} \\
(0.764)\end{array}$ & $\begin{array}{c}37.737^{* * *} \\
(0.935)\end{array}$ & $\begin{array}{c}36.937^{* * *} \\
(1.026)\end{array}$ & $\begin{array}{c}36.188^{* * *} \\
(1.115)\end{array}$ & $\begin{array}{c}35.278^{* * *} \\
(1.241)\end{array}$ & $\begin{array}{c}34.365^{* * *} \\
(1.269)\end{array}$ & $\begin{array}{c}32.573^{* * *} \\
(1.421)\end{array}$ & $\begin{array}{c}31.836^{* * *} \\
(1.508)\end{array}$ & $\begin{array}{c}31.554^{* * *} \\
(1.585)\end{array}$ \\
\hline Observations & 40541 & 40645 & 40734 & 40771 & 39335 & 39249 & 39192 & 39185 & 39177 & 39113 & 39096 & 39062 & 39085 \\
\hline Adjusted $R^{2}$ & 0.939 & 0.937 & 0.933 & 0.87 & 0.896 & 0.887 & 0.883 & 0.88 & 0.876 & 0.871 & 0.865 & 0.86 & 0.853 \\
\hline
\end{tabular}


Table 6: Imprecise Language in Disclosure and Informed Buying Activity

This table presents the estimation results of Model (3) regressing a proxy for informed buying activity over various weekly windows around 10-K filing on our linguistic imprecision measure as follows: For stock $i$ in year $t$,

$$
\text { Probability of informed buying }{ }_{i t n}=\alpha_{n}+\beta_{n} \text { Imprecision }_{i t}+\eta_{n}^{\prime} \mathbf{X}_{i t}+\epsilon_{i t n},
$$

where Probability of informed buying itn $_{\text {p }}$ proxies the trading activity of informed buyers based on Brennan, Huh, and Subrahmanyam (2018) over the $n t h$ week window (the 1st week window starts from the fourth day after the 10-K filing day and the 0th week window covers the four days between the $10-\mathrm{K}$ filing day and three days later), Imprecision It $_{i}$ is the percentage of linguistic imprecision keywords (out of total words), and $\mathbf{X}_{i t}$ is a column vector that contains various control variables: Sentiment, Market value, Book-to-market, Turnover, Institutional ownership, Fama-French alpha, Filing-day abnormal return, Nasdaq dummy, and Pre-filing informed buying. The detailed definitions of these independent variables are given in the Appendix. We estimate Model (3) for each week separately over the previous 3-week period before 10-K filing and the subsequent 9-week period after 10-K filing (thus $n=-3, \ldots, 9)$. (Z) indicates that the variable is standardized to have zero mean and one standard deviation. We also control for filing year-month fixed effect. Standard errors that are clustered by firm and filing year-month are calculated and reported in parentheses. Slope coefficients and standard errors are reported in percentage. ${ }^{* * *},{ }^{* *}$, and ${ }^{*}$ indicate statistical significance at the $1 \%, 5 \%$, and $10 \%$ level, respectively.

\begin{tabular}{|c|c|c|c|c|c|c|c|c|c|c|c|c|c|}
\hline & \multicolumn{13}{|c|}{ Dependent variable $=$ Probability of informed buying } \\
\hline & Week $(-3)$ & Week $(-2)$ & Week $(-1)$ & Week $(0)$ & Week(1) & Week $(2)$ & Week(3) & Week(4) & Week(5) & Week $(6)$ & Week(7) & Week(8) & Week $(9)$ \\
\hline $\operatorname{Imprecision}(\mathrm{Z})$ & $\begin{array}{l}-0.248 \\
(0.182)\end{array}$ & $\begin{array}{l}-0.041 \\
(0.203)\end{array}$ & $\begin{array}{c}0.108 \\
(0.183)\end{array}$ & $\begin{array}{c}0.613^{* *} \\
(0.285)\end{array}$ & $\begin{array}{c}0.659^{* * * *} \\
(0.203)\end{array}$ & $\begin{array}{c}0.408^{* *} \\
(0.200)\end{array}$ & $\begin{array}{c}0.443^{* *} \\
(0.194)\end{array}$ & $\begin{array}{c}0.502^{* *} \\
(0.213)\end{array}$ & $\begin{array}{c}0.394^{* *} \\
(0.190)\end{array}$ & $\begin{array}{l}0.369^{*} \\
(0.214)\end{array}$ & $\begin{array}{c}0.338 \\
(0.216)\end{array}$ & $\begin{array}{c}0.222 \\
(0.238)\end{array}$ & $\begin{array}{c}0.171 \\
(0.211)\end{array}$ \\
\hline Sentiment(Z) & $\begin{array}{c}-0.051 \\
(0.096)\end{array}$ & $\begin{array}{c}-0.274^{* * *} \\
(0.102)\end{array}$ & $\begin{array}{l}-0.147 \\
(0.125)\end{array}$ & $\begin{array}{c}-0.425^{* *} \\
(0.199)\end{array}$ & $\begin{array}{c}-0.309^{* *} \\
(0.149)\end{array}$ & $\begin{array}{l}-0.059 \\
(0.144)\end{array}$ & $\begin{array}{l}-0.057 \\
(0.140)\end{array}$ & $\begin{array}{l}-0.117 \\
(0.171)\end{array}$ & $\begin{array}{l}-0.081 \\
(0.165)\end{array}$ & $\begin{array}{c}0.287^{* *} \\
(0.134)\end{array}$ & $\begin{array}{c}0.123 \\
(0.149)\end{array}$ & $\begin{array}{l}-0.157 \\
(0.181)\end{array}$ & $\begin{array}{c}0.139 \\
(0.146)\end{array}$ \\
\hline Pre-filing informed buying(Z) & $\begin{array}{c}16.496^{* * *} \\
(0.152)\end{array}$ & $\begin{array}{c}15.763^{* * *} \\
(0.188)\end{array}$ & $\begin{array}{c}14.564^{* * *} \\
(0.188)\end{array}$ & $\begin{array}{c}8.613^{* * *} \\
(0.215)\end{array}$ & $\begin{array}{c}6.509^{* * * *} \\
(0.182)\end{array}$ & $\begin{array}{c}5.351^{* * *} \\
(0.294)\end{array}$ & $\begin{array}{c}4.334^{* * *} \\
(0.209)\end{array}$ & $\begin{array}{c}3.419^{* * *} \\
(0.176)\end{array}$ & $\begin{array}{c}2.275^{* * *} \\
(0.180)\end{array}$ & $\begin{array}{c}1.607^{* * *} \\
(0.184)\end{array}$ & $\begin{array}{c}1.206^{* * *} \\
(0.174)\end{array}$ & $\begin{array}{c}1.008^{* * *} \\
(0.161)\end{array}$ & $\begin{array}{c}0.650^{* * *} \\
(0.189)\end{array}$ \\
\hline Observations & 33218 & 33339 & 33334 & 32766 & 31747 & 31553 & 31355 & 31320 & 31390 & 31171 & 31151 & 30956 & 31135 \\
\hline Adjusted $R^{2}$ & 0.430 & 0.396 & 0.345 & 0.122 & 0.087 & 0.065 & 0.053 & 0.055 & 0.050 & 0.051 & 0.054 & 0.048 & 0.040 \\
\hline
\end{tabular}


Table 7: Imprecise Language in Disclosure and Insider Buying Activity

This table presents the estimation results of regressing a proxy for insider trading activity over various weekly windows around 10-K filing on our linguistic imprecision measure as follows: For stock $i$ in year $t$,

Dollar volume of insider buying ${ }_{i t n}=\alpha_{n}+\beta_{n}$ Imprecision $_{i t}+\eta_{n}^{\prime} \mathbf{X}_{i t}+\epsilon_{i t n}$,

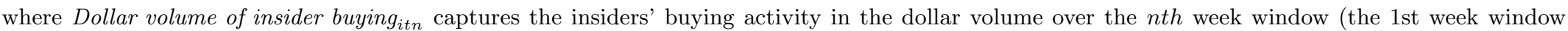
starts from the fourth day after the 10-K filing day and the 0th week window covers the four days between the 10-K filing day and three days later), Imprecision $_{i t}$ is the percentage of linguistic imprecision keywords (out of total words), and $\mathbf{X}_{i t}$ is a column vector that contains various control variables: Sentiment, Market value, Book-to-market, Turnover, Institutional ownership, Fama-French alpha, Filing-day abnormal return, and Nasdaq dummy. The detailed definitions of these independent variables are given in the Appendix. We estimate the regression model above for each week separately over the previous 3 -week period before 10 -K filing and the subsequent 9 -week period after $10-\mathrm{K}$ filing (thus $n=-3, \ldots, 9$ ). (Z) indicates that

the variable is standardized to have zero mean and one standard deviation. We also control for filing year-month fixed effect. Standard errors that are clustered by firm and filing year-month are calculated and reported in parentheses. Slope coefficients and standard errors are reported in percentage. ${ }^{* * *},{ }^{* *}$, and ${ }^{*}$ indicate statistical significance at the $1 \%, 5 \%$, and $10 \%$ level, respectively.

\begin{tabular}{|c|c|c|c|c|c|c|c|c|c|c|c|c|c|}
\hline & \multicolumn{13}{|c|}{ Dependent variable $=$ Dollar volume of insider buying } \\
\hline & Week(-3) & Week $(-2)$ & Week(-1) & Week $(0)$ & Week(1) & $\operatorname{Week}(2)$ & Week(3) & $\operatorname{Week}(4)$ & Week(5) & Week $(6)$ & $\operatorname{Week}(7)$ & Week $(8)$ & Week $(9)$ \\
\hline $\operatorname{Imprecision}(\mathrm{Z})$ & $\begin{array}{c}23.132^{* * *} \\
(8.383)\end{array}$ & $\begin{array}{c}20.916^{* *} \\
(9.050)\end{array}$ & $\begin{array}{c}24.360^{* * *} \\
(8.240)\end{array}$ & $\begin{array}{c}24.057^{* * *} \\
(8.270)\end{array}$ & $\begin{array}{c}23.836^{* * *} \\
(8.248)\end{array}$ & $\begin{array}{c}36.369^{* * *} \\
(9.516)\end{array}$ & $\begin{array}{c}49.362^{* * *} \\
(11.488)\end{array}$ & $\begin{array}{c}38.129^{* * *} \\
(9.980)\end{array}$ & $\begin{array}{c}33.601^{* * *} \\
(11.170)\end{array}$ & $\begin{array}{c}20.689^{* *} \\
(9.184)\end{array}$ & $\begin{array}{c}26.999^{* * *} \\
(9.639)\end{array}$ & $\begin{array}{c}31.381^{* * *} \\
(10.816)\end{array}$ & $\begin{array}{c}26.373^{* * *} \\
(6.931)\end{array}$ \\
\hline Sentiment $(Z)$ & $\begin{array}{l}-8.951 \\
(6.616)\end{array}$ & $\begin{array}{l}-8.446 \\
(7.044)\end{array}$ & $\begin{array}{l}-0.209 \\
(7.614)\end{array}$ & $\begin{array}{l}-0.880 \\
(8.235)\end{array}$ & $\begin{array}{l}-2.867 \\
(7.334)\end{array}$ & $\begin{array}{l}-7.230 \\
(8.037)\end{array}$ & $\begin{array}{c}4.575 \\
(9.803)\end{array}$ & $\begin{array}{l}10.509 \\
(7.652)\end{array}$ & $\begin{array}{l}-3.294 \\
(8.220)\end{array}$ & $\begin{array}{l}-5.164 \\
(6.731)\end{array}$ & $\begin{array}{l}-5.823 \\
(6.813)\end{array}$ & $\begin{array}{l}-0.732 \\
(6.779)\end{array}$ & $\begin{array}{l}-2.157 \\
(5.678)\end{array}$ \\
\hline Observations & 1939 & 1824 & 1774 & 1448 & 1896 & 1421 & 1056 & 1085 & 1258 & 1444 & 1769 & 2054 & 2247 \\
\hline Adjusted $R^{2}$ & 0.141 & 0.167 & 0.134 & 0.124 & 0.125 & 0.102 & 0.146 & 0.135 & 0.057 & 0.079 & 0.146 & 0.111 & 0.152 \\
\hline
\end{tabular}




\section{Table 8: Imprecise Language in Disclosure and News Sentiment}

This table presents the estimation results of Model (4) regressing the level of news sentiment over various weekly windows on our linguistic imprecision measure as follows: For stock $i$ in year $t$,

$$
\text { News sentiment } t_{i t n}=\alpha_{n}+\beta_{n} \text { Imprecision }_{i t}+\eta_{n}^{\prime} \mathbf{X}_{i t}+\epsilon_{i t n}
$$

where News sentiment $t_{i t n}$ is the average news-related sentiment score over the $n$th week window (the 1st week window starts from the fourth day after the 10-K filing day and the 0th week window covers the four days between the 10-K filing day and three days later). The average news-sentiment score is calculated based on the ESS variable available from the RavenPack News Analytics database. Imprecision it is the percentage of linguistic imprecision keywords (out of total words) and $\mathbf{X}_{i t}$ is a column vector that contains various control variables: Sentiment, Market value, Book-to-market, Turnover, Institutional ownership, Fama-French alpha, Filing-day abnormal return, Pre-filing news sentiment, and nth-week market news sentiment. The detailed definitions of these independent variables are given in the Appendix. We estimate Model (4) for each week separately over the previous 3-week period before $10-\mathrm{K}$ filing and the subsequent 9 -week period after $10-\mathrm{K}$ filing (thus $n=-3, \ldots, 9$ ). (Z) indicates that the variable is standardized to have zero mean and one standard deviation. Standard errors that are clustered by firm and filing year-month are calculated and reported in parentheses. Slope coefficients and standard errors are reported in percentage. ${ }^{* * *},{ }^{* *}$, and ${ }^{*}$ indicate statistical significance at the $1 \%, 5 \%$, and $10 \%$ level, respectively.

\begin{tabular}{|c|c|c|c|c|c|c|c|c|c|c|c|c|c|}
\hline & \multicolumn{13}{|c|}{ Dependent variable $=$ Average news sentiment score } \\
\hline & Week $(-3)$ & Week(-2) & Week $(-1)$ & Week $(0)$ & Week $(1)$ & Week(2) & Week (3) & Week(4) & Week(5) & Week(6) & Week $(7)$ & Week $(8)$ & Week $(9)$ \\
\hline $\operatorname{Imprecision}(\mathrm{Z})$ & $\begin{array}{c}0.014 \\
(0.133)\end{array}$ & $\begin{array}{l}-0.225 \\
(0.173)\end{array}$ & $\begin{array}{l}-0.069 \\
(0.134)\end{array}$ & $\begin{array}{c}0.175 \\
(0.186)\end{array}$ & $\begin{array}{l}0.330^{*} \\
(0.192)\end{array}$ & $\begin{array}{c}0.595^{* * *} \\
(0.212)\end{array}$ & $\begin{array}{c}0.758^{* * *} \\
(0.230)\end{array}$ & $\begin{array}{c}0.981^{* * *} \\
(0.161)\end{array}$ & $\begin{array}{c}0.372^{* *} \\
(0.167)\end{array}$ & $\begin{array}{c}0.410^{* *} \\
(0.200)\end{array}$ & $\begin{array}{c}0.534^{* * *} \\
(0.161)\end{array}$ & $\begin{array}{c}0.103 \\
(0.185)\end{array}$ & $\begin{array}{c}0.009 \\
(0.168)\end{array}$ \\
\hline Sentiment(Z) & $\begin{array}{l}-0.018 \\
(0.128)\end{array}$ & $\begin{array}{l}-0.244 \\
(0.153)\end{array}$ & $\begin{array}{l}-0.069 \\
(0.152)\end{array}$ & $\begin{array}{c}0.003 \\
(0.222)\end{array}$ & $\begin{array}{c}-0.534^{* *} \\
(0.210)\end{array}$ & $\begin{array}{l}-0.213 \\
(0.266)\end{array}$ & $\begin{array}{l}-0.173 \\
(0.193)\end{array}$ & $\begin{array}{c}0.258 \\
(0.172)\end{array}$ & $\begin{array}{c}-0.567^{* * *} \\
(0.204)\end{array}$ & $\begin{array}{l}-0.376 \\
(0.234)\end{array}$ & $\begin{array}{c}-0.341^{* *} \\
(0.166)\end{array}$ & $\begin{array}{c}0.105 \\
(0.162)\end{array}$ & $\begin{array}{l}-0.248 \\
(0.239)\end{array}$ \\
\hline Pre-filing news sentiment(Z) & $\begin{array}{c}13.552^{* * *} \\
(0.185)\end{array}$ & $\begin{array}{c}13.777^{* * *} \\
(0.172)\end{array}$ & $\begin{array}{c}14.141^{* * *} * \\
(0.232)\end{array}$ & $\begin{array}{c}2.636^{* * *} \\
(0.269)\end{array}$ & $\begin{array}{c}2.865^{* * *} \\
(0.203)\end{array}$ & $\begin{array}{c}2.840^{* * *} \\
(0.247)\end{array}$ & $\begin{array}{c}2.536^{* * *} \\
(0.268)\end{array}$ & $\begin{array}{c}2.628^{* * *} \\
(0.261)\end{array}$ & $\begin{array}{c}2.234^{* * *} \\
(0.242)\end{array}$ & $\begin{array}{c}2.318^{* * *} \\
(0.205)\end{array}$ & $\begin{array}{c}2.609^{* * *} \\
(0.263)\end{array}$ & $\begin{array}{c}2.421^{* * *} \\
(0.203)\end{array}$ & $\begin{array}{c}2.195^{* * *} \\
(0.203)\end{array}$ \\
\hline nth-week market news sentiment $(\mathrm{Z})$ & $\begin{array}{c}0.507^{* * *} \\
(0.133)\end{array}$ & $\begin{array}{c}0.198 \\
(0.122)\end{array}$ & $\begin{array}{c}0.051 \\
(0.168)\end{array}$ & $\begin{array}{c}0.619^{* *} \\
(0.269)\end{array}$ & $\begin{array}{l}-0.139 \\
(0.184)\end{array}$ & $\begin{array}{c}0.307 \\
(0.287)\end{array}$ & $\begin{array}{c}0.168 \\
(0.279)\end{array}$ & $\begin{array}{c}0.372^{* *} \\
(0.164)\end{array}$ & $\begin{array}{l}-0.033 \\
(0.188)\end{array}$ & $\begin{array}{c}0.765^{* * *} \\
(0.216)\end{array}$ & $\begin{array}{c}0.391^{* *} \\
(0.186)\end{array}$ & $\begin{array}{c}0.328 \\
(0.236)\end{array}$ & $\begin{array}{c}0.493^{* *} \\
(0.201)\end{array}$ \\
\hline Observations & 21632 & 21499 & 22047 & 18274 & 19146 & 18568 & 19093 & 19208 & 20189 & 21266 & 21833 & 21886 & 21232 \\
\hline Adjusted $R^{2}$ & 0.310 & 0.324 & 0.349 & 0.027 & 0.024 & 0.022 & 0.021 & 0.021 & 0.019 & 0.017 & 0.018 & 0.014 & 0.012 \\
\hline
\end{tabular}


Table 9: Imprecise Language in Disclosure and Cumulative BHARs by Heterogeneous Characteristics

For each subsample based on heterogeneity characteristics, this table presents the estimation results of Model (1) regressing cumulative buy and hold abnormal returns (BHARs) over various multiple-week windows after 10-K filing on our linguistic imprecision measure as follows: For stock $i$ in year $t$,

$$
\text { Cumlative BHAR } \text { Btn }_{i t}=\alpha_{n}+\beta_{n} \text { Imprecision }_{i t}+\eta_{n}^{\prime} \mathbf{X}_{i t}+\epsilon_{i t n},
$$

where Cumlative BHAR $R_{i t n}$ is the return difference between stock $i$ and the CRSP value-weighted index over multiple-week window (as in Panel B of Table 4). Imprecision It $_{i}$ is the percentage of linguistic imprecision keywords (out of the total words), and $\mathbf{X}_{i t}$ is a column vector that contains various control variables used in prior studies: Sentiment, Market value, Book-to-market, Turnover, Institutional ownership, Fama-French alpha, and Filing-day abnormal return. The detailed definitions of these independent variables are given in the Appendix. For post-filing weeks, each cumulative BHAR is computed over the period from the start of the 1 st week to the end of the $n$th week, i.e., Week $[1, \mathrm{n}]$, where $n=1, \ldots, 9$. For pre-filing weeks and the 0th week, each "reverse" cumulative BHAR is computed over the period from the end of the 0th week to the start of the $n$th week, i.e., Week[n,0], where $n=-3, \ldots, 0$ and used as the dependent variable. ( $\mathrm{Z}$ ) indicates that the variable is standardized to have zero mean and one standard deviation. Standard errors that are clustered by filing year-month to account for cross-sectional correlation of cumulative BHARs are reported in parentheses. Slope coefficients and standard errors are reported in percentage. ${ }^{* * *},{ }^{* *}$, and ${ }^{*}$ indicate statistical significance at the $1 \%, 5 \%$, and $10 \%$ level, respectively. For brevity, the only slope coefficient of Imprecision $_{i t}$ is reported although all control variables are included in the estimation. We consider the following five firm characteristics for heterogeneity tests: Forward-looking disclosure, R\&D disclosure, bid-ask spread, idiosyncratic volatility of returns, and analyst coverage. High and Low of each of these variables refer to firms with the variable above and below its median, respectively. For analyst coverage, firms with no analyst following (Absence) and those with at least one analyst following (Presence) are grouped.

\begin{tabular}{|c|c|c|c|c|c|c|c|c|c|c|c|c|c|c|}
\hline \multirow[b]{2}{*}{ Subsamples by } & & \multirow[b]{2}{*}{ Week $[-3,0]$} & \multirow[b]{2}{*}{ Week $[-2,0]$} & \multirow[b]{2}{*}{ Week $[-1,0]$} & \multicolumn{4}{|c|}{ Dependent variable $=$ Cumulative BHARs } & \multirow[b]{2}{*}{ Week $[1,4]$} & \multirow[b]{2}{*}{ Week $[1,5]$} & \multirow[b]{2}{*}{ Week $[1,6]$} & \multirow[b]{2}{*}{ Week $[1,7]$} & \multirow[b]{2}{*}{ Week $[1,8]$} & \multirow[b]{2}{*}{ Week $[1,9]$} \\
\hline & & & & & Week $[0,0]$ & Week $[1,1]$ & Week $[1,2]$ & Week $[1,3]$ & & & & & & \\
\hline \multicolumn{15}{|c|}{ Forward-looking disclosure } \\
\hline High & $\operatorname{Imprecision}(\mathrm{Z})$ & $\begin{array}{c}0.060 \\
(0.300)\end{array}$ & $\begin{array}{c}0.056 \\
(0.196)\end{array}$ & $\begin{array}{c}0.003 \\
(0.095)\end{array}$ & $\begin{array}{c}0.009 \\
(0.017)\end{array}$ & $\begin{array}{c}0.096 \\
(0.069)\end{array}$ & $\begin{array}{l}0.211^{*} \\
(0.121)\end{array}$ & $\begin{array}{l}0.276^{*} \\
(0.158)\end{array}$ & $\begin{array}{c}0.475^{* * *} \\
(0.176)\end{array}$ & $\begin{array}{c}0.651^{* * *} \\
(0.196)\end{array}$ & $\begin{array}{c}0.831^{* * *} \\
(0.227)\end{array}$ & $\begin{array}{c}1.089^{* * *} \\
(0.277)\end{array}$ & $\begin{array}{c}1.137 * * * \\
(0.297)\end{array}$ & $\begin{array}{c}1.227^{* * *} \\
(0.317)\end{array}$ \\
\hline Low & $\operatorname{Imprecision}(\mathrm{Z})$ & $\begin{array}{c}0.027 \\
(0.252)\end{array}$ & $\begin{array}{c}0.098 \\
(0.177)\end{array}$ & $\begin{array}{l}-0.085 \\
(0.068)\end{array}$ & $\begin{array}{l}-0.021 \\
(0.016)\end{array}$ & $\begin{array}{l}-0.039 \\
(0.081)\end{array}$ & $\begin{array}{c}0.084 \\
(0.121)\end{array}$ & $\begin{array}{c}0.203 \\
(0.161)\end{array}$ & $\begin{array}{c}0.237 \\
(0.195)\end{array}$ & $\begin{array}{c}0.252 \\
(0.228)\end{array}$ & $\begin{array}{c}0.277 \\
(0.267)\end{array}$ & $\begin{array}{c}0.411 \\
(0.300)\end{array}$ & $\begin{array}{c}0.555 \\
(0.338)\end{array}$ & $\begin{array}{c}0.571 \\
(0.354)\end{array}$ \\
\hline \multicolumn{15}{|c|}{ RED disclosure } \\
\hline High & $\operatorname{Imprecision}(\mathrm{Z})$ & $\begin{array}{c}0.155 \\
(0.245)\end{array}$ & $\begin{array}{c}0.170 \\
(0.182)\end{array}$ & $\begin{array}{c}0.028 \\
(0.094)\end{array}$ & $\begin{array}{c}-0.02 \\
(0.018)\end{array}$ & $\begin{array}{c}0.012 \\
(0.073)\end{array}$ & $\begin{array}{l}0.178^{*} \\
(0.105)\end{array}$ & $\begin{array}{l}0.249^{*} \\
(0.150)\end{array}$ & $\begin{array}{c}0.409^{* *} \\
(0.171)\end{array}$ & $\begin{array}{c}0.564^{* * *} \\
(0.192)\end{array}$ & $\begin{array}{c}0.693^{* * *} \\
(0.218)\end{array}$ & $\begin{array}{c}0.962^{* * *} \\
(0.258)\end{array}$ & $\begin{array}{c}1.077^{* * *} \\
(0.288)\end{array}$ & $\begin{array}{c}1.126^{* * *} \\
(0.312)\end{array}$ \\
\hline Low & $\operatorname{Imprecision}(\mathrm{Z})$ & $\begin{array}{l}-0.086 \\
(0.335)\end{array}$ & $\begin{array}{l}-0.036 \\
(0.230)\end{array}$ & $\begin{array}{l}-0.128 \\
(0.090)\end{array}$ & $\begin{array}{c}0.005 \\
(0.016)\end{array}$ & $\begin{array}{l}-0.003 \\
(0.098)\end{array}$ & $\begin{array}{c}0.073 \\
(0.143)\end{array}$ & $\begin{array}{c}0.167 \\
(0.171)\end{array}$ & $\begin{array}{c}0.233 \\
(0.192)\end{array}$ & $\begin{array}{c}0.295 \\
(0.231)\end{array}$ & $\begin{array}{c}0.376 \\
(0.282)\end{array}$ & $\begin{array}{c}0.491 \\
(0.329)\end{array}$ & $\begin{array}{c}0.562 \\
(0.364)\end{array}$ & $\begin{array}{c}0.57 \\
(0.382)\end{array}$ \\
\hline \multicolumn{15}{|c|}{ Bid-ask spread } \\
\hline High & $\operatorname{Imprecision}(\mathrm{Z})$ & $\begin{array}{c}0.291 \\
(0.334)\end{array}$ & $\begin{array}{c}0.190 \\
(0.231)\end{array}$ & $\begin{array}{c}0.006 \\
(0.082)\end{array}$ & $\begin{array}{l}-0.014 \\
(0.022)\end{array}$ & $\begin{array}{c}0.067 \\
(0.097)\end{array}$ & $\begin{array}{c}0.234 \\
(0.149)\end{array}$ & $\begin{array}{c}0.362^{* *} \\
(0.181)\end{array}$ & $\begin{array}{c}0.511^{* *} \\
(0.203)\end{array}$ & $\begin{array}{c}0.632^{* *} \\
(0.253)\end{array}$ & $\begin{array}{c}0.838^{* * *} \\
(0.315)\end{array}$ & $\begin{array}{c}1.029^{* * *} \\
(0.369)\end{array}$ & $\begin{array}{c}1.172^{* * *} \\
(0.408)\end{array}$ & $\begin{array}{c}1.203^{* * *} \\
(0.444)\end{array}$ \\
\hline Low & $\operatorname{Imprecision}(\mathrm{Z})$ & $\begin{array}{l}-0.176 \\
(0.248)\end{array}$ & $\begin{array}{l}-0.020 \\
(0.179)\end{array}$ & $\begin{array}{l}-0.078 \\
(0.090)\end{array}$ & $\begin{array}{c}0.007 \\
(0.013)\end{array}$ & $\begin{array}{l}-0.015 \\
(0.053)\end{array}$ & $\begin{array}{c}0.086 \\
(0.071)\end{array}$ & $\begin{array}{c}0.158 \\
(0.102)\end{array}$ & $\begin{array}{c}0.259^{* *} \\
(0.122)\end{array}$ & $\begin{array}{c}0.392^{* * *} \\
(0.134)\end{array}$ & $\begin{array}{c}0.426^{* * *} \\
(0.159)\end{array}$ & $\begin{array}{c}0.644^{* * *} \\
(0.185)\end{array}$ & $\begin{array}{c}0.691^{* * *} \\
(0.196)\end{array}$ & $\begin{array}{c}0.725^{* * *} \\
(0.211)\end{array}$ \\
\hline \multicolumn{15}{|c|}{ Idiosyncratic volatility of returns } \\
\hline High & $\operatorname{Imprecision}(\mathrm{Z})$ & $\begin{array}{c}0.341 \\
(0.327)\end{array}$ & $\begin{array}{c}0.258 \\
(0.228)\end{array}$ & $\begin{array}{l}-0.055 \\
(0.099)\end{array}$ & $\begin{array}{l}-0.023 \\
(0.024)\end{array}$ & $\begin{array}{c}0.019 \\
(0.110)\end{array}$ & $\begin{array}{c}0.234 \\
(0.156)\end{array}$ & $\begin{array}{c}0.328 \\
(0.200)\end{array}$ & $\begin{array}{c}0.525^{* *} \\
(0.217)\end{array}$ & $\begin{array}{c}0.633^{* *} \\
(0.257)\end{array}$ & $\begin{array}{c}0.718^{* *} \\
(0.303)\end{array}$ & $\begin{array}{c}1.040^{* * *} \\
(0.369)\end{array}$ & $\begin{array}{c}1.173^{* * *} \\
(0.414)\end{array}$ & $\begin{array}{c}1.230^{* * *} \\
(0.440)\end{array}$ \\
\hline Low & $\operatorname{Imprecision}(\mathrm{Z})$ & $\begin{array}{l}-0.208 \\
(0.224) \\
\end{array}$ & $\begin{array}{c}-0.079 \\
(0.154) \\
\end{array}$ & $\begin{array}{l}-0.006 \\
(0.065) \\
\end{array}$ & $\begin{array}{l}0.014^{*} \\
(0.007) \\
\end{array}$ & $\begin{array}{c}-0.009 \\
(0.048) \\
\end{array}$ & $\begin{array}{c}0.028 \\
(0.086) \\
\end{array}$ & $\begin{array}{c}0.128 \\
(0.107) \\
\end{array}$ & $\begin{array}{c}0.186 \\
(0.116) \\
\end{array}$ & $\begin{array}{c}0.307^{* *} \\
(0.139)\end{array}$ & $\begin{array}{c}0.448^{* * *} \\
(0.164) \\
\end{array}$ & $\begin{array}{c}0.548^{* * *} \\
(0.183) \\
\end{array}$ & $\begin{array}{c}0.588^{* * *} \\
(0.200) \\
\end{array}$ & $\begin{array}{c}0.596^{* * *} \\
(0.223) \\
\end{array}$ \\
\hline \multicolumn{15}{|c|}{ Analyst coverage } \\
\hline Absence & Imprecision $(\mathrm{Z})$ & $\begin{array}{c}0.132 \\
(0.221)\end{array}$ & $\begin{array}{c}0.102 \\
(0.156)\end{array}$ & $\begin{array}{c}0.017 \\
(0.094)\end{array}$ & $\begin{array}{l}-0.011 \\
(0.022)\end{array}$ & $\begin{array}{c}0.094 \\
(0.080)\end{array}$ & $\begin{array}{l}0.210^{*} \\
(0.118)\end{array}$ & $\begin{array}{l}0.280^{*} \\
(0.150)\end{array}$ & $\begin{array}{c}0.433^{* * *} \\
(0.163)\end{array}$ & $\begin{array}{c}0.561^{* * *} \\
(0.198)\end{array}$ & $\begin{array}{c}0.682^{* * * *} \\
(0.233)\end{array}$ & $\begin{array}{c}0.852^{* * *} \\
(0.257)\end{array}$ & $\begin{array}{c}1.039^{* * *} \\
(0.278)\end{array}$ & $\begin{array}{c}1.092^{* * * *} \\
(0.313)\end{array}$ \\
\hline Presence & Imprecision $(\mathrm{Z})$ & $\begin{array}{c}0.058 \\
(0.278)\end{array}$ & $\begin{array}{c}0.113 \\
(0.196)\end{array}$ & $\begin{array}{l}-0.026 \\
(0.076)\end{array}$ & $\begin{array}{l}-0.003 \\
(0.016)\end{array}$ & $\begin{array}{l}-0.038 \\
(0.063)\end{array}$ & $\begin{array}{c}0.096 \\
(0.098)\end{array}$ & $\begin{array}{c}0.207 \\
(0.128)\end{array}$ & $\begin{array}{l}0.348^{* *} \\
(0.141)\end{array}$ & $\begin{array}{c}0.442^{* *} \\
(0.176)\end{array}$ & $\begin{array}{c}0.548^{* *} \\
(0.220)\end{array}$ & $\begin{array}{c}0.729 * * * \\
(0.268)\end{array}$ & $\begin{array}{c}0.846^{* * *} \\
(0.296)\end{array}$ & $\begin{array}{c}0.877^{* * *} \\
(0.315)\end{array}$ \\
\hline
\end{tabular}


Appendix Figure and Tables to:

Imprecise and Informative: Lessons from Market Reactions to Imprecise Disclosure 


\section{Table A.1: Top 100 Frequently Used Bigrams by Saliency Scores}

This table presents the top 100 meaningful neighboring bigrams in the $10-\mathrm{K}$ paragraphs that contain the linguistic imprecision keywords by saliency scores. We analyze 5,597,740 pairs of bigrams in the $10-\mathrm{K}$ paragraphs and compute the saliency score of each bigram in paragraphs with the linguistic imprecision keywords relative to paragraphs without such keywords.

\begin{tabular}{|c|c|c|c|}
\hline Rank & Bigram & Rank & Bigram \\
\hline 1 & (adverse, effect) & 51 & (sole, discretion) \\
\hline 2 & (adversely, affect) & 52 & (accounting, standard) \\
\hline 3 & (material, adverse) & 53 & (impairment, test) \\
\hline 4 & (internal, control) & 54 & (material, effect) \\
\hline 5 & (third, party) & 55 & (significant, estimate) \\
\hline 6 & (forward-looking, statement) & 56 & (business, day) \\
\hline 7 & (market, value) & 57 & (property, right) \\
\hline 8 & (company, belief) & 58 & (reasonable, basis) \\
\hline 9 & (comprehensive, income) & 59 & (new, product) \\
\hline 10 & (financial, reporting) & 60 & (trade, secret) \\
\hline 11 & (actual, result) & 61 & (public, offering) \\
\hline 12 & (market, price) & 62 & (regulatory, approval) \\
\hline 13 & (financial, condition) & 63 & (holding, company) \\
\hline 14 & (operating, result) & 64 & (closing, price) \\
\hline 15 & (intellectual, property) & 65 & (stock, outstanding) \\
\hline 16 & (management, belief) & 66 & (period, presented) \\
\hline 17 & (adversely, affected) & 67 & (good, faith) \\
\hline 18 & (fair, market) & 68 & (significant, role) \\
\hline 19 & (loan, document) & 69 & (material, information) \\
\hline 20 & (certifying, officer) & 70 & (made, known) \\
\hline 21 & (economic, condition) & 71 & (obtain, reasonable) \\
\hline 22 & (written, notice) & 72 & (involves, management) \\
\hline 23 & (clinical, trial) & 73 & (voting, power) \\
\hline 24 & (applicable, law) & 74 & (standard, require) \\
\hline 25 & (market, condition) & 75 & (company, issued) \\
\hline 26 & (share, outstanding) & 76 & (material, impact) \\
\hline 27 & (materially, affect) & 77 & (report, financial) \\
\hline 28 & (financial, institution) & 78 & (information, included) \\
\hline 29 & (average, number) & 79 & (adverse, impact) \\
\hline 30 & (future, cash) & 80 & (person, performing) \\
\hline 31 & (product, candidate) & 81 & (materially, adversely) \\
\hline 32 & (administrative, agent) & 82 & (material, misstatement) \\
\hline 33 & (outstanding, share) & 83 & (security, act) \\
\hline 34 & (reported, amount) & 84 & (maintaining, disclosure) \\
\hline 35 & (material, weakness) & 85 & (requires, management) \\
\hline 36 & (taxable, income) & 86 & (equivalent, function) \\
\hline 37 & (materially, affected) & 87 & (reasonable, assurance) \\
\hline 38 & (par, value) & 88 & (pay, dividend) \\
\hline 39 & (differ, materially) & 89 & (company, also) \\
\hline 40 & (carrying, value) & 90 & (either, party) \\
\hline 41 & (future, period) & 91 & (overall, financial) \\
\hline 42 & (act, rule) & 92 & (prior, written) \\
\hline 43 & (ordinary, course) & 93 & (bank, holding) \\
\hline 44 & (stock, price) & 94 & (estimate, made) \\
\hline 45 & (make, estimate) & 95 & (certain, circumstance) \\
\hline 46 & (fiscal, quarter) & 96 & (exclude, empty) \\
\hline 47 & (equity, instrument) & 97 & (market, participant) \\
\hline 48 & (circumstance, indicate) & 98 & (also, includes) \\
\hline 49 & (reporting, period) & 99 & (financial, result) \\
\hline 50 & (significant, deficiency) & 100 & (trading, day) \\
\hline
\end{tabular}


Table A.2: Imprecise Language in Disclosure and BHARs (All Slope Coefficients)

This table present the slope coefficient estimates for all control variables in Table 4. Slope coefficients and standard errors are reported in percentage. For brevity, intercept is not reported although it is included in the estimation.

\begin{tabular}{|c|c|c|c|c|c|c|c|c|c|c|c|c|c|}
\hline & \multicolumn{13}{|c|}{ Dependent variable $=$ BHARs } \\
\hline & Week(-3) & Week(-2) & Week $(-1)$ & Week $(0)$ & Week(1) & Week $(2)$ & Week(3) & Week(4) & Week $(5)$ & Week $(6)$ & $\operatorname{Week}(7)$ & Week(8) & Week $(9)$ \\
\hline $\operatorname{Imprecision}(\mathrm{Z})$ & $\begin{array}{c}0.005 \\
(0.134)\end{array}$ & $\begin{array}{l}-0.108 \\
(0.144)\end{array}$ & $\begin{array}{c}0.033 \\
(0.067)\end{array}$ & $\begin{array}{l}-0.000 \\
(0.000)\end{array}$ & $\begin{array}{c}0.005 \\
(0.060)\end{array}$ & $\begin{array}{c}0.097 \\
(0.060)\end{array}$ & $\begin{array}{c}0.125^{* *} \\
(0.051)\end{array}$ & $\begin{array}{c}0.136^{* * *} \\
(0.048)\end{array}$ & $\begin{array}{l}0.120^{* *} \\
(0.058)\end{array}$ & $\begin{array}{c}0.118^{* *} \\
(0.059)\end{array}$ & $\begin{array}{c}0.134^{* *} \\
(0.062)\end{array}$ & $\begin{array}{c}0.100 \\
(0.063)\end{array}$ & $\begin{array}{c}0.063 \\
(0.054)\end{array}$ \\
\hline Sentiment(Z) & $\begin{array}{c}0.013 \\
(0.088)\end{array}$ & $\begin{array}{c}0.033 \\
(0.094)\end{array}$ & $\begin{array}{l}-0.065 \\
(0.052)\end{array}$ & $\begin{array}{c}0.000 \\
(0.000)\end{array}$ & $\begin{array}{l}-0.019 \\
(0.055)\end{array}$ & $\begin{array}{c}0.062 \\
(0.045)\end{array}$ & $\begin{array}{c}0.029 \\
(0.050)\end{array}$ & $\begin{array}{l}0.049 \\
(0.044)\end{array}$ & $\begin{array}{l}-0.073 \\
(0.050)\end{array}$ & $\begin{array}{c}0.006 \\
(0.058)\end{array}$ & $\begin{array}{c}0.067 \\
(0.043)\end{array}$ & $\begin{array}{l}-0.064 \\
(0.039)\end{array}$ & $\begin{array}{l}-0.044 \\
(0.040)\end{array}$ \\
\hline Market value(Z) & $\begin{array}{c}0.359^{* * *} \\
(0.123)\end{array}$ & $\begin{array}{c}0.456^{* * *} \\
(0.159)\end{array}$ & $\begin{array}{c}0.290^{* * *} \\
(0.059)\end{array}$ & $\begin{array}{l}-0.000 \\
(0.000)\end{array}$ & $\begin{array}{l}-0.136^{*} \\
(0.079)\end{array}$ & $\begin{array}{c}-0.157^{* * *} \\
(0.059)\end{array}$ & $\begin{array}{c}-0.183^{* * *} \\
(0.057)\end{array}$ & $\begin{array}{c}-0.218^{* * *} \\
(0.070)\end{array}$ & $\begin{array}{c}-0.146^{* *} \\
(0.057)\end{array}$ & $\begin{array}{c}-0.132^{*} \\
(0.068)\end{array}$ & $\begin{array}{l}-0.084 \\
(0.066)\end{array}$ & $\begin{array}{l}-0.065 \\
(0.066)\end{array}$ & $\begin{array}{c}0.024 \\
(0.069)\end{array}$ \\
\hline Book-to-market(Z) & $\begin{array}{c}0.204^{* * *} \\
(0.074)\end{array}$ & $\begin{array}{c}0.186^{* *} \\
(0.094)\end{array}$ & $\begin{array}{c}0.064 \\
(0.055)\end{array}$ & $\begin{array}{l}-0.000 \\
(0.000)\end{array}$ & $\begin{array}{l}0.135^{*} \\
(0.070)\end{array}$ & $\begin{array}{c}0.071 \\
(0.076)\end{array}$ & $\begin{array}{c}0.077 \\
(0.061)\end{array}$ & $\begin{array}{l}-0.012 \\
(0.063)\end{array}$ & $\begin{array}{l}-0.013 \\
(0.074)\end{array}$ & $\begin{array}{c}0.018 \\
(0.068)\end{array}$ & $\begin{array}{c}0.005 \\
(0.042)\end{array}$ & $\begin{array}{c}0.126^{* *} \\
(0.049)\end{array}$ & $\begin{array}{c}0.022 \\
(0.056)\end{array}$ \\
\hline Turnover(Z) & $\begin{array}{c}0.118 \\
(0.154)\end{array}$ & $\begin{array}{c}0.003 \\
(0.123)\end{array}$ & $\begin{array}{c}-0.195^{* *} \\
(0.086)\end{array}$ & $\begin{array}{c}0.000 \\
(0.000)\end{array}$ & $\begin{array}{l}-0.040 \\
(0.133)\end{array}$ & $\begin{array}{l}-0.007 \\
(0.163)\end{array}$ & $\begin{array}{c}0.219^{* *} \\
(0.085)\end{array}$ & $\begin{array}{c}0.013 \\
(0.086)\end{array}$ & $\begin{array}{c}0.070 \\
(0.092)\end{array}$ & $\begin{array}{c}0.055 \\
(0.110)\end{array}$ & $\begin{array}{l}-0.012 \\
(0.105)\end{array}$ & $\begin{array}{l}-0.007 \\
(0.104)\end{array}$ & $\begin{array}{l}-0.042 \\
(0.094)\end{array}$ \\
\hline Institutional ownership(Z) & $\begin{array}{l}-0.046 \\
(0.107)\end{array}$ & $\begin{array}{c}0.033 \\
(0.110)\end{array}$ & $\begin{array}{l}-0.001 \\
(0.070)\end{array}$ & $\begin{array}{l}-0.000 \\
(0.000)\end{array}$ & $\begin{array}{c}0.218^{* * *} \\
(0.083)\end{array}$ & $\begin{array}{l}-0.030 \\
(0.085)\end{array}$ & $\begin{array}{l}-0.032 \\
(0.049)\end{array}$ & $\begin{array}{c}0.025 \\
(0.076)\end{array}$ & $\begin{array}{l}-0.059 \\
(0.069)\end{array}$ & $\begin{array}{l}-0.059 \\
(0.072)\end{array}$ & $\begin{array}{l}0.141^{*} \\
(0.080)\end{array}$ & $\begin{array}{c}0.004 \\
(0.073)\end{array}$ & $\begin{array}{l}0.030 \\
(0.068)\end{array}$ \\
\hline Fama-French alpha(Z) & $\begin{array}{c}0.852^{* * *} \\
(0.110)\end{array}$ & $\begin{array}{c}0.723^{* * *} \\
(0.136)\end{array}$ & $\begin{array}{c}1.070^{* * *} \\
(0.154)\end{array}$ & $\begin{array}{c}0.000 \\
(0.000)\end{array}$ & $\begin{array}{l}-0.007 \\
(0.135)\end{array}$ & $\begin{array}{l}-0.218 \\
(0.241)\end{array}$ & $\begin{array}{c}0.183 \\
(0.123)\end{array}$ & $\begin{array}{c}0.088 \\
(0.081)\end{array}$ & $\begin{array}{c}0.060 \\
(0.071)\end{array}$ & $\begin{array}{l}-0.037 \\
(0.088)\end{array}$ & $\begin{array}{l}-0.131 \\
(0.095)\end{array}$ & $\begin{array}{c}-0.245^{* * *} \\
(0.092)\end{array}$ & $\begin{array}{c}0.127 \\
(0.161)\end{array}$ \\
\hline Filing-day abnormal return $(\mathrm{Z})$ & $\begin{array}{l}-0.147 \\
(0.094)\end{array}$ & $\begin{array}{c}0.029 \\
(0.083)\end{array}$ & $\begin{array}{c}-0.165^{* *} \\
(0.073)\end{array}$ & $\begin{array}{c}6.045^{* * *} \\
(0.000)\end{array}$ & $\begin{array}{c}-0.310^{* * *} \\
(0.095)\end{array}$ & $\begin{array}{c}0.015 \\
(0.122)\end{array}$ & $\begin{array}{c}-0.188^{* * *} \\
(0.069)\end{array}$ & $\begin{array}{c}0.068 \\
(0.045)\end{array}$ & $\begin{array}{l}-0.077 \\
(0.065)\end{array}$ & $\begin{array}{c}-0.024 \\
(0.063)\end{array}$ & $\begin{array}{l}-0.034 \\
(0.061)\end{array}$ & $\begin{array}{c}0.012 \\
(0.089)\end{array}$ & $\begin{array}{c}-0.226^{* * *} \\
(0.077)\end{array}$ \\
\hline Obsel & 42063 & 42173 & 42262 & 42298 & 41885 & 41711 & 41567 & 41505 & 41398 & 41248 & 41123 & 41010 & 40953 \\
\hline Adjusted $R^{2}$ & 0.013 & 0.011 & 0.020 & 1.000 & 0.003 & 0.002 & 0.004 & 0.002 & 0.002 & 0.001 & 0.001 & 0.002 & 0.001 \\
\hline
\end{tabular}

Panel B: Cumulative BHARs

Dependent variable $=$ Cumulative $\mathrm{BHARs}$

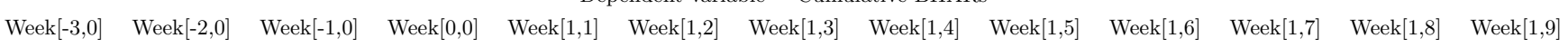

\begin{tabular}{|c|c|c|c|c|c|c|c|c|c|c|c|c|c|}
\hline $\operatorname{Imprecision}(\mathrm{Z})$ & $\begin{array}{c}0.055 \\
(0.255)\end{array}$ & $\begin{array}{c}0.085 \\
(0.177)\end{array}$ & $\begin{array}{l}-0.029 \\
(0.071)\end{array}$ & $\begin{array}{l}-0.006 \\
(0.013)\end{array}$ & $\begin{array}{c}0.005 \\
(0.060)\end{array}$ & $\begin{array}{c}0.101 \\
(0.071)\end{array}$ & $\begin{array}{c}0.228^{* *} \\
(0.113)\end{array}$ & $\begin{array}{c}0.353^{* * *} \\
(0.127)\end{array}$ & $\begin{array}{c}0.492^{* * *} \\
(0.157)\end{array}$ & $\begin{array}{c}0.610^{* * *} \\
(0.195)\end{array}$ & $\begin{array}{c}0.758^{* * *} \\
(0.235)\end{array}$ & $\begin{array}{c}0.886^{* * *} \\
(0.261)\end{array}$ & $\begin{array}{c}0.956^{* * *} \\
(0.281)\end{array}$ \\
\hline Sentiment(Z) & $\begin{array}{l}-0.096 \\
(0.158)\end{array}$ & $\begin{array}{l}-0.071 \\
(0.113)\end{array}$ & $\begin{array}{l}-0.009 \\
(0.048)\end{array}$ & $\begin{array}{c}-0.042^{* * *} \\
(0.015)\end{array}$ & $\begin{array}{l}-0.019 \\
(0.055)\end{array}$ & $\begin{array}{c}0.045 \\
(0.065)\end{array}$ & $\begin{array}{c}0.086 \\
(0.082)\end{array}$ & $\begin{array}{c}0.130 \\
(0.087)\end{array}$ & $\begin{array}{c}0.058 \\
(0.112)\end{array}$ & $\begin{array}{c}0.026 \\
(0.150)\end{array}$ & $\begin{array}{c}0.107 \\
(0.171)\end{array}$ & $\begin{array}{c}0.077 \\
(0.189)\end{array}$ & $\begin{array}{c}0.002 \\
(0.212)\end{array}$ \\
\hline Market value(Z) & $\begin{array}{c}-1.972^{* * *} \\
(0.321)\end{array}$ & $\begin{array}{c}-1.416^{* * *} \\
(0.219)\end{array}$ & $\begin{array}{c}-0.723^{* * *} \\
(0.086)\end{array}$ & $\begin{array}{c}-0.184^{* * *} \\
(0.014)\end{array}$ & $\begin{array}{c}-0.136^{*} \\
(0.079)\end{array}$ & $\begin{array}{c}-0.295^{* * *} \\
(0.088)\end{array}$ & $\begin{array}{c}-0.457^{* * *} \\
(0.128)\end{array}$ & $\begin{array}{c}-0.660^{* * *} \\
(0.169)\end{array}$ & $\begin{array}{c}-0.818^{* * *} \\
(0.211)\end{array}$ & $\begin{array}{c}-0.948^{* * *} \\
(0.259)\end{array}$ & $\begin{array}{c}-1.053^{* * *} \\
(0.311)\end{array}$ & $\begin{array}{c}-1.151^{* * *} \\
(0.373)\end{array}$ & $\begin{array}{c}-1.161^{* * *} \\
(0.405)\end{array}$ \\
\hline Book-to-market(Z) & $\begin{array}{c}-0.630^{* * *} \\
(0.180)\end{array}$ & $\begin{array}{c}-0.403^{* * *} \\
(0.132)\end{array}$ & $\begin{array}{c}-0.177^{* * *} \\
(0.059)\end{array}$ & $\begin{array}{c}-0.058^{* * *} \\
(0.012)\end{array}$ & $\begin{array}{l}0.135^{*} \\
(0.070)\end{array}$ & $\begin{array}{c}0.188 \\
(0.119)\end{array}$ & $\begin{array}{c}0.272^{* *} \\
(0.128)\end{array}$ & $\begin{array}{c}0.242 \\
(0.164)\end{array}$ & $\begin{array}{c}0.223 \\
(0.197)\end{array}$ & $\begin{array}{c}0.248 \\
(0.239)\end{array}$ & $\begin{array}{c}0.235 \\
(0.261)\end{array}$ & $\begin{array}{c}0.397 \\
(0.283)\end{array}$ & $\begin{array}{c}0.435 \\
(0.295)\end{array}$ \\
\hline Turnover(Z) & $\begin{array}{c}1.399^{* * * *} \\
(0.264)\end{array}$ & $\begin{array}{c}1.106^{* * *} \\
(0.191)\end{array}$ & $\begin{array}{c}0.676^{* * *} \\
(0.113)\end{array}$ & $\begin{array}{c}0.159^{* * *} \\
(0.021)\end{array}$ & $\begin{array}{l}-0.040 \\
(0.133)\end{array}$ & $\begin{array}{l}-0.049 \\
(0.243)\end{array}$ & $\begin{array}{c}0.116 \\
(0.300)\end{array}$ & $\begin{array}{c}0.113 \\
(0.357)\end{array}$ & $\begin{array}{c}0.155 \\
(0.381)\end{array}$ & $\begin{array}{l}0.280 \\
(0.463)\end{array}$ & $\begin{array}{c}0.294 \\
(0.519)\end{array}$ & $\begin{array}{c}0.359 \\
(0.574)\end{array}$ & $\begin{array}{c}0.375 \\
(0.623)\end{array}$ \\
\hline Institutional ownership(Z) & $\begin{array}{l}-0.430^{*} \\
(0.219)\end{array}$ & $\begin{array}{c}-0.308^{* *} \\
(0.152)\end{array}$ & $\begin{array}{l}-0.113 \\
(0.085)\end{array}$ & $\begin{array}{c}-0.030^{*} \\
(0.017)\end{array}$ & $\begin{array}{c}0.218^{* * *} \\
(0.083)\end{array}$ & $\begin{array}{c}0.175 \\
(0.117)\end{array}$ & $\begin{array}{c}0.189 \\
(0.153)\end{array}$ & $\begin{array}{c}0.206 \\
(0.187)\end{array}$ & $\begin{array}{c}0.174 \\
(0.190)\end{array}$ & $\begin{array}{c}0.078 \\
(0.229)\end{array}$ & $\begin{array}{c}0.226 \\
(0.269)\end{array}$ & $\begin{array}{c}0.235 \\
(0.306)\end{array}$ & $\begin{array}{c}0.253 \\
(0.324)\end{array}$ \\
\hline Fama-French alpha(Z) & $\begin{array}{c}-2.325^{* * *} \\
(0.434)\end{array}$ & $\begin{array}{c}-1.678^{* * *} \\
(0.305)\end{array}$ & $\begin{array}{c}-0.992^{* * *} \\
(0.187)\end{array}$ & $\begin{array}{c}0.010 \\
(0.020)\end{array}$ & $\begin{array}{l}-0.007 \\
(0.135)\end{array}$ & $\begin{array}{l}-0.223 \\
(0.338)\end{array}$ & $\begin{array}{l}-0.098 \\
(0.342)\end{array}$ & $\begin{array}{l}-0.005 \\
(0.353)\end{array}$ & $\begin{array}{c}0.049 \\
(0.402)\end{array}$ & $\begin{array}{l}-0.001 \\
(0.474)\end{array}$ & $\begin{array}{l}-0.151 \\
(0.539)\end{array}$ & $\begin{array}{l}-0.382 \\
(0.596)\end{array}$ & $\begin{array}{l}-0.418 \\
(0.561)\end{array}$ \\
\hline Filing-day abnormal return(Z) & $\begin{array}{c}-5.952^{* * *} \\
(0.207)\end{array}$ & $\begin{array}{c}-6.024^{* * *} \\
(0.182)\end{array}$ & $\begin{array}{c}-5.917^{* * *} \\
(0.134)\end{array}$ & $\begin{array}{c}-5.914^{* * *} \\
(0.097)\end{array}$ & $\begin{array}{c}-0.310^{* * *} \\
(0.095)\end{array}$ & $\begin{array}{c}-0.302^{* *} \\
(0.146)\end{array}$ & $\begin{array}{c}-0.479^{* * *} \\
(0.141)\end{array}$ & $\begin{array}{c}-0.405^{* * *} \\
(0.149)\end{array}$ & $\begin{array}{c}-0.473^{* * *} \\
(0.167)\end{array}$ & $\begin{array}{c}-0.508^{* *} \\
(0.196)\end{array}$ & $\begin{array}{c}-0.525^{* *} \\
(0.225)\end{array}$ & $\begin{array}{c}-0.537^{* *} \\
(0.259)\end{array}$ & $\begin{array}{c}-0.836^{* * *} \\
(0.299)\end{array}$ \\
\hline Obs & 42 & 42 & 42262 & 42298 & 41885 & 4 & 41498 & 41 & 41 & 40 & 40 & 40 & 40397 \\
\hline Adjusted $R^{2}$ & 0.173 & 0.241 & 0.381 & 0.928 & 0.003 & 0.003 & 0.004 & 0.004 & 0.006 & 0.006 & 0.006 & 0.007 & 0.007 \\
\hline
\end{tabular}


Table A.3: Imprecise Language in Disclosure and BHARs: Excluding Future Earnings Announcements

This table is similar to Table 4 except using a refined subsample that excludes all 10-K filing that have new earnings announcements over the next three to seven weeks after $10-\mathrm{K}$ release dates. The table presents the slope coefficient estimates for all control variables. Slope coefficients and standard errors are reported in percentage. For brevity, intercept is not reported although it is included in the estimation.

\begin{tabular}{|c|c|c|c|c|c|c|c|c|c|c|c|c|c|}
\hline \multicolumn{14}{|c|}{ Dependent variable $=$ BHARs } \\
\hline & Week(-3) & Week $(-2)$ & Week(-1) & Week $(0)$ & Week(1) & Week(2) & Week(3) & Week $(4)$ & $\operatorname{Week}(5)$ & Week $(6)$ & Week $(7)$ & Week $(8)$ & Week $(9)$ \\
\hline Imprecision(Z) & $\begin{array}{l}-0.027 \\
(0.128)\end{array}$ & $\begin{array}{l}-0.080 \\
(0.150)\end{array}$ & $\begin{array}{c}0.028 \\
(0.063)\end{array}$ & $\begin{array}{l}-0.000 \\
(0.000)\end{array}$ & $\begin{array}{c}0.014 \\
(0.061)\end{array}$ & $\begin{array}{c}0.093^{* *} \\
(0.045)\end{array}$ & $\begin{array}{c}0.119^{* *} \\
(0.053)\end{array}$ & $\begin{array}{c}0.130^{* * *} \\
(0.049)\end{array}$ & $\begin{array}{c}0.122^{* *} \\
(0.056)\end{array}$ & $\begin{array}{c}0.126^{* *} \\
(0.063)\end{array}$ & $\begin{array}{c}0.124^{* *} \\
(0.056)\end{array}$ & $\begin{array}{c}0.048 \\
(0.061)\end{array}$ & $\begin{array}{c}0.017 \\
(0.054)\end{array}$ \\
\hline Sentiment(Z) & $\begin{array}{c}0.010 \\
(0.087)\end{array}$ & $\begin{array}{c}0.043 \\
(0.108)\end{array}$ & $\begin{array}{l}-0.075 \\
(0.047)\end{array}$ & $\begin{array}{l}-0.000 \\
(0.000)\end{array}$ & $\begin{array}{l}-0.008 \\
(0.056)\end{array}$ & $\begin{array}{l}0.066 \\
(0.054)\end{array}$ & $\begin{array}{c}0.049 \\
(0.046)\end{array}$ & $\begin{array}{c}0.050 \\
(0.043)\end{array}$ & $\begin{array}{l}-0.035 \\
(0.048)\end{array}$ & $\begin{array}{c}0.028 \\
(0.064)\end{array}$ & $\begin{array}{c}0.067 \\
(0.044)\end{array}$ & $\begin{array}{l}-0.058 \\
(0.039)\end{array}$ & $\begin{array}{l}-0.026 \\
(0.039)\end{array}$ \\
\hline Market value( $(\mathrm{Z})$ & $\begin{array}{c}0.354^{* * *} \\
(0.124)\end{array}$ & $\begin{array}{c}0.437^{* * *} \\
(0.160)\end{array}$ & $\begin{array}{c}0.237^{* * *} \\
(0.060)\end{array}$ & $\begin{array}{l}-0.000 \\
(0.000)\end{array}$ & $\begin{array}{l}-0.087 \\
(0.080)\end{array}$ & $\begin{array}{c}-0.161^{* * *} \\
(0.061)\end{array}$ & $\begin{array}{c}-0.155^{* * *} \\
(0.056)\end{array}$ & $\begin{array}{c}-0.178^{* *} \\
(0.071)\end{array}$ & $\begin{array}{l}-0.088 \\
(0.057)\end{array}$ & $\begin{array}{l}-0.072 \\
(0.069)\end{array}$ & $\begin{array}{l}-0.083 \\
(0.072)\end{array}$ & $\begin{array}{l}-0.049 \\
(0.067)\end{array}$ & $\begin{array}{c}0.042 \\
(0.074)\end{array}$ \\
\hline Book-to-market(Z) & $\begin{array}{c}0.183^{* *} \\
(0.075)\end{array}$ & $\begin{array}{l}0.198^{*} \\
(0.106)\end{array}$ & $\begin{array}{l}0.072 \\
(0.062)\end{array}$ & $\begin{array}{c}0.000 \\
(0.000)\end{array}$ & $\begin{array}{c}0.169^{* *} \\
(0.069)\end{array}$ & $\begin{array}{c}0.104 \\
(0.075)\end{array}$ & $\begin{array}{c}0.085 \\
(0.064)\end{array}$ & $\begin{array}{c}0.005 \\
(0.067)\end{array}$ & $\begin{array}{c}0.007 \\
(0.074)\end{array}$ & $\begin{array}{c}0.007 \\
(0.068)\end{array}$ & $\begin{array}{l}-0.022 \\
(0.052)\end{array}$ & $\begin{array}{c}0.100^{* *} \\
(0.049)\end{array}$ & $\begin{array}{c}0.014 \\
(0.056)\end{array}$ \\
\hline Turnover(Z) & $\begin{array}{c}0.098 \\
(0.147)\end{array}$ & $\begin{array}{l}0.041 \\
(0.127)\end{array}$ & $\begin{array}{l}-0.140 \\
(0.096)\end{array}$ & $\begin{array}{l}-0.000 \\
(0.000)\end{array}$ & $\begin{array}{l}-0.015 \\
(0.132)\end{array}$ & $\begin{array}{l}-0.021 \\
(0.171)\end{array}$ & $\begin{array}{c}0.231^{* * *} \\
(0.084)\end{array}$ & $\begin{array}{c}0.058 \\
(0.085)\end{array}$ & $\begin{array}{c}0.082 \\
(0.088)\end{array}$ & $\begin{array}{c}0.073 \\
(0.121)\end{array}$ & $\begin{array}{c}0.051 \\
(0.106)\end{array}$ & $\begin{array}{c}0.006 \\
(0.120)\end{array}$ & $\begin{array}{l}-0.004 \\
(0.103)\end{array}$ \\
\hline Institutional ownership(Z) & $\begin{array}{l}-0.042 \\
(0.099)\end{array}$ & $\begin{array}{c}0.018 \\
(0.124)\end{array}$ & $\begin{array}{l}-0.018 \\
(0.080)\end{array}$ & $\begin{array}{l}-0.000 \\
(0.000)\end{array}$ & $\begin{array}{c}0.178^{* *} \\
(0.085)\end{array}$ & $\begin{array}{l}-0.003 \\
(0.088)\end{array}$ & $\begin{array}{l}-0.047 \\
(0.052)\end{array}$ & $\begin{array}{l}-0.008 \\
(0.079)\end{array}$ & $\begin{array}{l}-0.106 \\
(0.073)\end{array}$ & $\begin{array}{l}-0.122 \\
(0.083)\end{array}$ & $\begin{array}{c}0.052 \\
(0.076)\end{array}$ & $\begin{array}{l}-0.048 \\
(0.077)\end{array}$ & $\begin{array}{c}0.036 \\
(0.074)\end{array}$ \\
\hline Fama-French alpha(Z) & $\begin{array}{c}0.668^{* * * *} \\
(0.103)\end{array}$ & $\begin{array}{c}0.644^{* * *} \\
(0.144)\end{array}$ & $\begin{array}{c}0.887^{* * * *} \\
(0.170)\end{array}$ & $\begin{array}{l}-0.000 \\
(0.000)\end{array}$ & $\begin{array}{l}-0.034 \\
(0.156)\end{array}$ & $\begin{array}{l}-0.261 \\
(0.262)\end{array}$ & $\begin{array}{c}0.138 \\
(0.119)\end{array}$ & $\begin{array}{c}0.041 \\
(0.079)\end{array}$ & $\begin{array}{c}0.050 \\
(0.081)\end{array}$ & $\begin{array}{l}-0.057 \\
(0.100)\end{array}$ & $\begin{array}{l}-0.109 \\
(0.100)\end{array}$ & $\begin{array}{c}-0.300^{* * *} \\
(0.109)\end{array}$ & $\begin{array}{c}0.148 \\
(0.183)\end{array}$ \\
\hline Filing-day abnormal return(Z) & $\begin{array}{l}-0.144 \\
(0.091)\end{array}$ & $\begin{array}{c}0.088 \\
(0.084)\end{array}$ & $\begin{array}{c}-0.261 * * * \\
(0.081)\end{array}$ & $\begin{array}{c}5.403^{* * *} \\
(0.000)\end{array}$ & $\begin{array}{c}-0.413^{* * *} \\
(0.100)\end{array}$ & $\begin{array}{l}-0.002 \\
(0.146)\end{array}$ & $\begin{array}{c}-0.219^{* * *} \\
(0.078)\end{array}$ & $\begin{array}{c}0.061 \\
(0.059)\end{array}$ & $\begin{array}{l}-0.091 \\
(0.057)\end{array}$ & $\begin{array}{l}-0.057 \\
(0.077)\end{array}$ & $\begin{array}{l}-0.057 \\
(0.076)\end{array}$ & $\begin{array}{c}0.055 \\
(0.110)\end{array}$ & $\begin{array}{c}-0.151^{*} \\
(0.085)\end{array}$ \\
\hline Observations & 33020 & 33992 & 32483 & 37494 & 37047 & 36376 & 34580 & 33606 & 32913 & 31592 & 31209 & 30595 & 31938 \\
\hline Adjusted $R^{2}$ & 0.010 & 0.010 & 0.017 & 1.000 & 0.005 & 0.002 & 0.003 & 0.001 & 0.002 & 0.001 & 0.001 & 0.003 & 0.001 \\
\hline
\end{tabular}

Panel B: Cumulative BHARs

\begin{tabular}{|c|c|c|c|c|c|c|c|c|c|c|c|c|c|}
\hline & \multicolumn{13}{|c|}{ Dependent variable $=$ Cumulative BHARs } \\
\hline & Week $[-3,0]$ & Week $[-2,0]$ & Week $[-1,0]$ & Week $[0,0]$ & Week $[1,1]$ & Week $[1,2]$ & Week $[1,3]$ & Week $[1,4]$ & Week $[1,5]$ & Week $[1,6]$ & Week $[1,7]$ & Week $[1,8]$ & Week $[1,9]$ \\
\hline $\operatorname{Imprecision}(\mathrm{Z})$ & $\begin{array}{c}0.097 \\
(0.267)\end{array}$ & $\begin{array}{c}0.061 \\
(0.179)\end{array}$ & $\begin{array}{c}0.027 \\
(0.070)\end{array}$ & $\begin{array}{l}0.018 \\
(0.011)\end{array}$ & $\begin{array}{c}0.014 \\
(0.061)\end{array}$ & $\begin{array}{c}0.102 \\
(0.091)\end{array}$ & $\begin{array}{c}0.210^{* *} \\
(0.106)\end{array}$ & $\begin{array}{c}0.377^{* * *} \\
(0.136)\end{array}$ & $\begin{array}{c}0.421^{* * *} \\
(0.161)\end{array}$ & $\begin{array}{c}0.554^{* * *} \\
(0.199)\end{array}$ & $\begin{array}{c}0.699 * * * \\
(0.234)\end{array}$ & $\begin{array}{c}0.754^{* * *} \\
(0.267)\end{array}$ & $\begin{array}{c}0.828^{* * *} \\
(0.307)\end{array}$ \\
\hline Sentiment(Z) & $\begin{array}{l}-0.060 \\
(0.169)\end{array}$ & $\begin{array}{l}-0.080 \\
(0.130)\end{array}$ & $\begin{array}{c}0.007 \\
(0.044)\end{array}$ & $\begin{array}{c}-0.033^{* *} \\
(0.013)\end{array}$ & $\begin{array}{l}-0.008 \\
(0.056)\end{array}$ & $\begin{array}{c}0.062 \\
(0.067)\end{array}$ & $\begin{array}{c}0.067 \\
(0.091)\end{array}$ & $\begin{array}{l}0.192^{*} \\
(0.105)\end{array}$ & $\begin{array}{c}0.075 \\
(0.117)\end{array}$ & $\begin{array}{l}0.091 \\
(0.175)\end{array}$ & $\begin{array}{c}0.156 \\
(0.179)\end{array}$ & $\begin{array}{c}0.136 \\
(0.206)\end{array}$ & $\begin{array}{c}0.069 \\
(0.224)\end{array}$ \\
\hline Market value(Z) & $\begin{array}{c}-1.917^{* * *} \\
(0.331)\end{array}$ & $\begin{array}{c}-1.274^{* * *} \\
(0.219)\end{array}$ & $\begin{array}{c}-0.537^{* * *} \\
(0.078)\end{array}$ & $\begin{array}{c}-0.130^{* * *} \\
(0.011)\end{array}$ & $\begin{array}{l}-0.087 \\
(0.080)\end{array}$ & $\begin{array}{c}-0.251^{* * *} \\
(0.084)\end{array}$ & $\begin{array}{c}-0.393^{* * *} \\
(0.125)\end{array}$ & $\begin{array}{c}-0.596 * * * \\
(0.163)\end{array}$ & $\begin{array}{c}-0.771^{* * *} \\
(0.205)\end{array}$ & $\begin{array}{c}-0.905^{* * *} \\
(0.246)\end{array}$ & $\begin{array}{c}-1.022^{* * *} \\
(0.299)\end{array}$ & $\begin{array}{c}-1.166^{* * *} \\
(0.360)\end{array}$ & $\begin{array}{c}-1.115^{* * *} \\
(0.399)\end{array}$ \\
\hline Book-to-market(Z) & $\begin{array}{c}-0.706^{* * *} \\
(0.210)\end{array}$ & $\begin{array}{c}-0.445^{* * *} \\
(0.137)\end{array}$ & $\begin{array}{c}-0.165 * * \\
(0.068)\end{array}$ & $\begin{array}{c}-0.042^{* * *} \\
(0.013)\end{array}$ & $\begin{array}{c}0.169^{* *} \\
(0.069)\end{array}$ & $\begin{array}{c}0.260^{* *} \\
(0.106)\end{array}$ & $\begin{array}{c}0.344^{* * *} \\
(0.121)\end{array}$ & $\begin{array}{l}0.317^{*} \\
(0.164)\end{array}$ & $\begin{array}{c}0.244 \\
(0.203)\end{array}$ & $\begin{array}{c}0.305 \\
(0.254)\end{array}$ & $\begin{array}{c}0.274 \\
(0.296)\end{array}$ & $\begin{array}{c}0.280 \\
(0.324)\end{array}$ & $\begin{array}{c}0.401 \\
(0.345)\end{array}$ \\
\hline Turnover(Z) & $\begin{array}{c}1.375^{* * *} \\
(0.262)\end{array}$ & $\begin{array}{c}1.017^{* * *} \\
(0.195)\end{array}$ & $\begin{array}{c}0.545^{* * *} \\
(0.120)\end{array}$ & $\begin{array}{c}0.151^{* * *} \\
(0.020)\end{array}$ & $\begin{array}{l}-0.015 \\
(0.132)\end{array}$ & $\begin{array}{l}-0.038 \\
(0.247)\end{array}$ & $\begin{array}{c}0.143 \\
(0.283)\end{array}$ & $\begin{array}{c}0.162 \\
(0.300)\end{array}$ & $\begin{array}{c}0.219 \\
(0.389)\end{array}$ & $\begin{array}{c}0.346 \\
(0.473)\end{array}$ & $\begin{array}{c}0.431 \\
(0.550)\end{array}$ & $\begin{array}{c}0.329 \\
(0.612)\end{array}$ & $\begin{array}{c}0.416 \\
(0.638)\end{array}$ \\
\hline Institutional ownership(Z) & $\begin{array}{c}-0.528^{* *} \\
(0.237)\end{array}$ & $\begin{array}{c}-0.387^{* *} \\
(0.162)\end{array}$ & $\begin{array}{c}-0.160^{*} \\
(0.093)\end{array}$ & $\begin{array}{c}-0.061^{* * *} \\
(0.018)\end{array}$ & $\begin{array}{l}0.178^{* *} \\
(0.085)\end{array}$ & $\begin{array}{c}0.159 \\
(0.123)\end{array}$ & $\begin{array}{c}0.180 \\
(0.158)\end{array}$ & $\begin{array}{c}0.198 \\
(0.161)\end{array}$ & $\begin{array}{c}0.084 \\
(0.209)\end{array}$ & $\begin{array}{l}-0.083 \\
(0.257)\end{array}$ & $\begin{array}{c}0.047 \\
(0.309)\end{array}$ & $\begin{array}{c}0.182 \\
(0.335)\end{array}$ & $\begin{array}{c}0.152 \\
(0.378)\end{array}$ \\
\hline Fama-French alpha(Z) & $\begin{array}{c}-2.182^{* * *} \\
(0.406)\end{array}$ & $\begin{array}{c}-1.555^{* * *} \\
(0.321)\end{array}$ & $\begin{array}{c}-0.772^{* * *} \\
(0.196)\end{array}$ & $\begin{array}{l}0.010 \\
(0.020)\end{array}$ & $\begin{array}{l}-0.034 \\
(0.156)\end{array}$ & $\begin{array}{l}-0.274 \\
(0.382)\end{array}$ & $\begin{array}{l}-0.181 \\
(0.333)\end{array}$ & $\begin{array}{l}-0.059 \\
(0.347)\end{array}$ & $\begin{array}{l}-0.116 \\
(0.427)\end{array}$ & $\begin{array}{l}-0.168 \\
(0.498)\end{array}$ & $\begin{array}{l}-0.173 \\
(0.588)\end{array}$ & $\begin{array}{l}-0.432 \\
(0.643)\end{array}$ & $\begin{array}{l}-0.348 \\
(0.600)\end{array}$ \\
\hline Filing-day abnormal return $(\mathrm{Z})$ & $\begin{array}{c}-5.402 * * * \\
(0.201)\end{array}$ & $\begin{array}{c}-5.511^{* * *} \\
(0.199)\end{array}$ & $\begin{array}{c}-5.234^{* * *} \\
(0.154)\end{array}$ & $\begin{array}{c}-5.344^{* * *} \\
(0.090)\end{array}$ & $\begin{array}{c}-0.413^{* * *} \\
(0.100)\end{array}$ & $\begin{array}{c}-0.401^{* *} \\
(0.165)\end{array}$ & $\begin{array}{c}-0.602 * * * \\
(0.151)\end{array}$ & $\begin{array}{c}-0.621^{* * *} \\
(0.189)\end{array}$ & $\begin{array}{c}-0.795^{* * *} \\
(0.250)\end{array}$ & $\begin{array}{c}-0.940^{* * *} \\
(0.288)\end{array}$ & $\begin{array}{c}-0.866^{* * *} \\
(0.293)\end{array}$ & $\begin{array}{c}-0.825^{* *} \\
(0.331)\end{array}$ & $\begin{array}{c}-1.015^{* * *} \\
(0.390)\end{array}$ \\
\hline Observ & 32987 & 33981 & 32483 & 37494 & 37047 & 36352 & 34530 & 33519 & 32702 & 31337 & 30895 & 30243 & 31483 \\
\hline Adjusted $R^{2}$ & 0.156 & 0.227 & 0.348 & 0.938 & 0.005 & 0.004 & 0.006 & 0.006 & 0.007 & 0.009 & 0.008 & 0.007 & 0.007 \\
\hline
\end{tabular}


Table A.4: Imprecise Language in Disclosure and CARs

This table is similar to Table 4 except that we employ cumulative abnormal returns (CARs) as the dependent variable instead of BHARs for Model (1). Slope coefficients and standard errors are reported in percentage. For post-filing weeks in Panel B, each cumulative CAR is computed over the period from the start of the 1 st week to the end of the $n$th week, i.e., Week[1,n], where $n=1, \ldots, 9$. For pre-filing weeks and the 0th week in Panel B, each "reverse" cumulative CAR is computed over the period from the end of the 0 th week to the start of the $n$th week, i.e., Week[n,0], where $n=-3, \ldots, 0$. For brevity, intercept is not reported although it is included in the estimation.

\begin{tabular}{|c|c|c|c|c|c|c|c|c|c|c|c|c|c|}
\hline & \multicolumn{13}{|c|}{ Dependent variable $=$ CARs } \\
\hline & Week $(-3)$ & Week(-2) & Week(-1) & Week $(0)$ & Week(1) & Week(2) & Week(3) & Week(4) & Week $(5)$ & Week $(6)$ & $\operatorname{Week}(7)$ & Week $(8)$ & Week(9) \\
\hline Imprecision(Z) & $\begin{array}{l}-0.026 \\
(0.047)\end{array}$ & $\begin{array}{l}-0.056 \\
(0.061)\end{array}$ & $\begin{array}{c}0.019 \\
(0.059)\end{array}$ & $\begin{array}{l}-0.000 \\
(0.000)\end{array}$ & $\begin{array}{c}0.002 \\
(0.060)\end{array}$ & $\begin{array}{c}0.099 \\
(0.063)\end{array}$ & $\begin{array}{c}0.135^{* * *} \\
(0.052)\end{array}$ & $\begin{array}{c}0.135^{* * *} \\
(0.048)\end{array}$ & $\begin{array}{c}0.123^{* *} \\
(0.058)\end{array}$ & $\begin{array}{c}0.120^{* *} \\
(0.060)\end{array}$ & $\begin{array}{c}0.133^{* *} \\
(0.062)\end{array}$ & $\begin{array}{c}0.095 \\
(0.059)\end{array}$ & $\begin{array}{c}0.063 \\
(0.053)\end{array}$ \\
\hline Sentiment(Z) & $\begin{array}{l}-0.028 \\
(0.051)\end{array}$ & $\begin{array}{c}0.022 \\
(0.042)\end{array}$ & $\begin{array}{l}-0.064 \\
(0.055)\end{array}$ & $\begin{array}{l}-0.000 \\
(0.000)\end{array}$ & $\begin{array}{l}-0.017 \\
(0.054)\end{array}$ & $\begin{array}{c}0.063 \\
(0.045)\end{array}$ & $\begin{array}{c}0.025 \\
(0.051)\end{array}$ & $\begin{array}{c}0.047 \\
(0.043)\end{array}$ & $\begin{array}{l}-0.075 \\
(0.049)\end{array}$ & $\begin{array}{c}0.007 \\
(0.057)\end{array}$ & $\begin{array}{c}0.064 \\
(0.042)\end{array}$ & $\begin{array}{c}-0.065^{*} \\
(0.039)\end{array}$ & $\begin{array}{l}-0.045 \\
(0.040)\end{array}$ \\
\hline Market value(Z) & $\begin{array}{c}0.166^{* * *} \\
(0.059)\end{array}$ & $\begin{array}{c}0.252^{* * *} \\
(0.091)\end{array}$ & $\begin{array}{c}0.230^{* * *} \\
(0.050)\end{array}$ & $\begin{array}{c}-0.000^{* *} \\
(0.000)\end{array}$ & $\begin{array}{c}-0.156^{* *} \\
(0.079)\end{array}$ & $\begin{array}{c}-0.169^{* * *} \\
(0.063)\end{array}$ & $\begin{array}{c}-0.203^{* * *} \\
(0.057)\end{array}$ & $\begin{array}{c}-0.222^{* * *} \\
(0.071)\end{array}$ & $\begin{array}{c}-0.156^{* * *} \\
(0.055)\end{array}$ & $\begin{array}{c}-0.141^{* *} \\
(0.067)\end{array}$ & $\begin{array}{l}-0.096 \\
(0.067)\end{array}$ & $\begin{array}{l}-0.075 \\
(0.068)\end{array}$ & $\begin{array}{c}0.013 \\
(0.065)\end{array}$ \\
\hline Book-to-market(Z) & $\begin{array}{c}0.161^{* * *} \\
(0.055)\end{array}$ & $\begin{array}{c}0.081 \\
(0.072)\end{array}$ & $\begin{array}{c}0.061 \\
(0.053)\end{array}$ & $\begin{array}{l}-0.000 \\
(0.000)\end{array}$ & $\begin{array}{l}0.124^{*} \\
(0.068)\end{array}$ & $\begin{array}{c}0.073 \\
(0.084)\end{array}$ & $\begin{array}{c}0.060 \\
(0.063)\end{array}$ & $\begin{array}{l}-0.015 \\
(0.063)\end{array}$ & $\begin{array}{l}-0.019 \\
(0.074)\end{array}$ & $\begin{array}{c}0.013 \\
(0.067)\end{array}$ & $\begin{array}{l}-0.004 \\
(0.042)\end{array}$ & $\begin{array}{c}0.121^{* *} \\
(0.049)\end{array}$ & $\begin{array}{c}0.021 \\
(0.057)\end{array}$ \\
\hline Turnover(Z) & $\begin{array}{l}0.091 \\
(0.097)\end{array}$ & $\begin{array}{l}-0.182 \\
(0.145)\end{array}$ & $\begin{array}{c}-0.274^{* * *} \\
(0.095)\end{array}$ & $\begin{array}{l}-0.000 \\
(0.000)\end{array}$ & $\begin{array}{l}-0.047 \\
(0.125)\end{array}$ & $\begin{array}{l}-0.059 \\
(0.197)\end{array}$ & $\begin{array}{c}0.232^{* * * *} \\
(0.085)\end{array}$ & $\begin{array}{c}0.017 \\
(0.082)\end{array}$ & $\begin{array}{c}0.073 \\
(0.090)\end{array}$ & $\begin{array}{c}0.055 \\
(0.109)\end{array}$ & $\begin{array}{l}-0.015 \\
(0.104)\end{array}$ & $\begin{array}{l}-0.001 \\
(0.107)\end{array}$ & $\begin{array}{l}-0.046 \\
(0.094)\end{array}$ \\
\hline Institutional ownership(Z) & $\begin{array}{l}-0.047 \\
(0.072)\end{array}$ & $\begin{array}{c}0.248^{* *} \\
(0.102)\end{array}$ & $\begin{array}{c}0.057 \\
(0.083)\end{array}$ & $\begin{array}{c}0.000 \\
(0.000)\end{array}$ & $\begin{array}{c}0.208^{* * *} \\
(0.079)\end{array}$ & $\begin{array}{c}0.003 \\
(0.106)\end{array}$ & $\begin{array}{l}-0.046 \\
(0.051)\end{array}$ & $\begin{array}{c}0.016 \\
(0.075)\end{array}$ & $\begin{array}{l}-0.066 \\
(0.068)\end{array}$ & $\begin{array}{l}-0.063 \\
(0.072)\end{array}$ & $\begin{array}{l}0.141^{*} \\
(0.081)\end{array}$ & $\begin{array}{c}0.001 \\
(0.074)\end{array}$ & $\begin{array}{c}0.015 \\
(0.067)\end{array}$ \\
\hline Fama-French alpha(Z) & $\begin{array}{c}0.973^{* * *} \\
(0.120)\end{array}$ & $\begin{array}{c}0.837^{* * *} \\
(0.156)\end{array}$ & $\begin{array}{c}1.065^{* * *} \\
(0.160)\end{array}$ & $\begin{array}{c}0.000 \\
(0.000)\end{array}$ & $\begin{array}{c}0.011 \\
(0.124)\end{array}$ & $\begin{array}{l}-0.276 \\
(0.289)\end{array}$ & $\begin{array}{c}0.200 \\
(0.127)\end{array}$ & $\begin{array}{c}0.088 \\
(0.081)\end{array}$ & $\begin{array}{c}0.074 \\
(0.068)\end{array}$ & $\begin{array}{c}-0.014 \\
(0.090)\end{array}$ & $\begin{array}{l}-0.131 \\
(0.095)\end{array}$ & $\begin{array}{c}-0.236^{* *} \\
(0.094)\end{array}$ & $\begin{array}{c}0.115 \\
(0.151)\end{array}$ \\
\hline Filing-day abnormal return(Z) & $\begin{array}{l}-0.039 \\
(0.073)\end{array}$ & $\begin{array}{l}0.107^{*} \\
(0.059)\end{array}$ & $\begin{array}{c}-0.153^{* *} \\
(0.066)\end{array}$ & $\begin{array}{c}6.030^{* * *} \\
(0.000)\end{array}$ & $\begin{array}{c}-0.299^{* * *} \\
(0.097)\end{array}$ & $\begin{array}{c}0.040 \\
(0.127)\end{array}$ & $\begin{array}{c}-0.199^{* * *} \\
(0.070)\end{array}$ & $\begin{array}{c}0.062 \\
(0.043)\end{array}$ & $\begin{array}{l}-0.079 \\
(0.061)\end{array}$ & $\begin{array}{l}-0.032 \\
(0.062)\end{array}$ & $\begin{array}{l}-0.023 \\
(0.058)\end{array}$ & $\begin{array}{c}0.004 \\
(0.088)\end{array}$ & $\begin{array}{c}-0.220^{* * *} \\
(0.075)\end{array}$ \\
\hline Observations & 42063 & 42173 & 42262 & 42298 & 41885 & 41711 & 41567 & 41505 & 41398 & 41248 & 41123 & 41010 & 40953 \\
\hline Adjusted $R^{2}$ & 0.018 & 0.014 & 0.021 & 1.000 & 0.003 & 0.003 & 0.004 & 0.002 & 0.002 & 0.001 & 0.001 & 0.002 & 0.001 \\
\hline
\end{tabular}

Panel B: Cumulative CARs

\begin{tabular}{|c|c|c|c|c|c|c|c|c|c|c|c|c|c|}
\hline & \multicolumn{13}{|c|}{ Dependent variable $=$ Cumulative $\mathrm{CARs}$} \\
\hline & Week $[-3,0]$ & Week $[-2,0]$ & Week $[-1,0]$ & Week $[0,0]$ & Week $[1,1]$ & Week $[1,2]$ & Week[1,3] & Week $[1,4]$ & Week $[1,5]$ & Week $[1,6]$ & Week $[1,7]$ & Week $[1,8]$ & Week $[1,9]$ \\
\hline $\operatorname{Imprecision}(\mathrm{Z})$ & $\begin{array}{c}0.053 \\
(0.095)\end{array}$ & $\begin{array}{c}0.033 \\
(0.082)\end{array}$ & $\begin{array}{l}-0.019 \\
(0.059)\end{array}$ & $\begin{array}{c}0.000 \\
(0.000)\end{array}$ & $\begin{array}{c}0.002 \\
(0.060)\end{array}$ & $\begin{array}{c}0.102 \\
(0.087)\end{array}$ & $\begin{array}{c}0.237^{* *} \\
(0.114)\end{array}$ & $\begin{array}{c}0.376^{* * *} \\
(0.125)\end{array}$ & $\begin{array}{c}0.502^{* * *} \\
(0.152)\end{array}$ & $\begin{array}{c}0.615^{* * *} \\
(0.189)\end{array}$ & $\begin{array}{c}0.743^{* * *} \\
(0.223)\end{array}$ & $\begin{array}{c}0.861^{* * *} * \\
(0.243)\end{array}$ & $\begin{array}{c}0.932 * * * \\
(0.262)\end{array}$ \\
\hline Sentiment( $(Z)$ & $\begin{array}{c}0.051 \\
(0.092)\end{array}$ & $\begin{array}{c}0.030 \\
(0.065)\end{array}$ & $\begin{array}{c}0.064 \\
(0.055)\end{array}$ & $\begin{array}{c}0.000 \\
(0.000)\end{array}$ & $\begin{array}{l}-0.017 \\
(0.054)\end{array}$ & $\begin{array}{c}0.046 \\
(0.063)\end{array}$ & $\begin{array}{c}0.073 \\
(0.081)\end{array}$ & $\begin{array}{c}0.134 \\
(0.085)\end{array}$ & $\begin{array}{c}0.064 \\
(0.106)\end{array}$ & $\begin{array}{c}0.056 \\
(0.139)\end{array}$ & $\begin{array}{c}0.127 \\
(0.160)\end{array}$ & $\begin{array}{c}0.085 \\
(0.176)\end{array}$ & $\begin{array}{c}0.041 \\
(0.192)\end{array}$ \\
\hline Market value $(Z)$ & $\begin{array}{c}-0.697^{* * *} \\
(0.141)\end{array}$ & $\begin{array}{c}-0.506^{* * *} \\
(0.120)\end{array}$ & $\begin{array}{c}-0.230 * * * \\
(0.050)\end{array}$ & $\begin{array}{c}0.000^{* *} \\
(0.000)\end{array}$ & $\begin{array}{c}-0.156^{* *} \\
(0.079)\end{array}$ & $\begin{array}{c}-0.326^{* * *} \\
(0.093)\end{array}$ & $\begin{array}{c}-0.512 * * * \\
(0.126)\end{array}$ & $\begin{array}{c}-0.714^{* * *} \\
(0.163)\end{array}$ & $\begin{array}{c}-0.870^{* * *} \\
(0.197)\end{array}$ & $\begin{array}{c}-0.994^{* * *} \\
(0.240)\end{array}$ & $\begin{array}{c}-1.102^{* * *} \\
(0.282)\end{array}$ & $\begin{array}{c}-1.167^{* * *} \\
(0.326)\end{array}$ & $\begin{array}{c}-1.141^{* * *} \\
(0.348)\end{array}$ \\
\hline Book-to-market(Z) & $\begin{array}{c}-0.311^{* *} \\
(0.125)\end{array}$ & $\begin{array}{l}-0.153 \\
(0.102)\end{array}$ & $\begin{array}{l}-0.061 \\
(0.053)\end{array}$ & $\begin{array}{c}0.000 \\
(0.000)\end{array}$ & $\begin{array}{l}0.124^{*} \\
(0.068)\end{array}$ & $\begin{array}{c}0.196 \\
(0.124)\end{array}$ & $\begin{array}{c}0.255^{* *} \\
(0.127)\end{array}$ & $\begin{array}{c}0.243 \\
(0.165)\end{array}$ & $\begin{array}{c}0.218 \\
(0.193)\end{array}$ & $\begin{array}{c}0.235 \\
(0.233)\end{array}$ & $\begin{array}{c}0.218 \\
(0.252)\end{array}$ & $\begin{array}{c}0.349 \\
(0.277)\end{array}$ & $\begin{array}{c}0.394 \\
(0.284)\end{array}$ \\
\hline Turnover(Z) & $\begin{array}{c}0.345 \\
(0.255)\end{array}$ & $\begin{array}{c}0.436^{* *} \\
(0.216)\end{array}$ & $\begin{array}{c}0.274 * * * \\
(0.095)\end{array}$ & $\begin{array}{c}0.000 \\
(0.000)\end{array}$ & $\begin{array}{l}-0.047 \\
(0.125)\end{array}$ & $\begin{array}{l}-0.105 \\
(0.277)\end{array}$ & $\begin{array}{c}0.114 \\
(0.294)\end{array}$ & $\begin{array}{c}0.135 \\
(0.346)\end{array}$ & $\begin{array}{c}0.211 \\
(0.352)\end{array}$ & $\begin{array}{c}0.272 \\
(0.426)\end{array}$ & $\begin{array}{c}0.276 \\
(0.474)\end{array}$ & $\begin{array}{c}0.286 \\
(0.542)\end{array}$ & $\begin{array}{c}0.259 \\
(0.549)\end{array}$ \\
\hline Institutional ownership $(\mathrm{Z})$ & $\begin{array}{l}-0.238 \\
(0.196)\end{array}$ & $\begin{array}{c}-0.291^{*} \\
(0.164)\end{array}$ & $\begin{array}{l}-0.057 \\
(0.083)\end{array}$ & $\begin{array}{l}-0.000 \\
(0.000)\end{array}$ & $\begin{array}{c}0.208^{* * *} \\
(0.079)\end{array}$ & $\begin{array}{c}0.205 \\
(0.139)\end{array}$ & $\begin{array}{c}0.166 \\
(0.152)\end{array}$ & $\begin{array}{c}0.178 \\
(0.186)\end{array}$ & $\begin{array}{c}0.108 \\
(0.178)\end{array}$ & $\begin{array}{c}0.036 \\
(0.215)\end{array}$ & $\begin{array}{c}0.163 \\
(0.252)\end{array}$ & $\begin{array}{c}0.149 \\
(0.286)\end{array}$ & $\begin{array}{c}0.148 \\
(0.294)\end{array}$ \\
\hline Fama-French alpha(Z) & $\begin{array}{c}-2.811^{* * *} \\
(0.388)\end{array}$ & $\begin{array}{c}-1.876^{* * *} \\
(0.303)\end{array}$ & $\begin{array}{c}-1.065^{* * *} \\
(0.160)\end{array}$ & $\begin{array}{l}-0.000 \\
(0.000)\end{array}$ & $\begin{array}{c}0.011 \\
(0.124)\end{array}$ & $\begin{array}{l}-0.267 \\
(0.393)\end{array}$ & $\begin{array}{l}-0.065 \\
(0.324)\end{array}$ & $\begin{array}{c}0.028 \\
(0.321)\end{array}$ & $\begin{array}{c}0.115 \\
(0.345)\end{array}$ & $\begin{array}{c}0.088 \\
(0.419)\end{array}$ & $\begin{array}{l}-0.075 \\
(0.468)\end{array}$ & $\begin{array}{l}-0.310 \\
(0.555)\end{array}$ & $\begin{array}{l}-0.187 \\
(0.461)\end{array}$ \\
\hline Filing-day abnormal return(Z) & $\begin{array}{c}-5.926^{* * *} \\
(0.110)\end{array}$ & $\begin{array}{c}-5.980^{* * *} \\
(0.100)\end{array}$ & $\begin{array}{c}-5.877^{* * *} \\
(0.066)\end{array}$ & $\begin{array}{c}-6.030 * * * \\
(0.000)\end{array}$ & $\begin{array}{c}-0.299^{* * *} \\
(0.097)\end{array}$ & $\begin{array}{c}-0.262^{* *} \\
(0.129)\end{array}$ & $\begin{array}{c}-0.448^{* * *} \\
(0.127)\end{array}$ & $\begin{array}{c}-0.360^{* * *} \\
(0.135)\end{array}$ & $\begin{array}{c}-0.439^{* * *} \\
(0.153)\end{array}$ & $\begin{array}{c}-0.457^{* * *} \\
(0.172)\end{array}$ & $\begin{array}{c}-0.476^{* *} \\
(0.190)\end{array}$ & $\begin{array}{c}-0.469^{* *} \\
(0.222)\end{array}$ & $\begin{array}{c}-0.673^{* * *} \\
(0.242)\end{array}$ \\
\hline Obsel & 42010 & 42156 & 42262 & 42298 & 41885 & 41681 & 41498 & 41376 & 41116 & 40909 & 40723 & 40570 & 40397 \\
\hline Adjusted $R^{2}$ & 0.251 & 0.311 & 0.439 & 1.000 & 0.003 & 0.004 & 0.005 & 0.005 & 0.007 & 0.008 & 0.008 & 0.008 & 0.008 \\
\hline
\end{tabular}


Table A.5: Imprecise Language in Disclosure and Illiquidity (All Slope Coefficients)

This table present the slope coefficient estimates for all control variables in Table 5. Slope coefficients and standard errors are reported in percentage. For brevity, intercept is not reported although it is included in the estimation.

\begin{tabular}{|c|c|c|c|c|c|c|c|c|c|c|c|c|c|}
\hline & \multicolumn{13}{|c|}{ Dependent variable $=$ Quoted relative bid-ask spread } \\
\hline & Week $(-3)$ & Week $(-2)$ & Week $(-1)$ & Week $(0)$ & Week(1) & Week (2) & Week(3) & Week(4) & Week(5) & Week $(6)$ & Week $(7)$ & Week $(8)$ & Week $(9)$ \\
\hline $\operatorname{Imprecision}(\mathrm{Z})$ & $\begin{array}{l}-0.078 \\
(0.108)\end{array}$ & $\begin{array}{c}0.026 \\
(0.094)\end{array}$ & $\begin{array}{c}0.069 \\
(0.122)\end{array}$ & $\begin{array}{l}-0.203 \\
(0.134)\end{array}$ & $\begin{array}{c}-0.306^{* *} \\
(0.138)\end{array}$ & $\begin{array}{c}-0.430^{* * *} \\
(0.142)\end{array}$ & $\begin{array}{c}-0.509^{* * *} \\
(0.151)\end{array}$ & $\begin{array}{c}-0.608^{* * *} \\
(0.165)\end{array}$ & $\begin{array}{c}-0.453^{* * *} \\
(0.142)\end{array}$ & $\begin{array}{c}-0.432^{* * *} \\
(0.144)\end{array}$ & $\begin{array}{c}-0.408^{* *} \\
(0.183)\end{array}$ & $\begin{array}{c}-0.395^{* *} \\
(0.187)\end{array}$ & $\begin{array}{l}-0.334^{*} \\
(0.196)\end{array}$ \\
\hline Sentiment $(Z)$ & $\begin{array}{l}-0.012 \\
(0.104)\end{array}$ & $\begin{array}{l}-0.076 \\
(0.123)\end{array}$ & $\begin{array}{c}0.037 \\
(0.110)\end{array}$ & $\begin{array}{l}-0.005 \\
(0.175)\end{array}$ & $\begin{array}{c}0.105 \\
(0.134)\end{array}$ & $\begin{array}{c}0.090 \\
(0.136)\end{array}$ & $\begin{array}{c}0.104 \\
(0.155)\end{array}$ & $\begin{array}{l}-0.179 \\
(0.171)\end{array}$ & $\begin{array}{l}-0.009 \\
(0.159)\end{array}$ & $\begin{array}{l}-0.135 \\
(0.186)\end{array}$ & $\begin{array}{c}-0.320^{*} \\
(0.181)\end{array}$ & $\begin{array}{c}-0.397^{* *} \\
(0.179)\end{array}$ & $\begin{array}{l}-0.175 \\
(0.189)\end{array}$ \\
\hline Market value(Z) & $\begin{array}{l}0.573^{*} \\
(0.292)\end{array}$ & $\begin{array}{c}-0.663^{*} \\
(0.344)\end{array}$ & $\begin{array}{c}-1.494^{* * *} \\
(0.342)\end{array}$ & $\begin{array}{c}-3.963^{* * *} \\
(0.560)\end{array}$ & $\begin{array}{c}-4.242^{* * *} \\
(0.530)\end{array}$ & $\begin{array}{c}-4.720^{* * *} \\
(0.543)\end{array}$ & $\begin{array}{c}-4.682^{* * *} \\
(0.585)\end{array}$ & $\begin{array}{c}-5.145^{* * *} \\
(0.836)\end{array}$ & $\begin{array}{c}-4.525^{* * *} \\
(0.878)\end{array}$ & $\begin{array}{c}-5.443^{* * *} \\
(1.005)\end{array}$ & $\begin{array}{c}-5.855^{* * *} \\
(0.828)\end{array}$ & $\begin{array}{c}-6.302^{* * *} \\
(0.717)\end{array}$ & $\begin{array}{c}-6.311^{* * *} \\
(0.828)\end{array}$ \\
\hline Book-to-market(Z) & $\begin{array}{c}-0.240^{*} \\
(0.124)\end{array}$ & $\begin{array}{c}-0.227^{*} \\
(0.132)\end{array}$ & $\begin{array}{l}-0.045 \\
(0.153)\end{array}$ & $\begin{array}{c}0.052 \\
(0.205)\end{array}$ & $\begin{array}{c}0.391^{* *} \\
(0.191)\end{array}$ & $\begin{array}{c}0.256 \\
(0.180)\end{array}$ & $\begin{array}{c}0.258 \\
(0.207)\end{array}$ & $\begin{array}{c}0.590^{* *} \\
(0.240)\end{array}$ & $\begin{array}{c}0.410^{* *} \\
(0.195)\end{array}$ & $\begin{array}{c}0.427^{* *} \\
(0.196)\end{array}$ & $\begin{array}{c}0.496^{* *} \\
(0.206)\end{array}$ & $\begin{array}{c}0.580^{* *} \\
(0.262)\end{array}$ & $\begin{array}{c}0.385 \\
(0.245)\end{array}$ \\
\hline Turnover(Z) & $\begin{array}{c}-0.274 \\
(0.170)\end{array}$ & $\begin{array}{c}-0.719 * * * \\
(0.173)\end{array}$ & $\begin{array}{c}-1.194^{* * *} \\
(0.228)\end{array}$ & $\begin{array}{c}-1.851^{* * *} \\
(0.299)\end{array}$ & $\begin{array}{c}-1.684^{* * *} \\
(0.306)\end{array}$ & $\begin{array}{c}-1.660^{* * *} \\
(0.339)\end{array}$ & $\begin{array}{c}-1.768^{* * *} \\
(0.368)\end{array}$ & $\begin{array}{c}-1.880^{* * *} \\
(0.362)\end{array}$ & $\begin{array}{c}-1.847^{* * *} \\
(0.374)\end{array}$ & $\begin{array}{c}-2.098^{* * *} \\
(0.372)\end{array}$ & $\begin{array}{c}-2.506^{* * *} \\
(0.358)\end{array}$ & $\begin{array}{c}-2.056^{* * *} \\
(0.423)\end{array}$ & $\begin{array}{c}-2.079^{* * *} \\
(0.438)\end{array}$ \\
\hline Institutional ownership $(\mathrm{Z})$ & $\begin{array}{c}0.051 \\
(0.190)\end{array}$ & $\begin{array}{c}0.377^{* *} \\
(0.187)\end{array}$ & $\begin{array}{l}0.539^{* *} \\
(0.217)\end{array}$ & $\begin{array}{l}-0.102 \\
(0.301)\end{array}$ & $\begin{array}{l}-0.213 \\
(0.285)\end{array}$ & $\begin{array}{c}-0.798^{* *} \\
(0.334)\end{array}$ & $\begin{array}{c}-0.712^{* *} \\
(0.322)\end{array}$ & $\begin{array}{c}-0.600^{* *} \\
(0.301)\end{array}$ & $\begin{array}{c}-0.615^{* *} \\
(0.285)\end{array}$ & $\begin{array}{l}-0.641^{*} \\
(0.336)\end{array}$ & $\begin{array}{c}-0.792^{* *} \\
(0.361)\end{array}$ & $\begin{array}{c}-1.268^{* * * *} \\
(0.358)\end{array}$ & $\begin{array}{c}-1.194 * * * \\
(0.371)\end{array}$ \\
\hline Fama-French alpha (Z) & $\begin{array}{c}-0.258^{*} \\
(0.134)\end{array}$ & $\begin{array}{c}-0.283^{* *} \\
(0.133)\end{array}$ & $\begin{array}{c}-0.686^{* * *} \\
(0.125)\end{array}$ & $\begin{array}{c}-0.907^{* * *} \\
(0.176)\end{array}$ & $\begin{array}{c}-1.118^{* * *} \\
(0.207)\end{array}$ & $\begin{array}{c}-0.984^{* * *} \\
(0.198)\end{array}$ & $\begin{array}{c}-1.196^{* * *} \\
(0.203)\end{array}$ & $\begin{array}{c}-1.257^{* * *} \\
(0.218)\end{array}$ & $\begin{array}{c}-1.047^{* * *} \\
(0.225)\end{array}$ & $\begin{array}{c}-1.163^{* * *} \\
(0.219)\end{array}$ & $\begin{array}{c}-1.216^{* * *} \\
(0.220)\end{array}$ & $\begin{array}{c}-1.021^{* * *} \\
(0.236)\end{array}$ & $\begin{array}{c}-0.920^{* * *} \\
(0.246)\end{array}$ \\
\hline Filing-day abnormal return $(\mathrm{Z})$ & $\begin{array}{c}0.010 \\
(0.078)\end{array}$ & $\begin{array}{l}-0.051 \\
(0.090)\end{array}$ & $\begin{array}{c}0.030 \\
(0.097)\end{array}$ & $\begin{array}{c}-0.623^{* * *} \\
(0.165)\end{array}$ & $\begin{array}{c}-0.957^{* * *} \\
(0.116)\end{array}$ & $\begin{array}{c}-1.034^{* * *} \\
(0.121)\end{array}$ & $\begin{array}{c}-0.898^{* * *} \\
(0.138)\end{array}$ & $\begin{array}{c}-0.859^{* * *} \\
(0.119)\end{array}$ & $\begin{array}{c}-0.823^{* * *} \\
(0.119)\end{array}$ & $\begin{array}{c}-0.781^{* * *} \\
(0.119)\end{array}$ & $\begin{array}{c}-0.787^{* * *} \\
(0.130)\end{array}$ & $\begin{array}{c}-0.855^{* * *} \\
(0.133)\end{array}$ & $\begin{array}{c}-0.874^{* * *} \\
(0.122)\end{array}$ \\
\hline Nasdaq dummy & $\begin{array}{c}1.664^{* * *} \\
(0.574)\end{array}$ & $\begin{array}{c}0.155 \\
(0.612)\end{array}$ & $\begin{array}{c}-1.446^{* *} \\
(0.652)\end{array}$ & $\begin{array}{l}-1.928^{*} \\
(1.073)\end{array}$ & $\begin{array}{c}-2.056^{* *} \\
(0.815)\end{array}$ & $\begin{array}{l}-1.920^{*} \\
(1.041)\end{array}$ & $\begin{array}{l}-1.549 \\
(0.989)\end{array}$ & $\begin{array}{l}-1.567^{*} \\
(0.934)\end{array}$ & $\begin{array}{c}-2.307^{* *} \\
(1.067)\end{array}$ & $\begin{array}{l}-1.471 \\
(0.951)\end{array}$ & $\begin{array}{c}-2.473^{* *} \\
(1.197)\end{array}$ & $\begin{array}{c}-2.448^{* *} \\
(1.151)\end{array}$ & $\begin{array}{l}-2.418^{*} \\
(1.277)\end{array}$ \\
\hline Pre-filing spread(Z) & $\begin{array}{c}49.655^{* * *} \\
(0.337)\end{array}$ & $\begin{array}{c}48.158^{* * *} \\
(0.410)\end{array}$ & $\begin{array}{c}46.462^{* * * *} \\
(0.501)\end{array}$ & $\begin{array}{c}41.002^{* * *} \\
(0.742)\end{array}$ & $\begin{array}{c}39.534^{* * *} \\
(0.764)\end{array}$ & $\begin{array}{c}37.737^{* * *} \\
(0.935)\end{array}$ & $\begin{array}{c}36.937^{* * *} \\
(1.026)\end{array}$ & $\begin{array}{c}36.188^{* * *} \\
(1.115)\end{array}$ & $\begin{array}{c}35.278^{* * *} \\
(1.241)\end{array}$ & $\begin{array}{c}34.365^{* * *} \\
(1.269)\end{array}$ & $\begin{array}{c}32.573^{* * *} \\
(1.421)\end{array}$ & $\begin{array}{c}31.836^{* * *} \\
(1.508)\end{array}$ & $\begin{array}{c}31.554^{* * *} \\
(1.585)\end{array}$ \\
\hline Obs & 40 & 40 & 40 & 407 & 35 & 392 & 39192 & 39185 & 391 & 39113 & 390 & 39062 & 39085 \\
\hline Adjusted $R^{2}$ & 0.939 & 0.937 & 0.933 & 0.87 & 0.896 & 0.887 & 0.883 & 0.88 & 0.876 & 0.871 & 0.865 & 0.86 & 0.853 \\
\hline
\end{tabular}


Table A.6: Imprecise Language in Disclosure and Informed Buying Activity (All Slope Coefficients)

This table present the slope coefficient estimates for all control variables in Table 6. Slope coefficients and standard errors are reported in percentage. For brevity, intercept is not reported although it is included in the estimation.

\begin{tabular}{|c|c|c|c|c|c|c|c|c|c|c|c|c|c|}
\hline & \multicolumn{13}{|c|}{ Dependent variable $=$ Probability of Informed Buying } \\
\hline & Week(-3) & Week $(-2)$ & Week $(-1)$ & Week $(0)$ & $\operatorname{Week}(1)$ & Week $(2)$ & Week(3) & Week(4) & Week $(5)$ & Week $(6)$ & Week $(7)$ & Week $(8)$ & $\operatorname{Week}(9)$ \\
\hline $\operatorname{Imprecision}(\mathrm{Z})$ & $\begin{array}{l}-0.248 \\
(0.182)\end{array}$ & $\begin{array}{c}-0.041 \\
(0.203)\end{array}$ & $\begin{array}{c}0.108 \\
(0.183)\end{array}$ & $\begin{array}{c}0.613^{* *} \\
(0.285)\end{array}$ & $\begin{array}{c}0.659^{* * *} \\
(0.203)\end{array}$ & $\begin{array}{c}0.408^{* *} \\
(0.200)\end{array}$ & $\begin{array}{c}0.443^{* *} \\
(0.194)\end{array}$ & $\begin{array}{c}0.502^{* *} \\
(0.213)\end{array}$ & $\begin{array}{c}0.394^{* *} \\
(0.190)\end{array}$ & $\begin{array}{l}0.369^{*} \\
(0.214)\end{array}$ & $\begin{array}{c}0.338 \\
(0.216)\end{array}$ & $\begin{array}{c}0.222 \\
(0.238)\end{array}$ & $\begin{array}{c}0.171 \\
(0.211)\end{array}$ \\
\hline Sentiment(Z) & $\begin{array}{l}-0.051 \\
(0.096)\end{array}$ & $\begin{array}{c}-0.274^{* * *} \\
(0.102)\end{array}$ & $\begin{array}{l}-0.147 \\
(0.125)\end{array}$ & $\begin{array}{c}-0.425^{* *} \\
(0.199)\end{array}$ & $\begin{array}{c}-0.309 * * \\
(0.149)\end{array}$ & $\begin{array}{l}-0.059 \\
(0.144)\end{array}$ & $\begin{array}{l}-0.057 \\
(0.140)\end{array}$ & $\begin{array}{l}-0.117 \\
(0.171)\end{array}$ & $\begin{array}{l}-0.081 \\
(0.165)\end{array}$ & $\begin{array}{c}0.287^{* *} \\
(0.134)\end{array}$ & $\begin{array}{c}0.123 \\
(0.149)\end{array}$ & $\begin{array}{l}-0.157 \\
(0.181)\end{array}$ & $\begin{array}{c}0.139 \\
(0.146)\end{array}$ \\
\hline Market value(Z) & $\begin{array}{l}-0.164 \\
(0.223)\end{array}$ & $\begin{array}{l}-0.233 \\
(0.226)\end{array}$ & $\begin{array}{c}0.074 \\
(0.273)\end{array}$ & $\begin{array}{l}-0.217 \\
(0.446)\end{array}$ & $\begin{array}{c}0.322 \\
(0.348)\end{array}$ & $\begin{array}{c}0.504 \\
(0.316)\end{array}$ & $\begin{array}{c}0.489 \\
(0.370)\end{array}$ & $\begin{array}{c}0.241 \\
(0.357)\end{array}$ & $\begin{array}{c}0.070 \\
(0.389)\end{array}$ & $\begin{array}{c}0.551 \\
(0.399)\end{array}$ & $\begin{array}{c}0.395 \\
(0.373)\end{array}$ & $\begin{array}{c}0.505 \\
(0.334)\end{array}$ & $\begin{array}{l}0.652^{*} \\
(0.374)\end{array}$ \\
\hline Book-to-market(Z) & $\begin{array}{l}-0.095 \\
(0.128)\end{array}$ & $\begin{array}{c}-0.164 \\
(0.160)\end{array}$ & $\begin{array}{l}-0.042 \\
(0.155)\end{array}$ & $\begin{array}{l}-0.189 \\
(0.203)\end{array}$ & $\begin{array}{l}-0.254 \\
(0.176)\end{array}$ & $\begin{array}{l}-0.267 \\
(0.197)\end{array}$ & $\begin{array}{l}-0.023 \\
(0.183)\end{array}$ & $\begin{array}{l}-0.293 \\
(0.235)\end{array}$ & $\begin{array}{l}-0.206 \\
(0.204)\end{array}$ & $\begin{array}{l}-0.173 \\
(0.204)\end{array}$ & $\begin{array}{c}-0.462^{* *} \\
(0.215)\end{array}$ & $\begin{array}{c}-0.104 \\
(0.197)\end{array}$ & $\begin{array}{l}-0.239 \\
(0.170)\end{array}$ \\
\hline Turnover(Z) & $\begin{array}{l}0.240^{*} \\
(0.132)\end{array}$ & $\begin{array}{c}0.091 \\
(0.214)\end{array}$ & $\begin{array}{c}-0.713^{* * *} \\
(0.208)\end{array}$ & $\begin{array}{l}-0.185 \\
(0.294)\end{array}$ & $\begin{array}{c}-1.143^{* * *} \\
(0.212)\end{array}$ & $\begin{array}{c}-1.558^{* * *} \\
(0.335)\end{array}$ & $\begin{array}{c}-1.125^{* * *} \\
(0.234)\end{array}$ & $\begin{array}{c}-1.637^{* * *} \\
(0.240)\end{array}$ & $\begin{array}{c}-1.542^{* * *} \\
(0.215)\end{array}$ & $\begin{array}{c}-1.654^{* * *} \\
(0.268)\end{array}$ & $\begin{array}{c}-1.519^{* * *} \\
(0.262)\end{array}$ & $\begin{array}{c}-1.472^{* * *} \\
(0.207)\end{array}$ & $\begin{array}{c}-1.288^{* * *} \\
(0.221)\end{array}$ \\
\hline Institutional ownership(Z) & $\begin{array}{c}0.019 \\
(0.162)\end{array}$ & $\begin{array}{c}0.378^{* *} \\
(0.178)\end{array}$ & $\begin{array}{c}0.548^{* * *} \\
(0.189)\end{array}$ & $\begin{array}{c}1.024^{* * * *} \\
(0.306)\end{array}$ & $\begin{array}{c}1.314^{* * * *} \\
(0.237)\end{array}$ & $\begin{array}{c}1.575^{* * * *} \\
(0.324)\end{array}$ & $\begin{array}{c}1.557^{* * *} \\
(0.228)\end{array}$ & $\begin{array}{c}1.539 * * * \\
(0.226)\end{array}$ & $\begin{array}{c}1.480^{* * *} \\
(0.279)\end{array}$ & $\begin{array}{c}1.713^{* * *} \\
(0.266)\end{array}$ & $\begin{array}{c}2.060^{* * *} \\
(0.302)\end{array}$ & $\begin{array}{c}2.143^{* * *} \\
(0.279)\end{array}$ & $\begin{array}{c}2.060^{* * *} \\
(0.247)\end{array}$ \\
\hline Fama-French alpha(Z) & $\begin{array}{c}0.205 \\
(0.151)\end{array}$ & $\begin{array}{c}0.050 \\
(0.194)\end{array}$ & $\begin{array}{c}0.610^{* * *} \\
(0.198)\end{array}$ & $\begin{array}{l}0.445^{*} \\
(0.226)\end{array}$ & $\begin{array}{c}0.718^{* * *} \\
(0.193)\end{array}$ & $\begin{array}{c}0.753^{* * *} \\
(0.213)\end{array}$ & $\begin{array}{c}0.646^{* * *} \\
(0.227)\end{array}$ & $\begin{array}{c}0.885^{* * *} \\
(0.228)\end{array}$ & $\begin{array}{c}0.633^{* * *} \\
(0.214)\end{array}$ & $\begin{array}{c}0.636 * * * \\
(0.169)\end{array}$ & $\begin{array}{c}0.401^{* *} \\
(0.196)\end{array}$ & $\begin{array}{c}0.309 \\
(0.222)\end{array}$ & $\begin{array}{c}0.391^{* *} \\
(0.160)\end{array}$ \\
\hline Filing-day abnormal return(Z) & $\begin{array}{l}-0.144 \\
(0.099)\end{array}$ & $\begin{array}{l}0.259^{*} \\
(0.148)\end{array}$ & $\begin{array}{c}0.050 \\
(0.125)\end{array}$ & $\begin{array}{c}5.003^{* * * *} \\
(0.404)\end{array}$ & $\begin{array}{c}1.182^{* * *} \\
(0.231)\end{array}$ & $\begin{array}{c}0.580^{* * * *} \\
(0.189)\end{array}$ & $\begin{array}{c}0.815^{* * *} \\
(0.166)\end{array}$ & $\begin{array}{c}0.804^{* * *} \\
(0.182)\end{array}$ & $\begin{array}{c}0.704^{* * *} \\
(0.164)\end{array}$ & $\begin{array}{c}0.493^{* * *} \\
(0.141)\end{array}$ & $\begin{array}{c}0.434^{* * *} \\
(0.153)\end{array}$ & $\begin{array}{c}0.379 * * \\
(0.157)\end{array}$ & $\begin{array}{l}0.305^{*} \\
(0.163)\end{array}$ \\
\hline Nasdaq dummy & $\begin{array}{l}-0.296 \\
(0.325)\end{array}$ & $\begin{array}{l}-0.033 \\
(0.319)\end{array}$ & $\begin{array}{c}0.069 \\
(0.383)\end{array}$ & $\begin{array}{c}0.532 \\
(0.652)\end{array}$ & $\begin{array}{c}0.665 \\
(0.616)\end{array}$ & $\begin{array}{l}1.698^{* *} \\
(0.702)\end{array}$ & $\begin{array}{l}1.767^{* *} \\
(0.682)\end{array}$ & $\begin{array}{l}1.303^{*} \\
(0.682)\end{array}$ & $\begin{array}{l}1.682^{* *} \\
(0.671)\end{array}$ & $\begin{array}{c}1.764^{* *} \\
(0.754)\end{array}$ & $\begin{array}{c}1.766^{* * * *} \\
(0.640)\end{array}$ & $\begin{array}{l}1.104^{*} \\
(0.597)\end{array}$ & $\begin{array}{l}1.564^{* * *} \\
(0.643)\end{array}$ \\
\hline Pre-filing informed buying(Z) & $\begin{array}{c}16.496^{* * *} \\
(0.152)\end{array}$ & $\begin{array}{c}15.763^{* * *} \\
(0.188)\end{array}$ & $\begin{array}{c}14.564^{* * *} \\
(0.188)\end{array}$ & $\begin{array}{c}8.613^{* * *} \\
(0.215)\end{array}$ & $\begin{array}{c}6.509^{* * * *} \\
(0.182)\end{array}$ & $\begin{array}{c}5.351^{* * *} \\
(0.294)\end{array}$ & $\begin{array}{c}4.334^{* * *} \\
(0.209)\end{array}$ & $\begin{array}{c}3.419^{* * * *} \\
(0.176)\end{array}$ & $\begin{array}{c}2.275^{* * *} \\
(0.180)\end{array}$ & $\begin{array}{c}1.607^{* * *} \\
(0.184)\end{array}$ & $\begin{array}{c}1.206^{* * *} \\
(0.174)\end{array}$ & $\begin{array}{c}1.008^{* * *} \\
(0.161)\end{array}$ & $\begin{array}{c}0.650^{* * *} \\
(0.189)\end{array}$ \\
\hline Obs & 33218 & 33339 & 33334 & 32766 & 31747 & 31553 & 31355 & 31320 & 31390 & 31171 & 31151 & 30956 & 31135 \\
\hline Adjusted $R^{2}$ & 0.430 & 0.396 & 0.345 & 0.122 & 0.087 & 0.065 & 0.053 & 0.055 & 0.050 & 0.051 & 0.054 & 0.048 & 0.040 \\
\hline
\end{tabular}


Table A.7: Imprecise Language in Disclosure and Insider Buying Activity (All Slope Coefficients)

This table present the slope coefficient estimates for all control variables in Table 7. Slope coefficients and standard errors are reported in percentage. For brevity, intercept is not reported although it is included in the estimation.

\begin{tabular}{|c|c|c|c|c|c|c|c|c|c|c|c|c|c|}
\hline & \multicolumn{13}{|c|}{ Dependent variable $=$ Dollar volume of insider buying } \\
\hline & Week $(-3)$ & Week(-2) & Week(-1) & Week $(0)$ & Week $(1)$ & Week (2) & Week (3) & Week $(4)$ & Week(5) & Week (6) & Week $(7)$ & Week $(8)$ & Week $(9)$ \\
\hline $\operatorname{Imprecision}(\mathrm{Z})$ & $\begin{array}{c}23.132^{* * *} \\
(8.383)\end{array}$ & $\begin{array}{c}20.916^{* *} \\
(9.050)\end{array}$ & $\begin{array}{c}24.360^{* * *} \\
(8.240)\end{array}$ & $\begin{array}{c}24.057^{* * *} \\
(8.270)\end{array}$ & $\begin{array}{c}23.836^{* * *} \\
(8.248)\end{array}$ & $\begin{array}{c}36.369^{* * *} \\
(9.516)\end{array}$ & $\begin{array}{c}49.362^{* * *} \\
(11.488)\end{array}$ & $\begin{array}{c}38.129 * * * \\
(9.980)\end{array}$ & $\begin{array}{c}33.601^{* * *} \\
(11.170)\end{array}$ & $\begin{array}{c}20.689^{* *} \\
(9.184)\end{array}$ & $\begin{array}{c}26.999^{* * *} \\
(9.639)\end{array}$ & $\begin{array}{c}31.381^{* * *} \\
(10.816)\end{array}$ & $\begin{array}{c}26.373^{* * *} \\
(6.931)\end{array}$ \\
\hline Sentiment(Z) & $\begin{array}{l}-8.951 \\
(6.616)\end{array}$ & $\begin{array}{l}-8.446 \\
(7.044)\end{array}$ & $\begin{array}{l}-0.209 \\
(7.614)\end{array}$ & $\begin{array}{l}-0.880 \\
(8.235)\end{array}$ & $\begin{array}{l}-2.867 \\
(7.334)\end{array}$ & $\begin{array}{l}-7.230 \\
(8.037)\end{array}$ & $\begin{array}{c}4.575 \\
(9.803)\end{array}$ & $\begin{array}{l}10.509 \\
(7.652)\end{array}$ & $\begin{array}{l}-3.294 \\
(8.220)\end{array}$ & $\begin{array}{l}-5.164 \\
(6.731)\end{array}$ & $\begin{array}{l}-5.823 \\
(6.813)\end{array}$ & $\begin{array}{l}-0.732 \\
(6.779)\end{array}$ & $\begin{array}{l}-2.157 \\
(5.678)\end{array}$ \\
\hline Market value(Z) & $\begin{array}{c}24.452^{* * *} \\
(6.795)\end{array}$ & $\begin{array}{c}27.172^{* * *} \\
(8.796)\end{array}$ & $\begin{array}{c}21.717^{* * *} \\
(8.290)\end{array}$ & $\begin{array}{c}29.732^{* * * *} \\
(6.435)\end{array}$ & $\begin{array}{c}25.939^{* * *} \\
(7.966)\end{array}$ & $\begin{array}{c}30.885^{* *} \\
(12.694)\end{array}$ & $\begin{array}{c}37.308^{* * *} \\
(10.846)\end{array}$ & $\begin{array}{c}11.052 \\
(11.562)\end{array}$ & $\begin{array}{c}5.615 \\
(11.709)\end{array}$ & $\begin{array}{c}27.702^{* * *} \\
(6.931)\end{array}$ & $\begin{array}{c}46.466^{* * *} \\
(6.649)\end{array}$ & $\begin{array}{c}29.984^{* * *} \\
(8.412)\end{array}$ & $\begin{array}{c}37.298^{* * *} \\
(7.874)\end{array}$ \\
\hline Book-to-market(Z) & $\begin{array}{c}-23.806^{* * *} \\
(7.209)\end{array}$ & $\begin{array}{c}-28.253^{* * *} \\
(7.589)\end{array}$ & $\begin{array}{c}-22.064^{* * *} \\
(7.307)\end{array}$ & $\begin{array}{l}-6.859 \\
(6.735)\end{array}$ & $\begin{array}{c}-16.524^{* *} \\
(7.473)\end{array}$ & $\begin{array}{l}-4.350 \\
(8.397)\end{array}$ & $\begin{array}{l}-4.602 \\
(9.607)\end{array}$ & $\begin{array}{c}-22.475^{* * *} \\
(8.454)\end{array}$ & $\begin{array}{l}-7.481 \\
(7.688)\end{array}$ & $\begin{array}{l}-10.599 \\
(7.379)\end{array}$ & $\begin{array}{l}-8.260 \\
(6.114)\end{array}$ & $\begin{array}{l}-12.069 \\
(9.659)\end{array}$ & $\begin{array}{c}-12.031^{* *} \\
(5.294)\end{array}$ \\
\hline Turnover(Z) & $\begin{array}{c}38.932^{* * *} \\
(6.712)\end{array}$ & $\begin{array}{c}59.125^{* * *} \\
(7.485)\end{array}$ & $\begin{array}{c}43.910^{* * *} \\
(7.196)\end{array}$ & $\begin{array}{c}41.598^{* * *} \\
(7.238)\end{array}$ & $\begin{array}{c}35.660^{* * *} \\
(7.865)\end{array}$ & $\begin{array}{c}43.496^{* * *} \\
(10.204)\end{array}$ & $\begin{array}{c}38.853^{* * *} \\
(11.401)\end{array}$ & $\begin{array}{c}37.991^{* * *} \\
(8.927)\end{array}$ & $\begin{array}{c}39.127^{* * *} \\
(7.687)\end{array}$ & $\begin{array}{c}24.189^{* * *} \\
(8.034)\end{array}$ & $\begin{array}{c}43.479^{* * *} \\
(6.767)\end{array}$ & $\begin{array}{c}27.418^{* * *} \\
(8.310)\end{array}$ & $\begin{array}{c}37.282^{* * *} \\
(5.634)\end{array}$ \\
\hline Institutional ownership(Z) & $\begin{array}{l}15.992^{*} \\
(8.272)\end{array}$ & $\begin{array}{l}-13.538 \\
(9.093)\end{array}$ & $\begin{array}{c}5.212 \\
(8.439)\end{array}$ & $\begin{array}{l}-2.827 \\
(8.126)\end{array}$ & $\begin{array}{c}4.715 \\
(7.919)\end{array}$ & $\begin{array}{c}0.680 \\
(9.220)\end{array}$ & $\begin{array}{l}-7.290 \\
(11.886)\end{array}$ & $\begin{array}{c}17.916 \\
(12.511)\end{array}$ & $\begin{array}{c}-5.094 \\
(12.269)\end{array}$ & $\begin{array}{l}12.458 \\
(9.083)\end{array}$ & $\begin{array}{c}0.530 \\
(8.509)\end{array}$ & $\begin{array}{l}16.609^{*} \\
(9.649)\end{array}$ & $\begin{array}{l}1.951 \\
(7.861)\end{array}$ \\
\hline Fama-French alpha(Z) & $\begin{array}{c}8.595 \\
(6.478)\end{array}$ & $\begin{array}{l}-1.948 \\
(5.751)\end{array}$ & $\begin{array}{c}7.756 \\
(6.033)\end{array}$ & $\begin{array}{c}2.163 \\
(6.437)\end{array}$ & $\begin{array}{c}1.759 \\
(5.263)\end{array}$ & $\begin{array}{c}2.369 \\
(8.769)\end{array}$ & $\begin{array}{c}-9.619 \\
(10.057)\end{array}$ & $\begin{array}{l}-12.123 \\
(9.855)\end{array}$ & $\begin{array}{l}12.728^{*} \\
(6.988)\end{array}$ & $\begin{array}{c}6.745 \\
(8.870)\end{array}$ & $\begin{array}{l}-1.990 \\
(7.183)\end{array}$ & $\begin{array}{l}6.800 \\
(6.156)\end{array}$ & $\begin{array}{c}4.343 \\
(6.694)\end{array}$ \\
\hline Filing-day abnormal return(Z) & $\begin{array}{l}-5.989 \\
(5.457)\end{array}$ & $\begin{array}{c}3.049 \\
(4.065)\end{array}$ & $\begin{array}{c}10.768^{* *} \\
(4.667)\end{array}$ & $\begin{array}{c}4.763 \\
(4.272)\end{array}$ & $\begin{array}{c}-12.052^{* * *} \\
(4.451)\end{array}$ & $\begin{array}{c}1.304 \\
(3.959)\end{array}$ & $\begin{array}{l}-3.102 \\
(8.237)\end{array}$ & $\begin{array}{c}8.407 \\
(6.035)\end{array}$ & $\begin{array}{l}-7.171 \\
(5.926)\end{array}$ & $\begin{array}{c}1.100 \\
(8.287)\end{array}$ & $\begin{array}{l}-4.119 \\
(5.966)\end{array}$ & $\begin{array}{c}8.676 \\
(5.473)\end{array}$ & $\begin{array}{c}5.158 \\
(4.202)\end{array}$ \\
\hline Nasdaq dummy & $\begin{array}{l}-21.650 \\
(15.461)\end{array}$ & $\begin{array}{c}-41.511^{* * *} \\
(10.754)\end{array}$ & $\begin{array}{c}-40.229 * * * \\
(11.609)\end{array}$ & $\begin{array}{c}-37.666^{* * *} \\
(13.275)\end{array}$ & $\begin{array}{c}-30.573^{* *} \\
(13.562)\end{array}$ & $\begin{array}{c}-8.721 \\
(16.864)\end{array}$ & $\begin{array}{c}-58.495 * * * \\
(21.103)\end{array}$ & $\begin{array}{l}-20.111 \\
(22.538)\end{array}$ & $\begin{array}{c}-49.249 * * \\
(18.875)\end{array}$ & $\begin{array}{l}-29.172 \\
(18.077)\end{array}$ & $\begin{array}{c}-27.152^{* *} \\
(12.873)\end{array}$ & $\begin{array}{l}-16.799 \\
(14.437)\end{array}$ & $\begin{array}{c}-45.731^{* * *} \\
(10.424)\end{array}$ \\
\hline Obse & 1939 & 1824 & 1774 & 1448 & 1896 & 1421 & 1056 & 1085 & 125 & 1444 & 1769 & 2054 & 2247 \\
\hline Adjusted $R^{2}$ & 0.141 & 0.167 & 0.134 & 0.124 & 0.125 & 0.102 & 0.146 & 0.135 & 0.057 & 0.079 & 0.146 & 0.111 & 0.152 \\
\hline
\end{tabular}


Table A.8: Imprecise Language in Disclosure and News Sentiment (All Slope Coefficients)

This table present the slope coefficient estimates for all control variables in Table 8. Slope coefficients and standard errors are reported in percentage. For brevity, intercept is not reported although it is included in the estimation.

\begin{tabular}{|c|c|c|c|c|c|c|c|c|c|c|c|c|c|}
\hline & \multicolumn{13}{|c|}{ Dependent variable $=$ Average news sentiment score } \\
\hline & Week $(-3)$ & Week $(-2)$ & Week $(-1)$ & Week $(0)$ & $\operatorname{Week}(1)$ & Week(2) & Week(3) & Week(4) & Week $(5)$ & Week(6) & Week(7) & Week (8) & Week(9) \\
\hline Imprecision $(\mathrm{Z})$ & $\begin{array}{c}0.014 \\
(0.133)\end{array}$ & $\begin{array}{l}-0.225 \\
(0.173)\end{array}$ & $\begin{array}{l}-0.069 \\
(0.134)\end{array}$ & $\begin{array}{c}0.175 \\
(0.186)\end{array}$ & $\begin{array}{l}0.330^{*} \\
(0.192)\end{array}$ & $\begin{array}{c}0.595^{* * *} \\
(0.212)\end{array}$ & $\begin{array}{c}0.758^{* * *} \\
(0.230)\end{array}$ & $\begin{array}{c}0.981^{* * *} \\
(0.161)\end{array}$ & $\begin{array}{l}0.372^{* *} \\
(0.167)\end{array}$ & $\begin{array}{c}0.410^{* *} \\
(0.200)\end{array}$ & $\begin{array}{c}0.534^{* * *} \\
(0.161)\end{array}$ & $\begin{array}{c}0.103 \\
(0.185)\end{array}$ & $\begin{array}{c}0.009 \\
(0.168)\end{array}$ \\
\hline Sentiment(Z) & $\begin{array}{l}-0.018 \\
(0.128)\end{array}$ & $\begin{array}{l}-0.244 \\
(0.153)\end{array}$ & $\begin{array}{l}-0.069 \\
(0.152)\end{array}$ & $\begin{array}{c}0.003 \\
(0.222)\end{array}$ & $\begin{array}{c}-0.534^{* *} \\
(0.210)\end{array}$ & $\begin{array}{l}-0.213 \\
(0.266)\end{array}$ & $\begin{array}{l}-0.173 \\
(0.193)\end{array}$ & $\begin{array}{c}0.258 \\
(0.172)\end{array}$ & $\begin{array}{c}-0.567^{* * *} \\
(0.204)\end{array}$ & $\begin{array}{l}-0.376 \\
(0.234)\end{array}$ & $\begin{array}{c}-0.341^{* *} \\
(0.166)\end{array}$ & $\begin{array}{c}0.105 \\
(0.162)\end{array}$ & $\begin{array}{l}-0.248 \\
(0.239)\end{array}$ \\
\hline Market value(Z) & $\begin{array}{c}0.151 \\
(0.153)\end{array}$ & $\begin{array}{c}0.059 \\
(0.145)\end{array}$ & $\begin{array}{l}-0.250 \\
(0.167)\end{array}$ & $\begin{array}{c}0.352 \\
(0.236)\end{array}$ & $\begin{array}{c}0.348 \\
(0.255)\end{array}$ & $\begin{array}{l}0.401^{*} \\
(0.234)\end{array}$ & $\begin{array}{c}0.497^{* *} \\
(0.193)\end{array}$ & $\begin{array}{l}-0.127 \\
(0.205)\end{array}$ & $\begin{array}{c}0.671^{* * *} \\
(0.191)\end{array}$ & $\begin{array}{l}0.382^{*} \\
(0.209)\end{array}$ & $\begin{array}{c}0.950^{* * *} \\
(0.217)\end{array}$ & $\begin{array}{c}1.025^{* * *} \\
(0.194)\end{array}$ & $\begin{array}{c}0.733^{* * *} \\
(0.208)\end{array}$ \\
\hline Book-to-market(Z) & $\begin{array}{c}0.111 \\
(0.115)\end{array}$ & $\begin{array}{c}0.031 \\
(0.143)\end{array}$ & $\begin{array}{c}-0.262 * * \\
(0.126)\end{array}$ & $\begin{array}{l}-0.210 \\
(0.203)\end{array}$ & $\begin{array}{l}-0.224 \\
(0.185)\end{array}$ & $\begin{array}{l}-0.062 \\
(0.183)\end{array}$ & $\begin{array}{c}-0.389^{* * *} \\
(0.117)\end{array}$ & $\begin{array}{l}-0.206 \\
(0.154)\end{array}$ & $\begin{array}{l}-0.242 \\
(0.160)\end{array}$ & $\begin{array}{c}-0.368^{*} \\
(0.200)\end{array}$ & $\begin{array}{c}0.046 \\
(0.160)\end{array}$ & $\begin{array}{l}0.313^{*} \\
(0.181)\end{array}$ & $\begin{array}{l}-0.239 \\
(0.166)\end{array}$ \\
\hline Turnover(Z) & $\begin{array}{l}-0.045 \\
(0.184)\end{array}$ & $\begin{array}{c}0.023 \\
(0.164)\end{array}$ & $\begin{array}{l}-0.133 \\
(0.139)\end{array}$ & $\begin{array}{c}-0.984^{* * *} \\
(0.269)\end{array}$ & $\begin{array}{l}-0.092 \\
(0.187)\end{array}$ & $\begin{array}{l}0.422^{*} \\
(0.250)\end{array}$ & $\begin{array}{c}0.283 \\
(0.238)\end{array}$ & $\begin{array}{c}0.000 \\
(0.234)\end{array}$ & $\begin{array}{l}-0.417^{*} \\
(0.236)\end{array}$ & $\begin{array}{l}-0.011 \\
(0.249)\end{array}$ & $\begin{array}{c}-0.560^{* *} \\
(0.257)\end{array}$ & $\begin{array}{c}-0.366^{* *} \\
(0.184)\end{array}$ & $\begin{array}{c}0.006 \\
(0.274)\end{array}$ \\
\hline Institutional ownership $(\mathrm{Z})$ & $\begin{array}{l}-0.095 \\
(0.197)\end{array}$ & $\begin{array}{l}-0.313^{*} \\
(0.184)\end{array}$ & $\begin{array}{l}-0.174 \\
(0.186)\end{array}$ & $\begin{array}{l}-0.577^{*} \\
(0.296)\end{array}$ & $\begin{array}{c}-1.995^{* * *} \\
(0.251)\end{array}$ & $\begin{array}{c}-1.724^{* * *} \\
(0.295)\end{array}$ & $\begin{array}{c}-1.905^{* * *} \\
(0.332)\end{array}$ & $\begin{array}{c}-1.203^{* * *} \\
(0.346)\end{array}$ & $\begin{array}{c}-1.581^{* * *} \\
(0.325)\end{array}$ & $\begin{array}{c}-1.088^{* * *} \\
(0.227)\end{array}$ & $\begin{array}{c}-0.848^{* * *} \\
(0.251)\end{array}$ & $\begin{array}{c}-0.648^{* * *} \\
(0.212)\end{array}$ & $\begin{array}{c}-1.006^{* * *} \\
(0.277)\end{array}$ \\
\hline Fama-French alpha(Z) & $\begin{array}{l}-0.092 \\
(0.181)\end{array}$ & $\begin{array}{l}-0.193 \\
(0.217)\end{array}$ & $\begin{array}{c}-0.577^{* * *} \\
(0.152)\end{array}$ & $\begin{array}{c}0.145 \\
(0.304)\end{array}$ & $\begin{array}{c}-0.629^{* *} \\
(0.283)\end{array}$ & $\begin{array}{l}-0.196 \\
(0.335)\end{array}$ & $\begin{array}{l}-0.111 \\
(0.295)\end{array}$ & $\begin{array}{l}-0.022 \\
(0.263)\end{array}$ & $\begin{array}{l}0.406^{*} \\
(0.245)\end{array}$ & $\begin{array}{c}0.833^{* * *} \\
(0.276)\end{array}$ & $\begin{array}{c}0.247 \\
(0.249)\end{array}$ & $\begin{array}{c}0.658^{* * *} \\
(0.233)\end{array}$ & $\begin{array}{l}-0.078 \\
(0.261)\end{array}$ \\
\hline Filing-day abnormal return(Z) & $\begin{array}{c}-0.269^{*} \\
(0.143)\end{array}$ & $\begin{array}{c}0.030 \\
(0.102)\end{array}$ & $\begin{array}{c}0.283^{* * *} \\
(0.105)\end{array}$ & $\begin{array}{c}2.822^{* * *} \\
(0.222)\end{array}$ & $\begin{array}{l}-0.052 \\
(0.192)\end{array}$ & $\begin{array}{l}-0.454^{*} \\
(0.238)\end{array}$ & $\begin{array}{c}0.002 \\
(0.240)\end{array}$ & $\begin{array}{c}0.094 \\
(0.165)\end{array}$ & $\begin{array}{c}0.139 \\
(0.183)\end{array}$ & $\begin{array}{c}0.282 \\
(0.189)\end{array}$ & $\begin{array}{l}-0.021 \\
(0.135)\end{array}$ & $\begin{array}{c}0.105 \\
(0.166)\end{array}$ & $\begin{array}{l}-0.241 \\
(0.184)\end{array}$ \\
\hline Pre-filing news sentiment(Z) & $\begin{array}{c}13.552^{* * *} \\
(0.185)\end{array}$ & $\begin{array}{c}13.777^{* * *} \\
(0.172)\end{array}$ & $\begin{array}{c}14.141^{* * *} \\
(0.232)\end{array}$ & $\begin{array}{c}2.636^{* * *} \\
(0.269)\end{array}$ & $\begin{array}{c}2.865^{* * *} \\
(0.203)\end{array}$ & $\begin{array}{c}2.840^{* * *} \\
(0.247)\end{array}$ & $\begin{array}{c}2.536^{* * *} \\
(0.268)\end{array}$ & $\begin{array}{c}2.628^{* * *} \\
(0.261)\end{array}$ & $\begin{array}{c}2.234^{* * *} \\
(0.242)\end{array}$ & $\begin{array}{c}2.318^{* * *} \\
(0.205)\end{array}$ & $\begin{array}{c}2.609^{* * *} \\
(0.263)\end{array}$ & $\begin{array}{c}2.421^{* * *} \\
(0.203)\end{array}$ & $\begin{array}{c}2.195^{* * *} \\
(0.203)\end{array}$ \\
\hline nth-week market news sentiment $(Z)$ & $\begin{array}{c}0.507^{* * *} \\
(0.133)\end{array}$ & $\begin{array}{c}0.198 \\
(0.122)\end{array}$ & $\begin{array}{c}0.051 \\
(0.168)\end{array}$ & $\begin{array}{c}0.619^{* *} \\
(0.269)\end{array}$ & $\begin{array}{l}-0.139 \\
(0.184)\end{array}$ & $\begin{array}{c}0.307 \\
(0.287)\end{array}$ & $\begin{array}{c}0.168 \\
(0.279)\end{array}$ & $\begin{array}{c}0.372^{* *} \\
(0.164)\end{array}$ & $\begin{array}{l}-0.033 \\
(0.188)\end{array}$ & $\begin{array}{c}0.765^{* * *} \\
(0.216)\end{array}$ & $\begin{array}{c}0.391 * * \\
(0.186)\end{array}$ & $\begin{array}{c}0.328 \\
(0.236)\end{array}$ & $\begin{array}{l}0.493^{* *} \\
(0.201)\end{array}$ \\
\hline Observations & 21632 & 21499 & 22047 & 18274 & 19146 & 18568 & 19093 & 19208 & 20189 & 21266 & 21833 & 21886 & 21232 \\
\hline Adjusted $R^{2}$ & 0.310 & 0.324 & 0.349 & 0.027 & 0.024 & 0.022 & 0.021 & 0.021 & 0.019 & 0.017 & 0.018 & 0.014 & 0.012 \\
\hline
\end{tabular}


Table A.9: Imprecise Language in Disclosure and Subsequent Earnings Surprise

This table presents the estimation results from the regression of either an indicator or a rank for future standardized unexpected earnings (SUE) on our linguistic imprecision measure as follows:

$$
\text { Earnings surprise }_{i t q}=\alpha_{q}+\beta_{q} \text { Imprecision }_{i t}+\eta_{q}^{\prime} \mathbf{X}_{i t}+\epsilon_{i t q}
$$

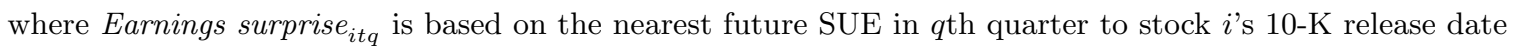
in year $t$. For the SUE indicator, Earnings surprise $_{i t q}$ is 1,0 , or -1 when the nearest future SUE in the $q$ th quarter is above zero, equal to zero, or below zero, respectively. For the SUE rank, Earnings surprise itq $_{\text {, }}$ is $+2,+1,0,-1$, or -2 when the nearest future SUE in the $q$ th quarter is above $80 \%$, between $80 \%$ (inclusive) and $60 \%$, between $60 \%$ (inclusive) and $40 \%$, between $40 \%$ (inclusive) and $20 \%$, or below $20 \%$ (inclusive), respectively, where the percentiles are computed based on all available SUEs of other firms within the three-week period before each of the nearest future SUE. Quarter 0 means that the nearest future earnings announcement and 10-K filing are made in the same quarter, and Quarter 1 means that the nearest future earnings is announced in the next quarter to $10-\mathrm{K}$ filing. Imprecision $_{\text {it }}$ is the percentage of imprecision keywords (out of total words), and $\mathbf{X}_{i t}$ is a column vector that contains various control variables: Sentiment, Market value, Book-to-market, Turnover, Institutional ownership, Fama-French alpha, Filing-day abnormal return, Analyst dispersion, and Analyst revision. The detailed definitions of these independent variables are given in the Appendix. (Z) indicates that the variable is standardized to have mean 0 and standard deviation 1. Standard errors that are clustered by firm and quarter are calculated and reported in parentheses. Slope coefficients and standard errors are reported in percentage. ${ }^{* * *},{ }^{* *}$, and * indicate statistical significance at the 1\%,5\%, and $10 \%$ level, respectively. For brevity, intercept is not reported although it is included in the estimation.

\begin{tabular}{lcccccc}
\hline & \multicolumn{5}{c}{ Dependent variable $=$ Earnings surprise } \\
\cline { 2 - 7 } & Indicator & Quarter 0 & Quintile & Decile & Indicator & Quarter 1 \\
Quintile & Decile \\
& $(1)$ & $(2)$ & $(3)$ & $(4)$ & $(5)$ & $(6)$ \\
\hline Imprecision(Z) & $6.323^{* *}$ & $5.944^{* *}$ & $5.858^{* *}$ & $2.274^{* *}$ & $1.830^{* *}$ & $1.636^{*}$ \\
& $(2.720)$ & $(2.378)$ & $(2.560)$ & $(0.883)$ & $(0.921)$ & $(0.884)$ \\
Sentiment(Z) & 1.363 & -1.792 & -1.751 & -0.040 & $-2.419^{* *}$ & $-2.598^{* * *}$ \\
& $(1.871)$ & $(2.021)$ & $(2.004)$ & $(0.989)$ & $(0.922)$ & $(0.895)$ \\
Market value(Z) & $12.384^{* * *}$ & 4.468 & 4.249 & $10.937^{* * *}$ & $3.063^{* *}$ & $3.025^{* *}$ \\
& $(2.637)$ & $(3.273)$ & $(3.541)$ & $(0.936)$ & $(1.262)$ & $(1.434)$ \\
Book-to-market(Z) & 1.112 & $7.581^{* * *}$ & $8.667^{* * *}$ & 0.830 & $6.241^{* * *}$ & $6.886^{* * *}$ \\
& $(2.065)$ & $(2.387)$ & $(2.372)$ & $(0.884)$ & $(0.885)$ & $(0.949)$ \\
Turnover(Z) & $7.507^{* *}$ & $8.776^{* *}$ & $9.372^{* *}$ & 2.063 & $5.355^{* * *}$ & $5.957^{* * *}$ \\
& $(3.137)$ & $(3.446)$ & $(3.721)$ & $(1.437)$ & $(1.239)$ & $(1.345)$ \\
Institutional ownership(Z) & 1.106 & -2.662 & -2.058 & $3.959^{* * *}$ & 1.877 & 1.601 \\
Fama-French alpha(Z) & $(2.605)$ & $(2.861)$ & $(2.952)$ & $(1.406)$ & $(1.543)$ & $(1.562)$ \\
& $9.053^{* * *}$ & 2.833 & 4.137 & $10.710^{* * *}$ & $6.500^{* * *}$ & $6.847^{* * *}$ \\
Filing-day abnormal return(Z) & $(2.627)$ & $(2.407)$ & $(2.675)$ & $(1.847)$ & $(1.515)$ & $(1.690)$ \\
& $9.109^{* * *}$ & $8.581^{* * *}$ & $8.864^{* * *}$ & $1.672^{* *}$ & 0.965 & 0.885 \\
Analyst dispersion(Z) & $(1.990)$ & $(2.253)$ & $(2.268)$ & $(0.733)$ & $(0.746)$ & $(0.754)$ \\
& $-7.712^{* * *}$ & $-5.669^{* * *}$ & $-5.882^{* *}$ & $-7.554^{* * *}$ & $-4.765^{* * *}$ & $-4.997^{* * *}$ \\
Analyst revision(Z) & $(2.258)$ & $(2.054)$ & $(2.239)$ & $(1.714)$ & $(0.799)$ & $(0.793)$ \\
& 0.145 & 0.885 & 0.874 & -0.008 & 0.511 & 0.739 \\
Observations & $(2.349)$ & $(2.753)$ & $(2.878)$ & $(0.688)$ & $(0.880)$ & $(0.882)$ \\
Adjusted $R^{2}$ & 2271 & 2271 & 2271 & 22903 & 22903 & 22903 \\
& 0.052 & 0.022 & 0.024 & 0.033 & 0.012 & 0.013 \\
\hline
\end{tabular}




\section{A.1 Discussion on the SUE Predictability}

To understand what value-relevant information comes with the imprecise language in 10-K disclosures on a deeper level, we now test whether our linguistic imprecision measure can predict subsequent earnings surprise, a proxy for news on future cash flow, after 10-K release dates.

For each firm and each quarterly earnings announcement, we first compute standardized unexpected earnings (SUE) as actual earnings minus the mean of analysts' forecasts divided by price which is available as of one day before the earnings announcement day. We then estimate the following regression model with either a SUE indicator or a SUE rank as the dependent variable:

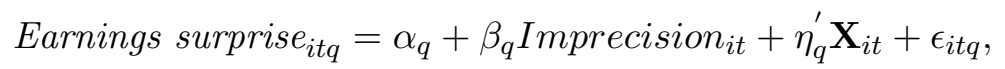

where Earnings surprise $_{i t q}$ is based on the nearest future SUE in qth quarter to stock $i$ 's 10$\mathrm{K}$ release date in year $t$. For the SUE indicator, Earnings surprise $e_{i t q}$ is 1,0 , or -1 when the nearest future SUE in the $q$ th quarter is above zero, equal to zero, or below zero, respectively. For the SUE rank, Earnings surprise $e_{i t q}$, is $+2,+1,0,-1$, or -2 when the nearest future SUE in the $q$ th quarter is above $80 \%$, between $80 \%$ (inclusive) and $60 \%$, between $60 \%$ (inclusive) and $40 \%$, between $40 \%$ (inclusive) and $20 \%$, or below $20 \%$ (inclusive), respectively, where the percentiles are computed based on all available SUEs of other firms within the threeweek period before each of the nearest future SUE. $q=0$ means that the nearest future earnings announcement and 10-K filing are made in the same quarter, and $q=1$ means that the nearest future earnings is announced in the next quarter to 10-K filing. In addition, $q=0 \& 1$ means that the nearest future earnings is announced either in the same quarter or in the next quarter of $10-\mathrm{K}$ filing (whichever comes earlier is selected).

In Model (A.1), the variable of interest is Imprecision $_{i t}$, the percentage of imprecision keywords (out of total words) used in firm $i$ 's 10-K disclosure in year $t$. $\mathbf{X}_{i t}$ is a column vector that contains various control variables, including Sentiment, Market value, Book-to-market, Turnover, Institutional ownership, Pre-filing Fama-French alpha, Filing-day abnormal return, Analyst dispersion, and Analyst revision. All these independent variables in Model (A.1) are standardized and their detailed definitions are provided in Appendix. To account for potential serial and cross-sectional correlations of SUEs, we cluster the standard errors by firm and quarter.

The test results of SUE predictability in Model (A.1) are presented in Table A.9. In Columns (1) and (2), when the nearest future SUE and 10-K filing are required to be in the same quarter $(q=0)$, the number of observations is significantly smaller than our earlier tests, which can potentially lead to lower power in statistical tests. Despite of this disadvantage, we find that our linguistic imprecision measure can predict future SUE positively and significantly in the $5 \%$ level both for the SUE indicator and rank variables. In Columns (3) and (4), when the nearest future SUE is in the next quarter to the corresponding 10-K filing $(q=1)$, the number of observations substantially increases relative to Columns (1) and (2) and we continue to find evidence that the imprecise language in 10-Ks leads to positive future SUE. 
We also find that the slope coefficient for Imprecision $_{i t}$ is much larger for $q=0$ (e.g., 0.086 in Column (2)) than for $q=1$ (e.g., 0.028 in Column (4)). This indicates that the magnitude of SUE predictability by linguistic imprecision attenuates quickly as longer time horizon is allowed for security analysts to digest the value-relevant information contained in the imprecise language used in $10-\mathrm{Ks}^{25}$ In Columns (5) and (6), we allow the nearest future SUE to be either in the same quarter or in the next quarter of each $10-\mathrm{K}$ filing and find again the significant and positive SUE predictability by our linguistic imprecision measure although its magnitude reduces compared to Columns (1) and (2).

In sum, we conclude that the test results in Table A.9 show that the imprecise language employed in 10-K disclosures contains the novel information on firms' cash flow in the near future and security analysts initially under-react to it possibly due to its embedded immaturity although they eventually digest and reflect its implication related to future cash flow into their earnings forecasts. These evidence and interpretation are also consistent with the initial under-reaction and eventual but delayed correction by stock prices to the linguistic imprecision in $10-\mathrm{Ks}$ as discussed above in our earlier tests.

\footnotetext{
${ }^{25}$ We also estimate Model (A.1) for $q=2$ when the nearest future SUE is required to be in the second next quarter to each 10-K filing, yielding positive but insignificant slope coefficients for Imprecision It. $_{\text {. }}$
} 